\title{
MAGNESIUM BIOMARKERS AND CARDIOMETABOLIC ENDPOINTS IN MULTIETHNIC POPULATIONS
}

\author{
Liana Del Gobbo \\ School of Dietetics \& Human Nutrition, McGill University, Montreal \\ December 2011
}

A thesis submitted to McGill University in partial fulfillment of the degree of Doctor of Philosophy

(C) Liana Del Gobbo 2011 


\section{TABLE OF CONTENTS}

ABSTRACT.....................................................................v

RÉSUMÉ.......................................................................viii

ADVANCE OF SCHOLARLY KNOWLEDGE............................xii

Original contributions to knowledge ..............................................................xii

Abstracts and manuscripts submitted to peer-reviewed journals..............xiii

CONTRIBUTIONS OF AUTHORS TO MANUSCRIPTS...................xiv

ACKNOWLEDGEMENTS....................................................

LIST OF TABLES....................................................xvii

LIST OF FIGURES..................................................xix

COMMON ABBREVIATIONS........................................xx

CHAPTER 1. INTRODUCTION..........................................1

Background \& rationale ..................................................................................................... 1

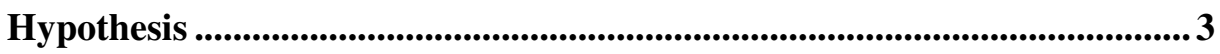

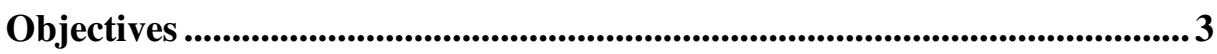

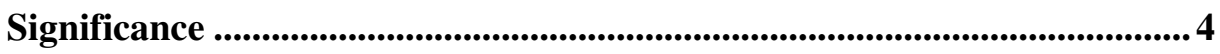

CHAPTER 2. LITERATURE REVIEW ...................................7

2.1. Body composition............................................................................................... 7

2.2. Absorption ...........................................................................................................

2.3. Risk factors and causes of $\mathrm{Mg}$ deficiency .......................................................8 8

PART 1: Mg, Inflammation \& Metabolic Derangements.............................9

2.4. Mg \& Inflammation..................................................................................................9

2.5. Mg \& Oxidative Stress ..........................................................................13

2.6. Mg \& The Metabolic Syndrome (MetS) .............................................14

2.6.1. Obesity …...................................................................................................................... 15

2.6.2. High Blood Pressure/Hypertension.................................................... 15

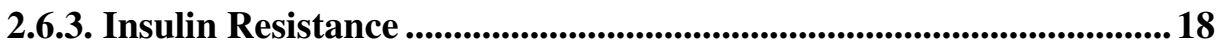

2.6.4. Dyslipidemia................................................................................21 
2.6.5.1. Mg \& MetS (grouped components) ....................................................22

2.7. Mg \& Impaired Glycemia..................................................................................24

PART 2: Mg \& Cardiovascular Endpoints.....................................................26

2.8. Mg: Drinking Water Studies \& Cardiovascular Health ......................26

2.9. Mg \& Carotid Intima-Media Thickness ..............................................227

2.10.1. Mg \& Arrhythmias: Ion Interactions .................................................28

2.10.2. Mg: Deficiency-related Arrhythmias.......................................................29

2.10.3. Mg \& Arrhythmias: Potential Confounding Factors ....................... 31

2.11. Mg \& Sudden Cardiac Death ......................................................................... 33

Mg: Intravenous Administration in Cardiovascular Care ...........................34

2.12.1. In Preventing Mortality After Acute Myocardial Infarction .........34

2.12.2. In Preventing Postoperative Atrial Fibrillation (AF) ....................... 36

2.12.3. During Ventricular Tachycardia......................................................337

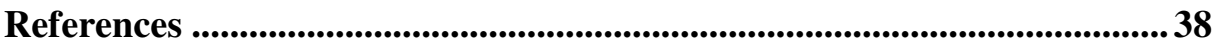

BRIDGE 1.....................................................................63

CHAPTER 3. MANUSCRIPT 1........................................65

Gestational glucose intolerance modifies the association between magnesium concentrations and glycemic measures in mothers and daughters 15

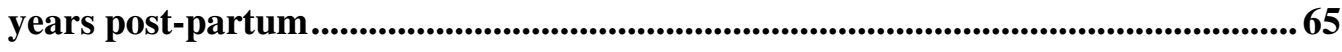

Abstract .........................................................................................................................................66

Introduction ................................................................................................................... 67

Methods ..................................................................................................................................... 68

Results....................................................................................................................................... 73

Discussion ......................................................................................................................... 76

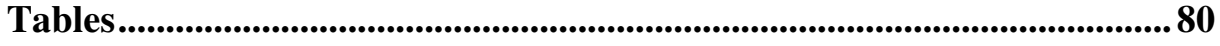

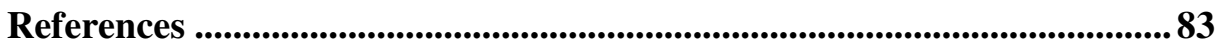


BRIDGE 2 (...................................................................87

CHAPTER 4. MANUSCRIPT 2..............................................89

Serum magnesium, erythrocyte magnesium and cardiovascular risk

profiles in two ethnically distinct populations..................................................89

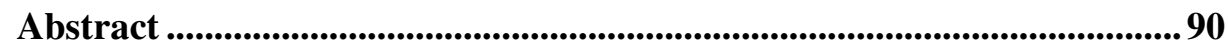

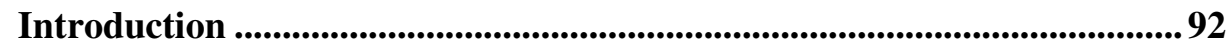

Methods .................................................................................................................................. 93

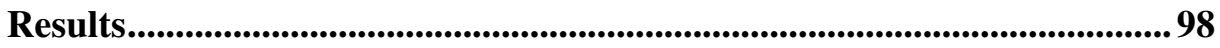

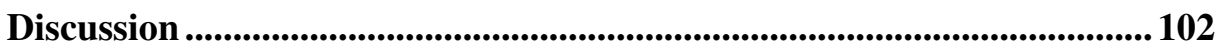

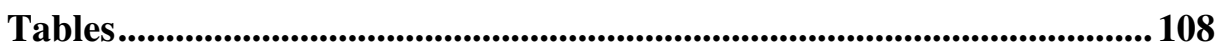

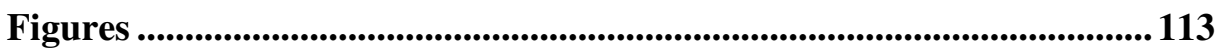

Supplement.............................................................................................................. 121

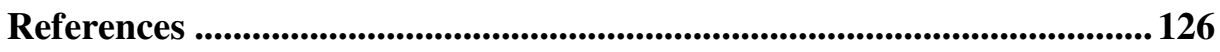

BRIDGE 3...........................................................131

CHAPTER 5: MANUSCRIPT 3........................................133

Low serum magnesium concentrations are associated with high

prevalence of ventricular ectopy in adults with type 2 diabetes............................ 133

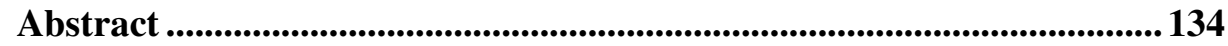

Introduction ..................................................................................................................... 136

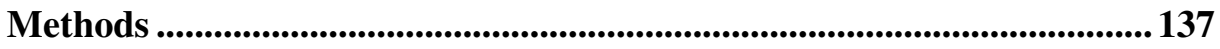

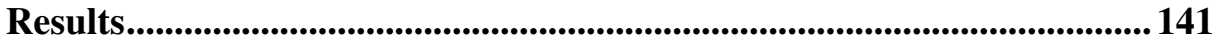

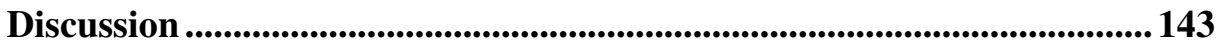

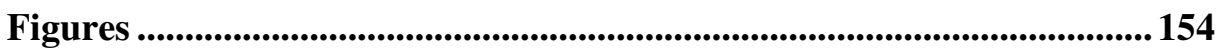

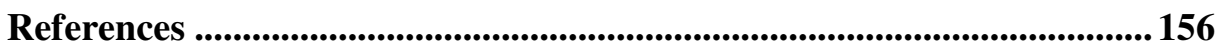

CHAPTER 6: CONCLUSIONS \& SIGNIFICANCE........................161 


\section{ABSTRACT}

Background: Magnesium (Mg) is known to exert diverse actions on cardiometabolic function; suboptimal $\mathrm{Mg}$ intake and status may contribute significantly to adverse metabolic and cardiovascular health (Nielsen, 2010). While type 2 diabetes mellitus (T2DM) is the most common cause of $\mathrm{Mg}$ depletion (Rude \& Shils, 2006), research gaps exist regarding the potential influence of transient states of impaired glycemia, such as gestational diabetes, on subsequent $\mathrm{Mg}$ biomarkers or $\mathrm{Mg}$-glycemic associations in affected mothers or their offspring. Further, whether or not diabetes is an important effect modifier of associations between $\mathrm{Mg}$ biomarkers and cardiovascular endpoints, such as arrhythmias, is unknown.

It has long been observed, however, that the determination of $\mathrm{Mg}$ status is riddled with challenges (Elin, 1985), and no simple, rapid and accurate test has emerged in subsequent decades (Arnaud, 2008). Plasma (pMg) and serum Mg $(\mathrm{sMg})$ remain the most commonly used biomarkers clinically and in the literature; comparatively little is known about erythrocyte $\mathrm{Mg}(\mathrm{rMg})$ and cardiometabolic outcomes.

Mg status across Canada: The Canadian Community Health Survey (2004) revealed that $45 \%$ of males $30-50 \mathrm{yrs}$ and a similar percentage of women had $\mathrm{Mg}$ intakes below the Estimated Average Requirement (EAR); 65\% of men over 71yrs had Mg intake below the EAR. Subpopulations living in Canada report especially low Mg intakes; among aboriginal populations, such as the James Bay Cree from Mistissini, 72.6\% of adult men and a similar percentage of women had 
Mg intake below the EAR. Canadian Inuit adults experiencing food insecurity also consume Mg below recommended levels (Egeland et al., 2011).

Objectives: The main objectives of this thesis were: 1.) to determine if gestational diabetes history prospectively influences $\mathrm{Mg}$ concentrations or associations between $\mathrm{Mg}$ and glycemic variables in mothers and offspring 15-years postpartum (Montreal cohort) 2.) to examine associations between $\mathrm{sMg}, \mathrm{rMg}$ and cardiovascular risk profiles in adults from two ethnically distinct, cross-sectional studies (Cree, Inuit) and evaluate the utility of $\mathrm{rMg}$ as a cardiovascular risk associate; and 3.) to estimate the risk of an arrhythmia associated with mortality, ventricular premature beats, across the $\mathrm{sMg}$ concentration gradient, and assess potential effect modification by T2DM status (Cree).

Methods: Secondary data analysis was conducted on data collected from three diverse studies: 1.) Diabetic Pregnancies: Longitudinal follow-up of motheroffspring pairs (multiethnic Montreal cohort) 2.) Nituuchischaayihtitaau Aschii: A multi-community environment \& health longitudinal study in Iiyiyiu Aschii (Cree survey) 3.) International Polar Year (IPY) Inuit Health Survey (Inuit survey). Associations between $\mathrm{Mg}$ biomarkers and endpoints were examined in multivariate linear and logistic regression models.

Results: Gestational diabetes history 15-yrs prior was associated with reduced $\mathrm{pMg}$ in mothers $(p=0.002)$ and elevated $\mathrm{pMg}$ in teenage offspring $(p=0.002)$ relative to mother and offspring controls without gestational diabetes history. Associations between $\mathrm{Mg}$ status and some glycemic variables (fasting glucose, insulin, and insulin sensitivity) were stronger in mothers and offspring with gestational diabetes history than those without. In Cree adults without T2DM, 
sMg was inversely associated with fasting glucose $(p=0.001)$, in addition to cardiovascular variables such as hsCRP $(p=0.038)$ and carotid-intima media thickness $(p=0.044) . \mathrm{rMg}$ was significantly associated with adiposity in both Cree and Inuit $(p<0.001)$, but no associations between $\mathrm{rMg}$ and fasting glucose, insulin, hsCRP, blood pressure, nor carotid intima-media thickness were observed. In Cree, hypomagnesaemia $(\mathrm{sMg}<0.70 \mathrm{mmol} / \mathrm{L})$ was associated with an increased prevalence of ventricular premature beats $(p<0.05)$. T2DM was a significant effect modifier of the association between $\mathrm{sMg}$ and risk of this arrhythmia $(p<0.05)$.

Conclusions: Transient states of impaired glycemia (gestational diabetes) may be associated with $\mathrm{pMg}$ and its associations with glycemic outcome variables in affected mothers and offspring 15-yrs post-partum. Unlike sMg or $\mathrm{pMg}$, there is no current evidence that total $\mathrm{rMg}$ is significantly associated with a favourable cardiovascular risk profile or adds value to cardiometabolic risk assessment. Prevalence of ventricular premature beats is more common in Cree adults with hypomagnesaemia and T2DM. Further investigations evaluating the potential utility and predictive value of $\mathrm{pMg}$ and $\mathrm{sMg}$ as markers of cardiometabolic risk are warranted. 


\section{RÉSUMÉ}

Contexte: Le magnésium $(\mathrm{Mg})$ est connu pour exercer diverses mesures pour soutenir la fonction cardiométabolique; consommation sous-optimale de Mg et le statut comme tel peuvent contribuer de manière significative à la santé métabolique et cardiovasculaire (Nielsen, 2010). Bien que le diabète de type 2 (T2DM) est la cause la plus courante de l'épuisement de Mg (Rude \& Shils, 2006), des lacunes dans la recherche existent concernant l'influence potentielle des états transitoires de la glycémie affaiblie, tel que le diabète gestationnel sur le statut de Mg ultérieur ou les associations Mg-glycémiques des mères touchées ou de leur progéniture. De plus, si le diabète est un modificateur avec un effet important des associations entre $\mathrm{Mg}$ et les bouts cardiovasculaires, tels que d'arrhythmias, est inconnue. Cependant, il y a longtemps été observé, que la détermination du statut de Mg pose plein de défis (Elin, 1985), et aucun test simple, rapide et précis a émergé dans les décennies suivantes (Arnaud, 2008). Le plasma $\mathrm{Mg}(\mathrm{pMg})$ et le sérum $\mathrm{Mg}(\mathrm{sMg})$ restent les bio-marqueurs utilisés le plus souvent cliniquement et dans la littérature; relativement peu est connu au sujet de $\mathrm{Mg}$ érythrocytaire (rMg) et les résultats cardiométaboliques.

Statut de Mg à travers le Canada: Le Sondage sur la santé des collectivités canadiennes (2004) a révélé que $45 \%$ des hommes de 30-50 ans et un pourcentage similaire de femmes avaient des apports en $\mathrm{Mg}$ dessous du besoin moyen estimatif (BME), 65\% des hommes de plus de 71 ans avait un apport de $\mathrm{Mg}$ dessous le BME. Les sous-populations qui vivent au Canada rapport de l'apport de Mg particulièrement bas ; parmi les populations autochtones, comme les Cris de la Baie James de Mistissini, 72,6\% des hommes adultes et un pourcentage 
semblable de femmes avaient un apport de Mg inférieur au BME. Adultes Inuits canadiens souffrent d'insécurité alimentaire consomment également $\mathrm{Mg}$ dessous des niveaux recommandés (Egeland et coll., 2011).

Objectivifs : Les objectif principaux de ce thèse était: 1.) De déterminer si l'histoire de diabète gestationnel influence prospectivement les concentrations de MG ou les associations entre les variables Mg et de la glycémie chez les mères et leurs enfants de 15 années post-partum (cohorte de Montréal), 2.) Etudier les associations entre le $\mathrm{sMg}, \mathrm{rMg}$ et des profils de risque cardiovasculaires chez les adultes concernant deux études transversales et distincts sur le plan ethnique (Cris, Inuits) et évaluer l'utilité de rMg en tant qu'associé de risque cardiovasculaire; et 3.) Pour estimer le risque d'une arythmie, extrasystoles ventriculaires, à travers le gradient de concentration de sMg et d'évaluer l'effet potentiel de modification selon le statut du T2DM (population Crie).

Méthodes: L'analyse des données secondaires a été réalisée sur des données recueillies auprès de trois études diverses: 1.) Grossesses diabétiques: Suivi longitudinal de la mère-enfants paires (Montréal cohorte multiethnique) 2.) Nituuchischaayihtitaau Aschii:. Une étude multi-communautaire et longitudinal sur l'environnement et la santé dans Iiyiyiu Aschii (sondage Cris) 3.) Songage sur la santé des Inuits:. Quanuippitaa? Comment sommes-nous? (Sondage Inuit). Les associations entre les bio-marqueurs et de paramètres de $\mathrm{Mg}$ ont été considérés dans la linéaire multivariée et la régression logistique.

Résultats : L'histoire du diabète gestationnel de 15 ans avant a été associée à du $\mathrm{pMg}$ réduit de mères $(p=0,002)$ et le $\mathrm{pMg}$ élevée chez leur progéniture adolescente $(p=0,002)$ par rapport aux contrôles des mères et leur progéniture 
sans histoire de diabète gestationnel. Les associations entre le statut de $\mathrm{Mg}$ et de certaines variables glycémique (glycémie à jeûne, l'insuline et la sensibilité à l'insuline) ont été plus prononcés chez les mères et leur progéniture avec l'histoire de diabète gestationnel que les autres. Chez les adultes Crie sans T2DM, le taux de sMg était inversement associé à une glycémie à jeûne $(p=0,001)$, en plus des variables cardiovasculaires telles que l'hsCRP $(p=0,038)$ et la carotide intimamédia d'épaisseur $(p=0,044)$. rMg était significativement associé à l'adiposité chez les Cris et les Inuits ( $p<0,001)$, mais aucune association entre le rMg et le glucose du jeûne, d'insuline, de hsCRP, la pression sanguine, ni carotidienne épaisseur intima-média ont été observées. Chez les Cris, la hypomagnésémie ( $\mathrm{sMg}<0.70 \mathrm{mmol} / \mathrm{L})$ était associée à une prévalence accrue des extrasystoles ventriculaires prématurés $(p<0,05)$. Le diabète de type 2 était un modificateur d'effet significatif de l'association entre le sMg et le risque de cette arythmie ( $p$ $<0,05)$.

Conclusions: Les états transitoires de la glycémie affaiblie (le diabète gestationnel) peuvent influencer le $\mathrm{pMg}$ et des associations avec les variables des résultats de la glycémie chez les mères touchées et leur progéniture de 15 ans post-partum. Contrairement au sMg ou au pMg, il n'existe aucune preuve actuelle que le rMg totale est associée à un profil de risque cardiovasculaire favorable ou ajoute une valeur à l'évaluation du risque cardiométabolique. Prévalence d'une arythmie associée à un risque élevé de mortalité est plus fréquente chez les adultes Cris avec l'hypomagnésémie et T2DM. D'autres investigations évaluent l'utilité potentielle et la valeur prédictive de $\mathrm{Mg}$ extracellulaire (pMg et $\mathrm{sMg}$ ) comme marqueurs du risque cardiométabolique sont appropriées. 


\section{References}

1. Arnaud, M.J., Update on the assessment of magnesium status. British Journal of Nutrition 2008, 99 (3), S24-36.

2. Canadian Community Health Survey: Nutrition focus. 2004. Available online: http://www.hc-sc.gc.ca/fn-an/surveill/nutrition/commun/cchs_focusvolet_escc-eng.php\#order. Last accessed: May 2010.

3. Egeland, G.M.; Johnson-Down, L.; Cao, Z.R.R.; Sheikh, N.; Weiler, H., Food insecurity and nutrition transition combine to affect nutrient intakes in Canadian Arctic communities. Journal of Nutrition 2011, 141 (9), 1746-1753.

4. Elin, R.J., Overview of problems in diagnosis of magnesium status. Journal of the American College of Nutrition 1985, 4 (3), 330-330 (abstract).

5. Nielsen, F.H., Magnesium, inflammation, and obesity in chronic disease. Nutrition Reviews 2010, 68 (6), 333-340.

6. Rude, R.K. \& Shils, M.E. Magnesium. In: Modern nutrition in health and disease, $10^{\text {th }}$ edition. 2006, Lippincott Williams \& Wilkins: Baltimore, MD. 


\section{ADVANCE OF SCHOLARLY KNOWLEDGE}

\section{Original contributions to knowledge}

-Observes significantly different $\mathrm{pMg}$ concentrations in mothers with history of gestational diabetes and offspring that developed during diabetic pregnancy in comparison to control mothers and offspring

-Shows that $\mathrm{pMg}$ is significantly associated with fasting insulin and insulin sensitivity in mothers with gestational diabetes history, but not control mothers

-Finds inverse associations between $\mathrm{pMg}$ and $\mathrm{dMg}$ to glycated hemoglobin and fasting glucose, respectively, among nondiabetic 15 -year olds

-Evaluates, for the first time, the utility of $\mathrm{rMg}$ as a potential cardiometabolic risk biomarker in a general population context; opposes its use -Reports the unadjusted and adjusted correlations between $\mathrm{sMg}$ and $\mathrm{rMg}$ for the first time, with modifying effects of age and gender

-Uncovers a positive association between rMg and adiposity, of similar magnitude, in two distinct ethnic populations

-Corroborates the debated literature finding that $\mathrm{sMg}$ is associated with LDL and total cholesterol in a general adult population

-Reports reduced prevalence of premature ventricular beats across the $\mathrm{sMg}$ concentration gradient in adults with T2DM

-Reveals, for the first time, that T2DM status is an important effect modifier of the association between $\mathrm{sMg}$ and an arrhythmia linked to increased mortality risk 


\section{Abstracts and manuscripts submitted to peer-reviewed scientific journals}

-Del Gobbo, L.C, Magnesium biomarkers and cardiometabolic endpoints in multiethnic populations

-Del Gobbo, L.C.; Song, Y.; Elin, R.J.; Meltzer, S.J.; Egeland, G.M., Gestational glucose intolerance modifies the association between magnesium concentrations and glycemic measures in mothers and daughters 15 - years postpartum

-Del Gobbo, L.C.; Song, Y.; Elin, R.J.; Noel, M.; Dewailly, E.; Egeland, G.M., Serum magnesium, erythrocyte magnesium \& cardiovascular risk profiles in two ethnically distinct populations

-Del Gobbo, L.C.; Song, Y.; Poirier, P.; Dewailly, E.; Elin, R.J.; Egeland, G.M., Low serum magnesium concentrations are associated with high prevalence of premature ventricular beats in obese adults with type 2 diabetes

-Del Gobbo, L.C.; Elin, R.J.; Poirier, P.; Egeland, G.M., Serum

magnesium: a biomarker of cardiovascular risk revisited? 


\section{CONTRIBUTIONS OF AUTHORS TO MANUSCRIPTS}

The candidate was responsible for conducting statistical analysis, primary interpretation, and writing of the abstracts, manuscripts and thesis. The candidate planned in collaboration with the supervisor, Dr. Grace Egeland, the analysis of erythrocyte $\mathrm{Mg}$ in Cree and Inuit populations, and was responsible for deciding which specific outcome variables would be examined for each manuscript.

Dr. Grace Egeland was a principal investigator of all three studies featured in this thesis, directed manuscript development, provided critical review of statistical analysis and data interpretation, and edited all manuscripts included in this thesis.

Dr. Yiqing Song was a committee member and co-author, provided guidance and critical review of statistical analyses and data interpretation, and edited all manuscripts included in this thesis.

Dr. Ronald Elin was a committee member and co-author, provided insight regarding Mg determination and methodology, suggested revisions and edits of all manuscripts included in this thesis.

Dr. Sara Meltzer was a principal investigator of the diabetic pregnancy study; Dr. Eric Dewailly was a principal investigator of the Inuit and Cree health surveys.

Dr. Martin Noel performed carotid intima-media thickness ultrasounds and critically reviewed manuscript 2 .

Dr. Paul Poirier provided cardiovascular expertise and critical review of manuscript 3 . 


\section{ACKNOWLEDGEMENTS}

First and foremost, I thank my parents, Lucy and Dave, for their loving support throughout my life and extraordinary patience during occasionally rambling and unsolicited phone lectures about magnesium. I thank my older brother David, who is admired more than he knows for his wisdom and kind heart by myself and his now two beautiful children, Brennan and Kiara. All three of you are great teachers, both literally and figuratively. To my younger brother Daniel, who began as my main playmate and accomplice in mischievous schemes, you have transitioned into a loving friend and impressive young man, despite your questionable fondness of bowties.

I thank also my extended family, my sister-in-law Tania, my uncles Danny and Pat, for their support and always open arms. Monali Ray, Ahmed Huzayyin, Abbey Radis, Ashley Cousins, Shaheen Alarakhia, Jayne Murdoch and Joseph Paul Flowers, I have valued your friendships greatly.

A very special thanks is due to the mother-daughter, Cree and Inuit research participants, without whom this thesis would have been impossible. I have been very fortunate with my supervisor, Grace Egeland, who has allowed me to work on such ground-breaking health surveys, with time spent both on computers and in small villages, and permitted latitude in manuscript design. My good fortune continued in collaborating with committee members. To Yiqing Song, your patience, kindness, expertise and critical review has been invaluable. I have been honored to have had Ronald Elin provide helpful commentary and share his insights on magnesium measurement and research. To Katherine Gray- 
Donald, I admire your passion for reducing obesity and disease burden through interventional approaches, and have enjoyed our office chats on these topics.

Undoubtedly, no academic thesis acknowledgments can be complete without an obscure quotation intelligible only to the author. When I was twenty, I preemptively fancied myself a scientist:

"What fascinates us is the unknown, yet we seek its mitigation. Mystery is a stone on which we hop, the greatest motivation to move at all. We leap from stone to stone, and if our methods support us, the stones become smaller and smaller with each leap. Yet the stones never disappear... maybe we do not want them to, completely. We fantasize about pebbles." 


\section{LIST OF TABLES}

Table 3-1. Plasma magnesium $(\mathrm{mmol} / \mathrm{L})$ in relation to demographic and lifestyle characteristics in mothers $(n=166)$ and their 15 -year old daughters $(n=166) \ldots \ldots .80$

Table 3-2. Linear regression results $(\beta \pm \mathrm{SE} ; p)$ for plasma $\mathrm{Mg}(\mathrm{pMg})$ and dietary $\mathrm{Mg}(\mathrm{dMg})$, covariates and glycemic dependent variables in mothers $(\mathrm{n}=166) \ldots . \mathbf{8 1}$ Table 3-3. Linear regression results $(\beta \pm \mathrm{SE} ; p)$ for plasma $\mathrm{Mg}(\mathrm{pMg})$ and dietary $\mathrm{Mg}(\mathrm{dMg})$, covariates and glycemic dependent variables in daughters $(\mathrm{n}=166) \ldots \mathbf{8 2}$ Table 4-1. Participant characteristics according to serum (sMg) and erythrocyte $(\mathrm{rMg})$ concentrations in nondiabetic Cree and Inuit adults $(\mathrm{n}=1327) \ldots \ldots \ldots \ldots . .108$

Table 4-2. Multivariate linear regression results for Mg biomarkers \&

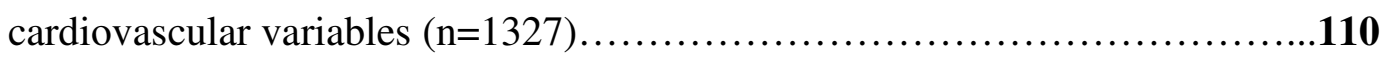

Table 4-3. Linear regression coefficients for $\mathrm{Mg} \mathrm{x}$ sex interaction terms.........111

Table 4-4. Linear regression coefficients for $\mathrm{Mg}$ x age interaction terms........112

Table 5-1. Medical chart review of adults $\geq 18$ yrs of the general Cree population $(n=750)$

Table 5-2. Characteristics of Cree adults $\geq 18$ yrs according to ventricular premature complexes (PVC) prevalence during Holter electrocardiogram

Table 5-3. Adjusted odds ratios \& $95 \%$ confidence intervals for presence of $\geq 1$ PVC on 2-hr Holters across the sMg concentration range $(n=750) \ldots \ldots \ldots \ldots \ldots . .150$ Table 5-4. Adjusted odds ratios \& 95\% confidence intervals for presence of $\geq 1$ PVC on 2-hr Holters among patients with T2DM but without CVD history $(n=149)$

Table 5-5. Adjusted odds ratios \& 95\% confidence intervals for presence of $>6$ 
Table 5-6. Odds ratios for the fully adjusted model for presence of $>6 \mathrm{PVC} / \mathrm{hr}$ on

Holters are minimized using $<0.75 \mathrm{mmol} / \mathrm{L}$ as the reference $(\mathrm{n}=750) \ldots \ldots \ldots . .153$ 


\section{LIST OF FIGURES}

Figure 4-1. Partial correlations between serum (sMg) and erythrocyte (rMg)

magnesium according to age and sex among nondiabetic adults $(\mathrm{n}=615)$.

Figure 4-2. Total erythrocyte magnesium (rMg) and body mass index (BMI) in

Inuit \& Cree adults $(\mathrm{n}=1327)$

Figure 4-3a. Adjusted mean fasting glucose according to sMg concentrations

$(\mathrm{mmol} / \mathrm{L})$ in participants with and without the metabolic syndrome (MetS)....115

Figure 4-3b. Adjusted mean hsCRP according to sMg concentrations (mmol/L) in participants with and without the metabolic syndrome (MetS)

Figure 4-3c. Adjusted mean total carotid IMT according to sMg concentrations

$(\mathrm{mmol} / \mathrm{L})$ in participants with and without the metabolic syndrome (MetS)....117

Figure 4-4a. Unadjusted rMg means (ANOVA) by sMg concentration groupings

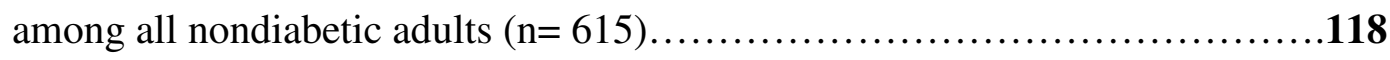

Figure 4-4b. Unadjusted rMg means (ANOVA) by sMg concentration groupings

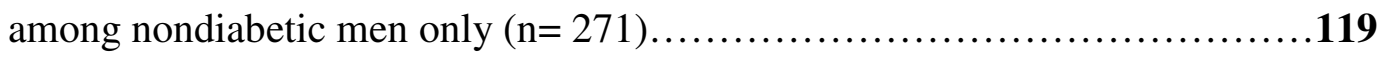

Figure 4-4c. Unadjusted rMg means (ANOVA) by sMg concentration groupings

among nondiabetic women only $(n=344)$

.120

Figure 5-1. Unadjusted prevalence of premature ventricular complexes (PVC)

during $2 \mathrm{hr}$ Holter electrocardiogram among adults $(\mathrm{n}=750)$ according to

groupings of $\mathrm{sMg}$ concentrations (mmol/L).

Figure 5-2. Unadjusted prevalence of PVC during 2hr Holter electrocardiogram among adults without CVD $(\mathrm{n}=652)$ by groupings of $\mathrm{sMg}$ concentrations

(mmol/L) and by diabetic status 


\section{COMMON ABBREVIATIONS}

CRP: C-reactive protein

$\mathrm{dMg}$ : dietary magnesium

EAR: estimated average requirement

GDM: gestational diabetes mellitus

IMT: intima-media thickness

MetS: the metabolic syndrome

Mg: magnesium

pMg: plasma magnesium

PVC: premature ventricular complexes

RDA: recommended dietary allowance

sMg: serum magnesium

T2DM: type 2 diabetes mellitus 


\section{CHAPTER 1. INTRODUCTION}

\section{Background \& rationale}

Magnesium (Mg) plays an integral role in diverse biological processes, acting as a cofactor in more than 300 essential metabolic reactions. The primary action of $\mathrm{Mg}$ is related to its crucial role in ATP utilization; ATP exists in all cells primarily as $\mathrm{MgATP}^{2-}$. In carbohydrate metabolism, $\mathrm{Mg}$ is required for hexokinase phospholyration in glycolysis, the citric acid cycle, and three of four requisite enzymes in gluconeogenesis (Cowan, 1995). $\mathrm{Mg}$ is also important for lipid metabolism, in the second messenger systems, and in electrolyte balance (Rude \& Shils, 2006). A growing body of evidence from animal and other physiologic studies has suggested that suboptimal Mg intake and status impairs glucose, lipid, and electrolyte metabolism. Accumulating observational evidence from large prospective studies suggests that suboptimal $\mathrm{Mg}$ intake or status is associated with T2DM development and increased cardiovascular risk. $\mathrm{Mg}$ supplementation trials in T2DM and clinical administration for arrhythmia termination and prevention have shown a potential benefit (eg. Song et al., 2006; Miller et al., 2005; Ho et al., 2007).

Dietary survey data suggests that the average intake of $\mathrm{Mg}$ in Western nations has declined during the last century and intakes often fall below the RDA (Saris et al., 2002). The Canadian Community Health Survey (2004) revealed that $45 \%$ of males $30-50 \mathrm{yrs}$ and a similar percentage of women had $\mathrm{Mg}$ intake below the EAR; $65 \%$ of men over $71 \mathrm{yrs}$ had Mg intake below the EAR. In aboriginal populations, $\mathrm{Mg}$ intakes are particularly low and vary by gender and community. In James Bay Cree from Mistissini, $72.6 \%$ of adult men and a similar percentage 
of women had a Mg intake below the EAR (Mistissini Report, 2007). In Cree from Eastmain, Wemindji, and Waskaganish, more men (>30yrs) had intakes below the EAR $(86.4 \%, 75.3 \%$, and $62.5 \%$, respectively) than women $(30.6 \%$, $40.4 \%$, and $45.7 \%$, respectively). Canadian Inuit adults experiencing food insecurity also consume $\mathrm{Mg}$ below recommended levels (Egeland et al., 2011a).

While T2DM is now a worldwide epidemic, currently affecting over 220 million people, and cardiovascular disease remaining the main cause of mortality across the globe, the prevalences of these conditions vary among different populations (Wild et al., 2004). Aboriginal communities living in Canada are facing marked increases in cardiometabolic risk due to lifestyle changes and dietary transition towards the unhealthy facets of a Westernized dietary pattern. The prevalence of T2DM in the Cree of Eastern James Bay is currently among highest in the world (Harris et al., 1997). In 2005, the age-adjusted prevalence diabetes in James Bay Cree (age >20 y) was approximately 22\%, 3-5 times 2005 age-adjusted prevalence of the general Canadian or American populations (Narayan et al., 2006). Increased rates of complications in Cree relative to the general North American diabetic population, exacerbated by constraints in healthcare resources, underscore the importance of prevention of T2DM in this high-risk population.

Elevated central adiposity and triglyceride concentrations in Inuit are increasing metabolic risk in this population, such that T2DM prevalence in Inuit is now comparable to that observed in the general Canadian population (Egeland et al., 2011b). Other at-risk subpopulations for developing T2DM and 
cardiovascular disease include women with a history of GDM and their offspring who developed during the diabetic pregnancy (Bellamy et al., 2009).

\section{Hypothesis}

Based on reports of inadequate $\mathrm{Mg}$ intakes and previous literature indicating the importance of $\mathrm{Mg}$ for cardiometabolic function, it is hypothesized that elevated magnesium biomarkers are associated with more favourable cardiometabolic risk profiles in these three aforementioned at-risk subpopulations: adult Cree, Inuit, and mother-offspring pairs with a history of gestational diabetes.

\section{Objectives}

The specific objectives of this work are:

1. to determine if GDM history modifies associations between $\mathrm{Mg}$ and glycemic variables in mothers and offspring 15-years post-partum (Montreal cohort)

2. to examine associations between $\mathrm{sMg}, \mathrm{rMg}$ and cardiovascular risk profiles in adults from two ethnically distinct, cross-sectional studies (Cree, Inuit)

3. to determine if the same cardiovascular associations observed with total $\mathrm{sMg}$ hold for $\mathrm{rMg}$

4. to comment on the use of $\mathrm{sMg}$ and $\mathrm{rMg}$ as cardiovascular risk biomarkers

5. to estimate the risk of an arrhythmia associated with increased mortality risk, premature ventricular beats, across the $\mathrm{sg}$ concentration gradient within the context of a general adult population

6. to evaluate potential effect modification by T2DM status on the association between sMg and premature ventricular beats 


\section{Significance}

If associations between $\mathrm{Mg}$ and cardiometabolic variables are revealed, this work will provide the foundation for future follow-up studies and potential interventions to improve $\mathrm{Mg}$ biomarkers among these high risk populations.

In Chapter 1, the current state of the evidence linking Mg to metabolic and cardiovascular endpoints is reviewed. 


\section{References}

1. Bellamy, L.; Casas, J.; Hingorani, A.D.; et al., Type 2 diabetes mellitus after gestational diabetes: a systematic review and meta-analysis. Lancet 2009, 373 (9677), 1773-1779.

2. Canadian Community Health Survey: Nutrition focus. 2004. Online available: http://www.hc-sc.gc.ca/fn-an/surveill/nutrition/commun/cchs_focusvolet_escc-eng.php\#order. Last accessed: May 2010.

3. Egeland, G.M.; Johnson-Down, L.; Cao, Z.R.R.; Sheikh, N.; Weiler, H., Food insecurity and nutrition transition combine to affect nutrient intakes in Canadian Arctic communities. Journal of Nutrition 2011a, 141 (9), 1746-1753.

4. Egeland, G.M.; Cao Z.; Young, Q.T., Hypertriglyceridemic-waist phenotype and glucose intolerance among Canadian Inuit: the International Polar Year Inuit Health Survey for Adults 2007-2008. Canadian Medical Journal 2011b, 183 (9), E553-E558.

4. Cowan, J.A., Ed. Introduction to the biological chemistry of magnesium. In: The biological chemistry of magnesium. 1995, VCH Publishers: New York, NY.

5. Harris, S.B.; Gittelsohn, J.; Hanley, A.; et al., The prevalence of NIDDM and associated risk factors in native Canadians. Diabetes Care 1997, 20, 185-187. 6. Ho, K.M.; Sheridan, D.J.; Paterson, T., Use of intravenous magnesium to treat acute onset atrial fibrillation: a meta-analysis. Heart 2007, 93 (11), 14331440. 
7. Miller, S.; Crystal, E.; Garfinkle, M.; Lau, C.; Lashevsky, I.; Connolly, S.J., Effects of magnesium on atrial fibrillation after cardiac surgery: a metaanalysis. Heart 2005, 91 (5), 618-623.

8. Mistissini technical report: summary of activities, results and recommendations of Nituuchischaayihtitaau Aschii Multi-community Environment-and-health Longitudinal Study in Iiyiyiu Aschii. 2007. Available online:

[http://www.creehealth.org/sites/default/files/Environmental\%20Health\%20Study -\%20Technical\%20Report\%20of\%20Mistissini.pdf]. Last accessed: Sept 2011.

9. Narayan, K.M.; Boyle, J.P.; Geiss, L.S.; Saaddine, J.B.; Thompson, T.J., Impact of recent increase in incidence on future diabetes burden: U.S., 2005-2050. Diabetes Care 2006, 29, 2114-2116.

10. Rude, R.K. \& Shils, M.E., Magnesium. In: Modern Nutrition in Health and Disease, $10^{\text {th }}$ edition. 2006,.Lippincott Williams \& Wilkins: Baltimore, MD. 11. Saris, N.E.; Mervaala, E.; Karppanen, H.; Khawaja, J.A.; Lewenstam, A., Magnesium. An update on physiological, clinical and analytical aspects. Clinica Chimica Acta 2000, 294, 1-26.

12. Song, Y.; He, K.; Levitan, E.B.; Manson, J. E.; Liu, S., Effects of oral magnesium supplementation on glycaemic control in Type 2 diabetes: a metaanalysis of randomized double-blind controlled trials. Diabetic Medicine 2006, 23 (10), 1050-1056.

13. Wild, S.; Roglic, G.; Green, A.; Sicree, R.; King, H., Global prevalence of diabetes: estimates for the year 2000 and projections for 2030. Diabetes Care 2004, 27, 1047-1053. 


\section{CHAPTER 2. LITERATURE REVIEW}

\subsection{Body composition}

Magnesium $(\mathrm{Mg})$ content of the human body ranges from less than $1 \mathrm{~g}$ at birth to approximately $25 \mathrm{~g}$ in adulthood (Widdowson et al., 1951; Schroeder et al., 1969; Forbes et al., 1987). Approximately 53\% of body $\mathrm{Mg}$ is found in the bone of healthy adults (Wallach, 1990), which can serve as a mineral store in times of deficiency to maintain extracellular (1\% of $\mathrm{Mg}$ ) and intracellular (99\% of Mg) pools (Elin, 1994; Rude \& Shils, 2006). Remaining total body Mg is found in muscle (27\%), soft tissue (19\%), adipose tissue (0.012\%) (Snyder et al., 1975), erythrocytes (rMg) (0.5\%) and serum (sMg) (0.3\%) (Rude \& Shils, 2006). Total $\mathrm{sMg}$ is largely found in free form (65\% of $\mathrm{Mg}), 8 \%$ is complexed, and the remainder is bound. Intracellular $\mathrm{Mg}$ ranges between 5 and $20 \mathrm{mM}$ and is mostly ligand-bound, with free $\mathrm{Mg}$ constituting only 1-5\% of the total cellular $\mathrm{Mg}$ (Gunther, 1986).

\subsection{Absorption}

The jejunum and ileum of the small intestine absorb approximately 30$50 \%$ of $\mathrm{Mg}$ intake in healthy adults. At high intraluminal concentrations, paracellular diffusion dominates, and active uptake by Mg-specific transporters

occurs at lower concentrations (Pham et al. 2007). Several transcellular $\mathrm{Mg}^{2+}$ transporters have been fairly recently identified; these include transient receptor potential melastatin 6 and 7 (TRPM6 and TRPM7), the former predominately expressed in epithelial cells, and the latter ubiquitously (Schlingmann et al., 2007; Chubanov et al., 2007, Yogi et al., 2011). 
Absorption of Mg decreases with age, the presence of some chronic diseases, and with increasing Mg consumption (Graham et al., 1960). Phosphate may decrease $\mathrm{Mg}$ absorption, as do major increases in zinc intake (from 12 to 142mg/day) (Spencer et al., 1994). Depletion of vitamin B6 may increase urinary excretion of Mg (Turnlund et al., 1992). Dephytinized barley fiber appears to decrease $\mathrm{Mg}$ utilization, while cellulose and fructo-oligosaccharides may increase absorption and utilization (Whisker et al., 1991; Slavin et al., 1980; van den Heuvel et al., 2009). Mg absorption may be reduced at low protein intakes: $\mathrm{Mg}$ absorption was lower at protein intakes of 43 grams/day vs. 93 grams/day in adolescent boys (Schwartz et al., 1973). Also, children who consumed the $\mathrm{Mg}$ Recommended Dietary Allowance (RDA) were in negative $\mathrm{Mg}$ balance at high calcium intakes (Abrams et al., 1997).

\subsection{Risk factors and causes of Mg deficiency}

Gastrointestinal disorders can cause Mg deficiency in different ways. The $\mathrm{Mg}$ content of diarrheal fluids is high, thus acute or chronic diarrhea may contribute to depletion in Crohn's disease, Whipple's disease, ulcerative colitis, celiac disease, and short bowel syndrome (Galland, 1988). Mg content is high in fistulous drainage and some $\mathrm{Mg}$ is also found in upper intestinal tract fluid, such that prolonged nasogastric suction or vomiting may contribute to $\mathrm{Mg}$ depletion (Alghamdi et al.,1994). Resection or bypass of the small bowel, especially the ileum, often results in Mg loss (Dyckner et al, 1982; Van Gaal et al., 1987). Other gastrointestinal causes of $\mathrm{Mg}$ deficiency include acute hemorrhagic pancreatitis, protein-calorie malnutrition, and primary defects in TRPM6 (Schlingmann et al., 2005). 
Renal causes of Mg deficiency include Bartter's and Gitelman's syndrome, post obstructive diuresis, tubular necrosis, transplantation, and nephropathy (Alghamdi et al., 1994). Renal reabsorption is inhibited by poor tubular fluid flow and retention of sodium and calcium; therefore, long-term use of parenteral fluid therapy with saline, volume expansion related to primary aldosteronism and hypercalcemia can result in Mg depletion (Rude \& Shils, 2006). Glucosuria can have an osmotic effect resulting in urinary Mg wasting (Mather et al., 1979); hypomagnesaemia $(\mathrm{sMg}<0.70 \mathrm{mmol} / \mathrm{L})$ is most common in diabetics. Excess alcohol consumption leads to high urinary $\mathrm{Mg}$ loss, contributing to $\mathrm{Mg}$ depletion in alcoholism (Abbott et al., 1994). As the major site of renal $\mathrm{Mg}$ reabsorption is the loop of Henle, diuretics such as furosemide result in $\mathrm{Mg}$ wasting.

Other drugs leading to $\mathrm{Mg}$ loss include but are not limited to cisplatin, aminoglycosides, cyclosporine, amphotericin B, proton-pump inhibitors (Kuipers et al., 2009). Hungry bone syndrome may also contribute to Mg deficiency (Frisch et al., 1993). Animal studies demonstrate altered membrane structure during $\mathrm{Mg}$ deficiency (Elin \& Tan, 1977).

\section{PART 1: Mg, Inflammation \& Metabolic Derangements}

\subsection{Mg \& Inflammation}

In response to stress or environmental insult, inflammatory mediators including interleukin 1 (IL-1) and IL6, glucocorticoids and growth factors, stimulate hepatic synthesis and regulate acute-phase proteins. Acute phase proteins, including $\mathrm{C}$ reactive protein (CRP), fibrinogen, serum amyloid and others, contribute to host defense but are atherosclerotic risk factors (Danesh et al., 2005; Shah et al., 2009), observed in elevated concentrations in many chronic 
inflammatory diseases. Mechanisms linking the inflammatory response to $\mathrm{Mg}$ deficiency are not clear, but available evidence suggests the involvement of: 1.) Cellular entry of calcium

In myocytes, $\mathrm{Mg}$ inhibits extracellular calcium influx via a voltage sensitive calcium channel, calcium release from sarcoplasmic reticulum (Meissner et al., 1987), and may suppress calcium overload in the myocardium (Hasebe \& Kukuchi., 2007). Excess extracellular calcium relative to Mg has been implicated in the inflammatory response of experimental $\mathrm{Mg}$-deficiency in animal models (Bussiere et al., 2002). In Mg-deficient rats, Ca-deficiency induced hypocalcemia and offered significant protection against the pro-inflammatory effect of $\mathrm{Mg}$ deficiency (Bussiere et al., 2002).

2.) N-methyl-D-aspartate (NMDA) receptor activation \& release of substance $P$ NMDA is a glutamate receptor with voltage-dependent activation that can be blocked by extracellular Mg ions. During experimental Mg deficiency, NMDA is activated (Mazur et al., 2007) and leads to release of neuropeptide substance P. During the progression of Mg deficiency in rodents, Weglicki \& Phillips (1992) observed a peak in the serum level of substance P after only 5 days on the restricted diet. Substance $\mathrm{P}$ degranulates mast cells; during degranulation, mast cells release histamine, cytokines, including IL-1, IL-6, TNF-alpha and other inflammatory markers. After an initial rise at day 12, after 3 weeks on a Mgdeficient diet, dramatic increases in serum levels of inflammatory cytokines (IL-1, IL-6, and TNF-alpha) were observed. The authors hypothesized that the release of substance P may be the earliest pathophysiological event leading to release of inflammatory cytokines in this model, which may consequently stimulate free 
radical damage. The association between $\mathrm{Mg}$ deficiency and elevated substance $\mathrm{P}$ was corroborated in another rodent model, in which Mg deficiency induced a 9fold elevation in plasma substance $\mathrm{P}$ (vs. Mg sufficient, $p<0.01$ ) (Mak et al., 2008). Further, when rats were treated with a substance P receptor blocker, inflammatory markers declined (Weglicki et al., 1994). Substance P promotes neutrophil activation and induces NO production (Mak et al., 2003), processes which may play a role in oxidative stress, subsequent blood glutathione depletion and cardiac dysfunction (Laires and Monteiro, 2007).

Tejero-Taldo et al. (2004) showed that in mice, blocking the NMDA receptor with an antagonist prevented substance $\mathrm{P}$ release and subsequent inflammatory marker increases in Mg-deficient mice. NMDA blockade also reduced prostaglandin E2 in plasma and loss of red blood cell glutathione, suggesting a role for SP in the pro-inflammatory/pro-oxidative events seen in $\mathrm{Mg}$ deficiency (Tejero-Taldo et al., 2006).

3.) Membrane oxidation and activation of nuclear factor-kappa $B(\mathrm{NF \kappa B})$

$\mathrm{NF \kappa B}$ is present in the cytoplasm in an inactive form, where it can be activated in response to many different stress conditions such as infection, inflammation, heat shock, and oxidative stress. NFkB expression in aortic and cerebral vascular smooth muscle cells were upregulated by a decrease in extracellular magnesium ions (Altura et al., 2003). Upregulation of these transcriptional factors was inversely proportional to the concentration of $\mathrm{Mg}$ in patients presenting with hypertension, ischemic heart disease, and stroke.

4.) Systemic inflammatory response 
Many epidemiological analyses have examined $\mathrm{Mg}$ in relation to $\mathrm{C}$ reactive protein (CRP). While integration of $\mathrm{CRP}$ into cardiovascular risk equations has proved challenging, and the causality of CRP in cardiovascular disease has been questioned (Arsenault et al., 2011), authors of the Emerging Risk Factors Collaboration (ERFC) provide evidence from a meta-analysis of 54 long term prospective studies demonstrating the importance of CRP as predictive of coronary heart disease and mortality (ERFC, 2010). Inverse associations between dietary and sMg concentrations and CRP have been reported in cross-sectional studies involving or exclusively including overweight and obese subjects (Evangelopoulos et al., 2008; Song et al., 2005; King et al., 2005; GuerreroRomero et al., 2002). In a cross-sectional analysis of 657 women from the Nurses' Health Study cohort $(n=657), d M g$ was inversely associated with plasma concentrations of CRP ( $p=0.003$ ) in linear analyses adjusted for age. Multivariateadusted mean CRP for women in the highest quintile of $\mathrm{dMg}$ was $24 \%$ lower than women in the lowest quintile (CRP: $1.70 \pm 0.18$ compared to $1.30 \pm 0.10 \mathrm{mg} / \mathrm{dL}$; $p=0.03$ ) (Song et al., 2007). In adults consuming less than 50\% of the $\mathrm{Mg} \mathrm{RDA}$, individuals consuming at least 50mg/day $\mathrm{Mg}$ through supplements were $22 \%$ less likely to have elevated serum CRP (King et al., 2005). By contrast, Bo et al. (2006) showed that healthy adults $(\mathrm{n}=205)$ within the lowest tertile of $\mathrm{Mg}$ intakes were 3-4 times more likely to have a high sensitivity C-reactive protein (hsCRP) concentration $\geq 3 \mathrm{mg} / \mathrm{L}$, but the association was no longer significant after correction for fiber.

Although small in size, $\mathrm{Mg}$ supplementation trials show promise in reducing systemic inflammation as measured by CRP. Among older individuals, 
Mg supplementation decreased plasma CRP in participants with baseline CRP values $>3.0 \mathrm{mg} / \mathrm{L}$ (Nielsen et al., 2010). In a small interventional study ( $\mathrm{n}=68$ ) supplementing 17 heart failure patients with $300 \mathrm{mg} /$ day oral magnesium citrate (12.5mmol), CRP declined significantly in the treated group but no significant change was observed in 18 untreated patients (Almoznino-Sarafian et al., 2007). Similarly, in subjects with low $\mathrm{sMg}(<0.74 \mathrm{mmol} / \mathrm{L})$, elevated serum CRP $(\geq 3 \mathrm{mg} / \mathrm{L})$ and TNF-alpha levels ( $\geq 3.5 \mathrm{pg} / \mathrm{mL}$ ), those randomly allocated daily magnesium chloride $\left(\mathrm{MgCl}_{2}\right)$ of $2.5 \mathrm{~g}$ (representing $\sim 300 \mathrm{mg} / \mathrm{day}$ of $\mathrm{Mg}$, or 12.5mmol, $\mathrm{n}=31$ ) experienced over a $40 \%$ decline in CRP and over a $30 \%$ decline in TNF-alpha after a 12 week trial while TNF-alpha increased in the placebo group (Guerrero-Romero et al., 2006).

\subsection{Mg \& Oxidative Stress}

Mg prevents catecholamine release and participates in synthesizing reduced glutathione (GSH) (Minnich et al., 1971). The formation of reactive oxygen species (ROS) and lipid peroxidation markers thibarbituric acid reactive substances (TBARS) are elevated in Mg deficient rodents (Rayssiguier et al., 1993). Structural damage affecting the sarcoplasmic reticulum was associated with these elevations and impairment of intracellular calcium homeostasis (Malpuech-Brugere et al., 1998). In rats fed low Mg diets, enhanced oxidative injury to lipids and proteins was indicated by significantly increased carbonyl content and TBARS compared to controls (Boparai et al., 2007) and reduced glutathione peroxidase activity (Martin et al., 2008).

In pre-eclamptic women, treatment with $\mathrm{MgSO}_{4}{ }^{2-}$ reduced lipid peroxidation markers (TBARS, conjugated dienes) to levels comparable to 
normotensive pregnant women (Abad et al., 2005, Abad et al., 2010). Interacting protein methionine sulfoxide reductase B1 (MsrB1) may modulate TRPM6 during oxidative stress (Cao et al., 2010).

\subsection{Mg \& The Metabolic Syndrome (MetS)}

MetS is a combination of health risk factors, which when simultaneously present, increase cardiovascular disease and T2DM risk. Major definitions were devised by the International Diabetes Association, World Health Organization, European Group for the Study of Insulin Resistance, and the American Diabetes Association/ US National Cholesterol Education Program Adult Treatment Panel, with some differences but common central features. In 2009, the MetS definition was unified among major organizations as any three of the following five factors: elevated waist circumference, elevated triglycerides (TG), decreased high density lipoprotein (HDL), elevated low density lipoprotein (LDL), and elevated fasting glucose (FG), or drug treatment of any of the latter four risk factors (Alberti et al., 2009). Obesity, low physical activity, poor diet and lifestyle habits, genetic factors and/or endocrine disorders contribute to MetS development.

MetS risk components are important in the prognosis of incident coronary heart disease (Knuiman et al., 2009). Increased dMg intake is associated with low prevalences and incidences of MetS; Mg reduces insulin resistance, improves serum lipid profiles, reduces inflammation, oxidative stress, and platelet aggregation (Bo \& Pisu, 2008). Individual components of MetS in relation to $\mathrm{Mg}$ are discussed below. 


\subsubsection{Obesity}

Obesity, particularly abdominal or visceral adiposity, is recognized as an important contributor to insulin resistance and T2DM (Wilson et al., 2002). While some studies have demonstrated a positive effect of whole grains or bran, as opposed to refined grains, on weight loss (Koh-Banerjee et al., 2004; Katcher et al., 2008), very little information exists on the association between $\mathrm{Mg}$ intake and body weight. Three small studies report conflicting results regarding the relationship between BMI and Mg status. In a small study of asthmatics $(n=54)$ matched with healthy controls $(\mathrm{n}=48)$, asthma subjects had significantly lower $\mathrm{Mg}$ intakes when they were overweight $(p=0.004)$ and obese $(p=0.001)$ than did normal-weight asthma subjects. When all subjects were stratified according to BMI, total body Mg stores decreased with increasing weight (Kazaks \& Stern, 2007). Huerta et al. (2005) showed that sMg was significantly lower in obese nondiabetic children $(n=24)$ than lean children $(0.75 \pm 0.02 \mathrm{mmol} / \mathrm{L}$ vs. $0.80 \pm 0.01$

$\mathrm{mmol} / \mathrm{L} ; p=0.009$ ), and that $\mathrm{dMg}$ intake was significantly lower in obese than lean children (obese: $0.12 \pm 0.004$ vs. lean: $0.14 \pm 0.004 \mathrm{mg} / \mathrm{kcal} ; p=0.003$ ). In another study of sedentary postmenopausal women, however, non-obese $(n=19)$ women did not differ from obese women $(n=55)$ in plasma or red blood cell Mg (Laires et al., 2004).

\subsubsection{High Blood Pressure/Hypertension}

Mg exerts anti-hypertensive effects via several possible mechanisms. $\mathrm{Mg}^{2+}$ reduces smooth muscle contraction and is required for endothelium-dependent vasodilation (Yogi et al., 2011). The function of transmembrane $\mathrm{Mg}^{2+}$ transporter TRPM7 is altered in experimental models of hypertension (Yogi et al., 2011). 
Among the earliest epidemiologic studies linking Mg to blood pressure was the Honululu Heart Study (Joffres et al., 1987). Magnesium intake (from food and supplements) derived from 24-hr recalls was determined for 615 men of Japanese ancestry living in Hawaii with no history of cardiovascular disease or treated hypertension. After adjusting for age and BMI, the mean systolic blood pressure (SBP) of men in the highest quartile of $\mathrm{Mg}$ intake (331-1429mg/24hr) was 6.4 points lower than men in the lowest quartile of intake $(38-174 \mathrm{mg} / 24 \mathrm{hr})$ $(p=0.006)$. Similarly, diastolic blood pressure (DBP) of men in the highest quartile of intake was 3.1 points lower than men in the lowest quartile $(p=0.008)$. Although Mg was most strongly associated with blood pressure among the examined nutrients, high correlations between $\mathrm{Mg}$ and other nutrients prevented the researchers from separating the effect of $\mathrm{Mg}$ from other variables. Decades later, a qualitative review examining 24 cross-sectional studies supported an overall negative association between $\mathrm{Mg}$ and blood pressure (Mizushima et al., 1998).

Several large prospective studies relating dietary $\mathrm{Mg}$ to blood pressure or hypertension have been conducted. In the Nurses' Health Study, nutritional factors and hypertension/blood pressure were evaluated in 41,541 predominately white US female nurses, normotensive at baseline, and without diagnosis of cardiovascular disease or cancer. After the four year follow-up period, 2,526 women reported a hypertension diagnosis. Dietary $\mathrm{Mg}$ was not significantly associated with hypertension risk after adjusting for age, BMI, alcohol and energy intake, but a significant inverse association was observed with SBP and DBP (Ascherio et al., 1996). 
The Women's Health Study assessed the outcome of $\mathrm{dMg}$ and hypertension in 28,349 US female health professionals, normotensive at baseline. After a median follow-up period of $9.8 \mathrm{yrs}, 8544$ women developed hypertension. Women in the highest quintile of $\mathrm{dMg}$ intake (median: $434 \mathrm{mg} / \mathrm{day}$ ) had a decreased risk for hypertension [RR 0.87 (95\% CI: 0.81-0.93) $p<0.0001]$ compared with those in the lowest quintile (median $256 \mathrm{mg} /$ day), and the association remained significant, albeit attenuated, after adjustment for known risk factors (Song et al., 2006).

The same outcome was examined prospectively among 30,681 American male health professionals, normotensive at baseline, in a follow-up of the Health Professionals Study. Among the 1,248 men reporting a hypertension diagnosis after a four year follow-up, Mg was significantly associated with lower risk of hypertension when considered alone and after adjustment for age, weight, alcohol and energy intake. When analyses were adjusted for fiber and potassium, the association lost significance [RR 0.89 (95\% CI: 0.64-1.25; $p<0.66$ )] (Ascherio et al., 1992).

After Ma et al. (1995) observed, in a cross-sectional report, inverse associations between $\mathrm{sMg}$ and dietary $\mathrm{Mg}$ with systolic blood pressure and incident hypertension in the ARIC cohort, Peacock et al. (1999) followed the 7,731 men and women of the ARIC cohort for 6 years, during which time 822 individuals developed hypertension. The authors found no association between dietary Mg and incident hypertension in either sex, but observed an inverse relationship between $\mathrm{sMg}$ and hypertension incidence, stronger in women than men. In the ARIC study, $\mathrm{sMg}$ and $\mathrm{dMg}$ were poorly correlated; clinical trials are 
mixed regarding the effect of oral $\mathrm{Mg}$ therapy on $\mathrm{sMg}$ concentrations in normomagnesemic individuals.

Results of Mg supplementation trials on blood pressure have been conflicting, with significant reductions reported in some trials (Dyckner \& Wester, 1983; Motoyama et al., 1989; Hatzistavri et al., 2009) but not in others (Ferrara et al. 1992; Cappuccio et al., 1985;). Of interest, trials that showed no effect tended to use lower Mg doses (10-15 $\square \mathrm{mmol} /$ day Mg vs. $\geq 20 \square \mathrm{mmol} /$ day) than studies demonstrated blood pressure lowering effects. A meta-analysis concluded there was an apparent dose-dependent effect of $\mathrm{Mg}$, with reductions of $4.3 \mathrm{~mm} \mathrm{Hg}$ in systolic blood pressure $(p<0.001)$ and of $2.3 \mathrm{~mm} \mathrm{Hg}$ in diastolic blood pressure ( $p=0.09$ ) for each $10 \mathrm{mmol} /$ day increase in $\mathrm{Mg}$ dose (Jee et al., 2002). Heterogeneity among trials is high (Dickinson et al., 2006).

\subsubsection{Insulin Resistance}

Rodent studies have helped elucidate the modes of action by which $\mathrm{Mg}$ influences insulin resistance. In 1996, Kandeel et al. showed that long-term (24hr) exposure of rat adipocytes to low Mg was associated with a significant $30 \%$ reduction in insulin-stimulated glucose incorporation into triglycerides, but normal incorporation could be restored through reincubation in a high $\mathrm{Mg}$ medium.

Suarez et al. 1995 exposed rats to a low Mg diet for four days and showed that comparison to controls, the hypomagnesemic rats showed higher basal serum glucose ( $6.8 \pm 0.2$ vs $5.5 \pm 0.2 \mathrm{mmol} / \mathrm{L}, p<0.05)$, a $40 \%$ reduction $(p<0.001)$ in the glucose disappearance rate after intravenous glucose was administered, and a 45\% reduction $(p<0.05)$ in glucose-stimulated insulin secretion. Upon examining 
insulin receptors in the gastrocnemius (calf) muscles of the rats, hypomagnesemic rats showed a $50 \%$ reduction in the autophosphorylation of the $\beta$-subunit of the insulin receptor and a reduction of tyrosine kinase activity of insulin receptors. No change was detected in insulin binding nor in abundance of glucose transporter protein (GLUT 4).

Vormann et al. 1997 showed that a high Mg diet reduced the rate of glucosuria in obese Zucker rats from $70 \%$ (14 of 20 rats) to $20 \%$ (4 of 20 rats) and decreased plasma insulin. Balon et al., 1995 also examined the effects of $\mathrm{Mg}$ supplemented $(\mathrm{Mg}-\mathrm{S})$ diet in the male obese Zucker diabetic rats in a model of non-insulin-dependent diabetes mellitus (NIDDM). The rats maintained on the $\mathrm{Mg}-\mathrm{S}$ diet had markedly lower fasting and fed-state blood glucose concentrations and an improved glucose disposal. By 12 weeks of age, all eight animals on the control diet became diabetic, whereas diabetes developed in only one of eight animals on the $\mathrm{Mg}-\mathrm{S}$ diet. Insulin, C-peptide concentrations, and insulin mRNA expression were higher in the male obese $\mathrm{Mg}$ supplemented rats than in their control-fed counterparts.

Other rodent models have supplemented $\mathrm{Mg}$ while simultaneously providing a high sugar diet. Chaudhary et al. 2007 divided rats into four groups and fed control, high sucrose, low $\mathrm{Mg}$ or combined high sucrose/low $\mathrm{Mg}$ diets for a period of three months. In vitro glucose uptake in the liver was maximally reduced in the combined high sucrose/ low $\mathrm{Mg}$ group, suggesting that low $\mathrm{Mg}$ may exacerbate insulin resistance by reducing glucose uptake in target tissues of rats. 
Large, population-based cross-sectional studies have shown significant inverse associations between dietary $\mathrm{Mg}$ intake and fasting insulin concentrations. In the ARIC cohort, among participants without coronary disease, $\mathrm{sMg}$ and $\mathrm{dMg}$ levels were inversely associated with fasting serum insulin (Ma et al., 1995). In a subsample of women from the Nurses' Health Study, after adjustment for age, body mass index (BMI), total energy, physical activity, hours per week spent sitting outside work, alcohol intake, smoking, and family history of diabetes, $\mathrm{dMg}$ was inversely associated with fasting insulin concentration (Fung et al., 2003). Similar results were reported by Manolio et al., 1991 and Song et al., 2004.

Oral glucose tolerance testing among 18 nondiabetics revealed that those with blood $\mathrm{Mg}(<0.80 \mathrm{mmol} / \mathrm{L})$ had significantly higher plasma glucose and insulin after the 75-g test (Roslova et al., 1997). In 2000, Roslova et al. corroborated this result in 98 subjects, showing that those in the tertile with lowest pMg had significantly higher fasting plasma insulin and glucose concentrations.

A few randomized double-blind placebo controlled trials have also supported the beneficial effect of $\mathrm{Mg}$ on insulin resistance and glucose tolerance. Sixty subjects with insulin resistance (HOMA-IR $\geq 3.0$ ) and $\mathrm{sMg} \leq 0.74 \mathrm{mmol} / \mathrm{L}$ were randomized to receive either $2.5 \mathrm{~g}$ daily of $\mathrm{MgCl}_{2}$ (12mmol) (or placebo for 3-months. sMg increased in the supplemented group and HOMA-IR was significantly reduced $(p<0.0001)$, whereas control subjects did not experience these changes (Guerrero-Romero et al., 2004). In 12 elderly subjects, Paolisso et al. 1992 administered Mg daily for 4 weeks in a double-blind, placebo controlled, crossover study. At the end of each treatment period an intravenous glucose tolerance test ( $0.33 \mathrm{~g} / \mathrm{kg}$ body $\mathrm{wt})$ and euglycemic glucose clamp with 
simultaneous glucose infusion and indirect calorimetry were performed. $\mathrm{rMg}$ concentration was significantly increased when $\mathrm{Mg}$ vs. the placebo was administered, as was insulin response and action.

\subsubsection{Dyslipidemia}

$\mathrm{dMg}$ has demonstrated a beneficial effect on lipid profiles and metabolism in animal models and some human trials. Mg deficiency in rodents produces hypertriglyceridemia and elevated free cholesterol (Nassir et al., 1995). Supplementation significantly lowers serum cholesterol and triglycerides in animal studies and impedes atherosclerotic development (Altura et al., 1990), particularly when animals are fed high-cholesterol diets, possibly by decreasing lecithin: cholesterol acyl-transferase (LCAT) and HMG-CoA reductase, and increasing lipoprotein lipase activity (Gueux et al., 1984). LCAT esterifies free cholesterol, HMG-CoA reductase is a rate limiting enzyme in cholesterol synthesis, and lipoprotein lipase converts triglycerides to the more favorable HDL cholesterol, such that very low density lipoprotein triglyceride synthesis and secretion is curbed.

A few cross-sectional studies and clinical trials have examined $\mathrm{Mg}$ in association with blood lipid profiles or postprandial lipid profiles, with conflicting results. Significant positive associations between $\mathrm{SMg}$ and LDL, HDL, triglycerides and/or total cholesterol have been reported in several populations (Randell et al., 2008; Ma et al., 1995; Hashimoto et al., 2010), with a binding interaction posited to explain these findings (Randell et al., 2008).

Participants from the general Dutch population $(\mathrm{n}=202)$ were randomized receive $\mathrm{Mg}$ supplementation for 12 months; except for marginal reductions in 
LDL, no statistically significant differences in the lipid profile were detected (Schuitemaker et al., 2001). Other trials evaluating the effect of $\mathrm{Mg}$ supplementation on lipid levels are of smaller size and used different formulations. One randomized, double blind, placebo controlled trial in normal volunteers failed to support the efficacy of magnesium oxide $(20 \mathrm{mmol} /$ day $)$ for 2 months in resulting in any significant changes in the lipid profile $(n=50)$ (Marken et al., 1989). Another randomized, double-blind, placebo controlled trial did find an effect with $12.5 \mathrm{mmol} /$ day magnesium chloride for 3 months among insulin resistant subjects, showing significant decreases in total cholesterol (10.7\%), triglycerides (39.3\%), and LDL cholesterol (11.8\%) and increased HDL cholesterol (22.2\%) (n=60) (Roslova et al., 1997). In T2DM patients, six randomized double-blind placebo-controlled trials failed to detect an effect of supplementing $\mathrm{Mg}$ (15-30mmol/day) from 6 weeks to 4 months, on plasma lipids (Eriksson \& Kohvakka, 1995; Eibl et al., 1995; Gilleran et al., 1996; RodriguezMoran \& Guerrero-Romero, 2003; de Valk et al., 1998; Purvis et al., 1994).

When $\mathrm{Mg}$ was supplemented with a fat-only meal in a randomized crossover trial $(\mathrm{n}=16)$, triglyceride responses were reduced and delayed by $\mathrm{Mg}$ supplementation and postprandial hyperlipidaemia improved in healthy subjects (Kishimoto et al., 2010).

\subsubsection{Mg \& MetS (grouped components)}

Epidemiological analyses show inverse associations between $\mathrm{Mg}$ intake, biomarkers and MetS as an aggregate outcome (Lima et al., 2009). Elderly Americans in the highest quartile of $\mathrm{Mg}$ intake had a substantially reduced risk of having MetS compared to the lowest quartile of intake [OR 0.36 (95\% CI: 0.19- 
0.69) $p=0.002$ ] (McKeown et al., 2008). Similarly, among 117 overweight and obese patients in Greece, $\mathrm{sMg}$ was inversely related to the presence of MetS (Evangelopoulos et al., 2008).

Lima et al. (2009) showed that sMg and intra-mononuclear Mg concentrations were significantly lower in patients with MetS than in controls (sMg: $1.81 \pm 0.19$ vs. $2.43 \pm 0.43 \mathrm{mg} / \mathrm{dL}, p<0.001)$ and the frequency of hypomagnesemia was higher in those with MetS $(n=72)$ than controls $(n=57)$ (23.2\% vs. $3.6 \%)$. Intra-mononuclear depletion was found in $36.1 \%$ of patients with MetS. Guerrero-Romero \& Rodriguez-Moran (2002) also reported a much higher incidence of hypomagnesemia in patients with MetS $(65.6 \%, \mathrm{n}=192)$, compared with $3.9 \%$ in a disorder-free control group $(n=384)$ matched for age and gender.

Bo et al. (2006) performed a cross-sectional analysis in adults $(n=1,653)$ on the association between $\mathrm{Mg}$ and MetS, but found that the association was confounded by fiber. In a nationally representative American sample of 4,519 adults from NHANES 1990-2004, a 100mg/day increase in Mg was associated with a reduction in the risk of MetS [OR 0.83 (95\% CI: 0.72-0.96) $p<0.05]$. While ethnic differences in some metabolic syndrome components were partly explained by other nutrients, fiber was not adjusted for in this analysis.

The three largest studies to date examining $\mathrm{Mg}$ and MetS, however, adjusted for fiber. In defining MetS, the three studies were also consistent; Song et al. (2005), Ford et al. (2007) and He et al. (2006) used modified National Cholesterol Education Program Adult Treatment Panel III (2001) criteria. 
Song et al. (2005) performed a cross-sectional analysis on 11,686 middleaged and older women from the Women's Health Study. After adjusting for dietary and lifestyle confounders, women in the highest quintile of $\mathrm{Mg}$ intake had a $27 \%$ lower risk of MetS compared with those in the lowest quintile [OR 0.73 (95\% CI: 0.60-0.88) $p<0.001]$. Ford et al. (2007) reported MetS prevalence a ranging from $29 \%$ in the lowest quintile of $\mathrm{Mg}$ intake to $21.8 \%$ in the highest quintile of intake ( $p=0.002)$ among 7,669 adults from the NHANES 1998-1994 cohort. No significant associations with individual MetS components, however, were noted. He et al. (2006) reported results from a prospective study of $\mathrm{Mg}$ intake and incident MetS among 4,637 Americans, aged 18 to 30 years, who did not meet the diagnosis for MetS nor diabetes at baseline. 608 incident cases of MetS developed over a period of 15 years. $\mathrm{Mg}$ intake was inversely associated with MetS incidence after adjustment for confounders and baseline MetS components. The hazard ratio, adjusted for multiple variables, for developing MetS for those in the highest quartile of intake was 0.69 (95\% CI: 0.52-0.91) $p<0.01$ relative to those in the lowest quartile. Unlike the findings of Ford et al. (2007), Mg intake was also inversely related to individual components of MetS.

\subsection{Mg \& Impaired Glycemia}

Hypomagnesemia has long been associated with T2DM (reviewed in Pham et al., 2007); glucosuria induces renal Mg wasting (de Valk et al., 1999), and fractional Mg excretion increases in hyperinsulinemia (Kalaitzidis et al., 2005). While it has been argued that T2DM per se, but not precursor states, such as impaired fasting glucose, is associated with hypomagnesaemia (Simmons et al., 2010), large prospective studies report that higher $\mathrm{Mg}$ intake is associated with a 
lower risk for T2DM (Kao et al., 1999; Song et al., 2004; Lopez-Ridaura et al., 2004). Induction of $\mathrm{Mg}$ deficiency has been shown to reduce insulin sensitivity in individuals without diabetes, whereas $\mathrm{Mg}$ supplementation improves $\beta$-cell function in nondiabetics with depleted sMg (Nielsen et al., 2007; GuerreroRomero \& Rodriguez-Moran, 2011).

Among patients with T2DM, preliminary evidence suggests that hypomagnesaemia may be associated with an increased risk of diabetic complications. In cross-sectional studies of individuals with the condition, low extracellular Mg was associated with advanced retinopathy (McNair et al., 1978; Ceriello et al., 1982; Hatwal et al., 1989). Intracellular Mg concentrations were lower in patients with peripheral neuropathy than those without the condition (Lima et al., 1998). Rodriguez-Moran \& Guerrero-Romero (2001) demonstrated a higher prevalence of hypomagnesemia among their patients with diabetic foot ulcers compared with those without the condition (93.9\% in patients with foot ulcers vs. $73.1 \%$ in patients without ulcers; $p=0.02$ ). Serum ionized $\mathrm{Mg}$ was also decreased in T2DM with microalbuminurea and frank proteinuria in comparison to those without these conditions (Corica et al., 1996).

The effect of $\mathrm{Mg}$ supplementation on glycemic control in T2DM has been reviewed in a meta-analysis by Song et al. (2006). After a median duration of 12 weeks of supplementation, the weighted mean post-intervention fasting glucose was significantly lower in the treatment groups compared with the placebo [-0.56 $\mathrm{mmol} / \mathrm{L}$ (95\% CI: -1.10 to -0.01$) ; p$ for heterogeneity=0.02]. Post-intervention glycated hemoglobin and blood pressure were not significantly different from controls. As follow-up periods were short and $\mathrm{Mg}$ doses and formulations were 
inconsistent between studies, long-term controlled trials in diabetic patients with hypomagnesaemia are desirable to assess the efficacy of $\mathrm{Mg}$ supplementation. The effect of Mg supplementation in adults without T2DM shows some promise (Paulisso et al., 1994, Mooren et al., 2011) but studies are few and of small sample size.

\section{PART 2: Mg \& Cardiovascular Endpoints}

\subsection{Mg: Drinking Water Studies \& Cardiovascular Health}

Since early papers demonstrating an inverse relationship between drinking water hardness and cardiovascular mortality were published over 50 years ago (Menaker, 1960; Schroeder, 1960), at least 45 studies of ecological design have followed on the topic. These studies have generally corroborated the observed inverse association, but due to inherent methodological limits, are unable to inform causality and correlations observed at a population level may not be reflected at the individual level due to confounding (ecological fallacy). However, in a 2008 meta-analysis of case-control studies, drinking water Mg concentrations in the highest exposure category (range: $8.3-19.4 \mathrm{mg} / \mathrm{L}$ ) were significantly associated with a decreased likelihood of cardiovascular mortality [OR 0.75 (95\% CI: $0.68-0.82) p<0.001$ ], compared with the baseline (range: 2.5 to $8.2 \mathrm{mg} / \mathrm{L}$ )

(Catling et al., 2008). Most studies did not show a significant effect for calcium.

It is critical to demonstrate, however, that the amount of $\mathrm{Mg}$ obtained through drinking water can sufficiently contribute to magnesium body status such that cardiovascular health might be impacted. Drinking water $\mathrm{Mg}$ at the concentrations reviewed in Catling et al. (2008) have been shown to significantly contribute to total daily intake and overall body status for Mg (Galan et al., 2002; 
Rubenowitz et al., 1998). The potential importance of drinking water as a source of $\mathrm{Mg}$ is also supported by the greater absorption efficiency seen with a frequent intake of smaller doses, as would be the intake pattern of regular water consumption throughout the day (Sabatier et al., 2011).

Animal studies have shown that supplemental $\mathrm{Mg}$ in drinking water significantly improved the lipid profile and inhibited atherosclerosis (Sherer et al., 1999; Sherer et al., 2000; Cohen et al., 2002). In humans, the consumption of mineralized drinking water led to improvements in cardiovascular risk factors, including significant blood pressure reductions (Rylander \& Arnaud, 2004) and beneficial changes in the lipid profile (Schoppen et al., 2005).

Challenges for future studies include accurate measurement of $\mathrm{Mg}$ intake from both drinking water and diet, $\mathrm{Mg}$ status of the studied population and determination of the biologically relevant dose (Catling et al., 2008).

\subsection{Mg \& Carotid Intima-Media Thickness}

Carotid arterial thickness has been measured using high-resolution Bmode ultrasonography to identify plaque and quantify intima-media thickness, which may predict future myocardial infarction and stroke more accurately than conventional risk factors (O’Leary et al., 1999; Bots et al., 1997). The relation between $\mathrm{Mg}$ and carotid intima-media thickness has been examined in two large cross-sectional populations.

In the ARIC cohort, predominately composed of Caucasians and African Americans, mean carotid wall thickness increased in women by $0.0118 \mathrm{~mm}(p=$ $0.006)$ in diuretic users and $0.0048 \mathrm{~mm}(p=0.017)$ in nonusers for each 0.1 $\mathrm{mmol} / \mathrm{L}$ decrease in serum $\mathrm{Mg}$ level, in an analysis adjusted for age, race, body 
mass index, smoking, hypertension, LDL and field center; the multivariate association in men was not significant (Ma et al., 1995). In a Japanese general population, serum $\mathrm{Mg}$ was significantly inversely associated with mean intimamedia thickness $(p=0.004)$ and risk of carotid plaques $(p=0.03)$ after multiple adjustment, including for potentially confounding serum minerals (sodium, potassium, calcium, and inorganic phosphorus) (Hashimoto et al., 2010).

\subsubsection{Mg \& Arrhythmias: Ion Interactions}

Magnesium exerts diverse actions in maintaining normal cardiac electrophysiology; its clinical role in preventing and treating arrhythmias has long been examined. Myocyte depolarization threshold can be increased by $\mathrm{Mg}$ administration, reducing the likelihood of arrhythmia caused by injury currents near ischemic or infarcted tissue (Li et al., 2007).

Mg deficiency changes ion fluxes across myocytes and other cells. $\mathrm{Mg}$ deficiency depletes the primary intracellular cation, potassium $\left(\mathrm{K}^{+}\right)$, via several mechanisms. Increased $\mathrm{K}^{+}$efflux from cells occurs via $\mathrm{Mg}^{2+}$ sensitive $\mathrm{K}^{+}$channels in both skeletal (Dorup, 1994) and heart muscle (Matsuda, 1991). When Mg is present in sufficient concentrations, $\mathrm{K}^{+}$is transported inside the cell at a greater rate than outside the cell; when $\mathrm{Mg}$ is depleted, $\mathrm{K}^{+}$is transported readily in both directions (Rude \& Shils, 2006). Mg deficiency depletes $\mathrm{K}^{+}$in the myocardium despite adequate dietary intake of potassium (MacIntyre \& Davidson, 1958). During $\mathrm{Mg}$ deficiency, intracellular $\mathrm{Ca}^{2+}$ rises; $\mathrm{Mg}^{2+}$ decreases the rate at which $\mathrm{Ca}^{2+}$ enters cells through voltage-sensitive $\mathrm{Ca}^{2+}$ channels and decreases release of $\mathrm{Ca}^{2+}$ from the sarcoplasmic reticulum into the cytosol (Hasebe \& Kikuchi, 2007). 
$\mathrm{Mg}^{2+}$ appears to suppress $\mathrm{Ca}^{2+}$ overload in cardiomyocytes, which may be of clinical significance as cardiomyocytes are injured by excessive $\mathrm{Ca}^{2+}$ influx.

\subsubsection{Mg: Deficiency-related Arrhythmias}

Electrocardiographic abnormalities in human $\mathrm{Mg}$ deficiency include prolonged PR and QT intervals; intracellular $\mathrm{K}^{+}$depletion and hypokalemia may contribute to these abnormalities (Rude \& Shils, 2006). Exercise can decrease serum $\mathrm{Mg}$, but in healthy normomagnesemic individuals, health risks appear to be negligible (Warburton et al., 2002). In those with low Mg, however, or in those who experience large increases in plasma free fatty acids during exercise, this may be a relevant problem. In myocardial injury after prolonged sustained exercise, $\mathrm{Mg}$ deficit may lead to an increased risk of coronary vasospasm (Laires \& Monteiro, 2007).

Although drug-induced hypomagnesemia may also increase myocardial electrical instability and thus the risk of arrhythmias (Bashir et al., 2007), the question of whether or not a low Mg status arising from a 'typical Western' diet in healthy individuals can cause arrhythmias had previously not been addressed. USDA scientists first examined this question by subjecting 22 postmenopausal women in a metabolic unit to a diet of conventional foods containing less than $50 \%$ of the RDA for $\mathrm{Mg}$ (320mg/day) in a randomized, double-blind crossover design [81 days placebo followed by 81 days supplemented with $200 \mathrm{mg}$ magnesium gluconate/day $(8.23 \mathrm{mmol})$, or vice versa]. Holter monitor analysis revealed an increase in the number of ectopic beats (100/day) with reduced $\mathrm{dMg}$ intakes (Klevay \& Milne, 2002). In 2007, a similar experiment was conducted, in which 13 postmenopausal women in a metabolic unit consumed a $\mathrm{Mg}$ restricted 
diet ( $33 \%$ of the Mg RDA, or $101 \mathrm{mg} \mathrm{Mg} / 2000 \mathrm{kcal}$ ) for 78 days, followed by a Mg repletion period (200mg magnesium gluconate/day) for 58 days. Atrial fibrillation and flutter was reported in 5 women during the depletion phase, resulting in 4 subjects prematurely entering the $\mathrm{Mg}$ repletion period (42 to 64 days of depletion instead of 78 days). Two women were fed an additional 100mg of $\mathrm{Mg}$ daily for four weeks because arrhythmias did not quickly return to baseline. In other subjects, $\mathrm{Mg}$ supplementation relieved the arrhythmias more quickly (Nielsen et al., 2007). The authors concluded that $\mathrm{Mg}$ deficiency resulting from a diet that would not be considered an atypical Western menu can induce heart arrhythmias in post-menopausal women.

The induction of ventricular ectopy in this study is of concern in light of new evidence demonstrating that premature ventricular complexes (PVC) predict mortality. Among adults 65 yrs and older participating in the Cardiovascular Health Study ( $\mathrm{n}=1172)$, ventricular premature beats on 24-hr Holter monitors predicted cardiovascular disease death in the high Framingham Risk Score group (median follow-up, $12.3 \mathrm{yrs}$ ) (Stein et al., 2008). In a prospective longitudinal study of the Atherosclerosis Risk In Communities (ARIC) population ( $n=15,070)$ of Caucasians and African-Americans, 45 to $64 \mathrm{yrs}$, the percentage of participants with CHD mortality was $>3$ times greater for those with PVC on a 2 minute electrocardiogram compared with those without PVC. After controlling for cardiovascular risk factors and therapy with proportional hazards regression, participants with PVC were $>2$ times more likely to die due to CHD than were those without PVC. Increased risk was found for participants with and without baseline cardiovascular disease (Massing et al., 2006). 


\subsubsection{Mg \& Arrhythmias: Potential Confounding Factors}

Common risk factors for cardiac arrhythmias include age, the presence of coronary disease, hypertension, obesity, diabetes, non-Mg electrolyte imbalance, drug, alcohol or caffeine use. Less frequently are nutrients such as long chain polyunsaturated fatty acids, contaminants such as mercury, or sex hormones considered for integration into epidemiological models. These latter three factors are discussed briefly below.

Long chain polyunsaturated fatty acids (LC-PUFA)

Experiments on cellular and animal models, epidemiological and clinical studies suggest that LC-PUFA exert anti-arrhythmic effects, as opposed to antithrombotic effects. Several large interventional fish/fish oil trials and prospective studies show reduced risk of sudden death and fatal myocardial infarction (MI), consistent with the hypothesis that LC-PUFA are anti-arrhythmic. In the Diet and Reinfarction Trial (DART), men who had recovered from myocardial infarction were randomized to receive different dietary advice: 1 .) to reduce total fat consumption while increasing the ratio of polyunsaturated to saturated fat $(\mathrm{n}=1,018)$, or 2 .) to increase fatty fish consumption $(200-400 \mathrm{~g} / \mathrm{week})(\mathrm{n}=1,015)$, or 3.) to increase cereal fiber intake $(n=1,017)$, or not to receive such advice. Men in the first and third groups showed no difference in mortality in comparison to those men who did not receive the corresponding dietary advice, while men advised to increase fatty fish consumption showed a $29 \%$ reduction in two year all cause mortality [RR 0.70 (95\% CI: 0.54-0.92)] (Ness et al., 2002). As recurrent non-fatal MI was not significantly reduced while the risk of sudden death and fatal MI were significantly reduced, it was suggested LC-PUFA are responsible 
for anti-arrhythmic effects, as opposed to anti-thrombotic or anti-atherosclerotic effects (Russo et al., 2009).

The Gruppo Italiano per lo Studio della Sopravvivenza nell'Infarto Miocardico (GISSI)- Prevenzione trial included a total of 11,323 patients randomly assigned to one of four treatment groups: 1.) to receive omega-3 PUFA, $1 \mathrm{~g} /$ day, or 2.) to receive vitamin $\mathrm{E}, 300 \mathrm{mg} / \mathrm{day}$, or 3.) to receive both omega-3 PUFA and vitamin E, or neither (controls). Among post-MI patients receiving a fish oil capsule (500-850 mg/day of LC-PUFA), a significant reduction in cardiac death was observed at 4 months and at 42 months (2.0\% vs. $2.7 \%)$ [RR 0.55 (95\% CI: 0.39-0.77)] (Marchioli et al., 2002).

\section{Mercury}

Marine mammals and predatory fish partially comprise a traditional Inuit diet, but accumulate methylmercury (MeHg). According to 2004 Qanuippitaa Health Survey data, heart rate variability was associated with blood mercury adults over age $40(n=205)$. Particularly, after adjusting for confounders including LC-PUFA, mercury was negatively associated with the standard deviation of the average R-R intervals calculated over 5-minute periods $(\mathrm{SDANN})$ (beta $=-0.086$; $p=0.026$ ) (Valera et al., 2008). Low SDANN is associated with a variety of adverse cardiovascular outcomes. However, Mozaffarian and colleagues prospectively evaluated toenail mercury concentrations and cardiovascular disease risk in the Health Professionals Follow-up Study and the Nurses Health Study (median follow up: $11.3 \mathrm{yrs}$ ); no increased risk in fatal coronary heart disease, stroke, nor total cardiovascular disease was detected in the highest vs. lowest quintile of toenail mercury (Mozaffarian et al., 2011). 


\section{Sex hormones}

Torsade de pointes- type ventricular tachycardia is an arrhythmia associated with a prolonged QT interval and hypomagnesemia. Women are more prone to develop torsades de pointes with prolonged QT. Kurokawa et al. (2009) describes that as sex hormone levels increase with puberty, QTc (rate-corrected QT) in males decrease, so that adult women have longer QTc intervals than men. However, the QTc interval length increases in men until approximately age 60, when it approximates the QTc length of women. This pattern is consistent with a potential protective effect of testosterone. Clinical evidence suggests that progesterone may shorten ventricular depolarization, thereby protecting against QT-associated arrhythmias. The effects of estrogen are equivocal, but postmenopausal women on estrogen replacement therapy show a slight QTc prolongation of a few milliseconds (Kurokawa et al., 2009).

\subsection{Mg \& Sudden Cardiac Death}

Circulating $\mathrm{Mg}$ (pMg or $\mathrm{sMg}$ ) and $\mathrm{dMg}$ have been assessed in relation to sudden cardiac death in two large prospective cohorts, the ARIC cohort and Nurses' Health cohort. In the first, 45-64yr old subjects $(n=14,232)$ were followed up after an average of $12 \mathrm{yrs}$, with 264 cases of sudden cardiac death observed. Proportional hazards regression demonstrated that individuals in the highest quartile of sMg were at significantly lower risk of sudden cardiac death in all multivariate models, with an almost $40 \%$ reduced risk of sudden cardiac death [HR 0.62 (95\% CI: 0.42-0.93)] in the highest vs. the lowest quartile (Peacock et al., 2010). In the Nurses' Health Study, 88,375 women were followed up after 26yrs, with 505 cases of sudden cardiac death observed. The relative risk of 
sudden cardiac death was significantly lower in women in the highest quartile compared with those in the lowest quartile of $\mathrm{dMg}$ [RR 0.63 (95\% CI: 0.440.91)]. pMg and cardiac death was examined using a nested case control analysis with 99 sudden cardiac death cases and 291 matched controls. For pMg, the relative risk of sudden cardiac death declined more dramatically across quartiles than $\mathrm{dMg}$ [RR 0.23 (95\% CI: 0.09-0.60)] for the lowest vs. highest quartile $\mathrm{Mg}$ (Chiuve et al., 2011).

\section{Mg: Intravenous Administration in Cardiovascular Care}

\subsubsection{In Preventing Mortality After Acute Myocardial Infarction (AMI)}

As $\mathrm{Mg}$ protects myocardial tissue in experimental models of ischemia and reperfusion, these effects were tested in vivo. Intravenous $\mathrm{Mg}$ administered within several hours of the onset of acute myocardial infarction (AMI) significantly reduced mortality in several small, randomized, placebo controlled trials (Teo \& Yusef, 1993). Based on positive findings, three major trials were conducted to assess Mg therapy after AMI: the Second Leicester Intravenous Magnesium Intervention Trial (LIMIT-2) (Woods et al., 1992), the Fourth International Study of Infarct Survival (ISIS-4) (Collins et al., 1995), and the Magnesium in Coronaries (MAGIC) trial (Antman et al., 2002).

In LIMIT-2, a randomised, double blind, placebo controlled study, 2,316 patients with suspected AMI received either intravenous magnesium sulphate (8 mmol over $5 \mathrm{~min}$, followed by $65 \mathrm{mmol}$ over $24 \mathrm{~h}$ ) or saline. An assessment of all cause mortality after 28 days revealed a $7.8 \%$ morality rate in the $\mathrm{Mg}$ group vs. $10.3 \%$ in the control, a relative reduction of $24 \%(p<0.04)$. The groups did not differ significantly in prognostic factors or in the use of anti-arrhythmic drugs, 
direct-current cardioversion, or temporary pacing. Until this time, intravenous $\mathrm{Mg}$ was considered an adjunctive therapy in standard treatment for AMI.

ISIS-4 randomized more than 58,050 patients entering hospitals up to 24 hours after the onset of AMI in a $2 \times 2 \times 2$ factorial design, of which one of the three treatments was administration of $24 \mathrm{~h}$ of magnesium sulphate $(8 \mathrm{mmol}$ initially, followed by $72 \mathrm{mmol}$ ). Mortality after 35 days in the $\mathrm{Mg}$-treated group $(n=2,216,7.64 \%)$ was not significantly lower than vs. the control group $(n=2,103$, 7.24\%), and further follow-up did not reveal any later differences in survival.

Main criticisms of ISIS-4 included the timing of the Mg therapy, timing of induced thrombolysis, and severity of illness (Seelig, 1995). Since ISIS-4 randomized patients up to $24 \mathrm{hrs}$ after presentation (most within $8 \mathrm{hr}$ ), and $\mathrm{Mg}$ therapy is thought to influence AMI mortality by preventing ischemia-reperfusion injury, it was argued that Mg may have been administered too late to see a protective effect. In response to these objections, the MAGIC trial, a randomized, double-blind trial of 6,213 patients, administered the intervention earlier and included higher-risk patients. 3,113 patients were given a $2 \mathrm{~g}$ intravenous bolus of magnesium sulphate within $6 \mathrm{hr}$ of the onset of symptoms, followed by a $17 \mathrm{~g}$ infusion of magnesium sulphate over $24 \mathrm{hr}$ (equivalent to $70 \mathrm{mmol}$ ), or matching placebo $(n=3,100)$. Patients were stratified into two groups; the first included patients over 65yrs and eligible for reperfusion therapy; the second included patients of any age who were ineligible for reperfusion therapy. At 30 days, 475 (15.3\%) patients in the Mg group and 472 (15.2\%) in the placebo group had died [OR 1.0 (95\% CI: 0.9-1.2) $p=0.96]$. The authors concluded that in light of all 
available evidence, there is no indication for the routine administration of intravenous $\mathrm{Mg}$ in patients post AMI (Antman et al., 2002).

Although MAGIC did not show an effect, the majority of the smaller trials showing benefit and LIMIT-2 administered a dose less than 75 mmol. A systematic review concluded that while it is unlikely $\mathrm{Mg}$ is beneficial in reducing mortality, uncertainty remains regarding the effect of $\mathrm{Mg}$ on mortality at doses below $75 \mathrm{mmol}$ or in patients not treated with thrombolysis (Li et al., 2007).

\subsubsection{In Preventing Postoperative Atrial Fibrillation (AF)}

Three recent meta-analyses have concluded that intravenous $\mathrm{Mg}$ is effective in preventing postoperative atrial fibrillation (AF) (Miller et al., 2005; Onalan et al., 2007; Shepherd et al., 2008) the first reporting a similar efficacy to common anti-arrhythmic drugs. Miller et al. (2005), based on 20 randomized controlled trials $(\mathrm{n}=2490)$, found that $18 \%$ of patients receiving Mg developed postoperative AF, compared to $28 \%$ in the treatment group [OR 0.54 (95\% CI: 0.38-0.75)]. Onalan et al. (2007) pooled 4 trials $(n=303)$ for rate control $(<100$ beats/min) and 8 trials $(n=476)$ for rhythm control as measures of AF using a fixed-effects model. Mg was effective in achieving rate control [OR 1.96 (95\% CI: 1.24-3.08)] and rhythm control [OR 1.60 (95\% CI: 1.07-2.39)]. An overall response was achieved in $86 \%$ and $56 \%$ of patients in the $\mathrm{Mg}$ and control groups, respectively [OR 4.61 (95\% CI: 2.67-7.96)]. Shepherd et al. (2008) pooled 15 trials ( $\mathrm{n}=1,070$ in the pooled $\mathrm{Mg}$ group, of which 230 (21\%) developed postoperative AF, compared with 307 of 1,031 (30\%) patients in the placebo or control group. 
A recent meta-analysis of 10 randomized controlled trials indicates that $\mathrm{Mg}$ is also useful at the onset of acute atrial fibrillation, as it reduces the ventricular response in acute onset atrial fibrillation (Ho et al., 2007).

\subsubsection{During Ventricular Tachycardia}

The American College of Cardiology/ American Heart Association/ European Society of Cardiology (ACC/AHA/ESC) recommends intravenous $\mathrm{Mg}$ administration in patients with episodes of torsade de pointes- type ventricular tachycardia associated with a prolonged QT interval (Zipes et al., 2006). Mg has been shown to reduce QT intervals even in patients with normal sMg (Naoyuki \& Kikuchi., 2007). The AHA recommends 1-2 $\mathrm{g}$ of $\mathrm{Mg}$ as an intravenous bolus over $5 \mathrm{~min} . \mathrm{Mg}$ is also indicated for refractory ventricular fibrillation if the patient is on diuretics that deplete potassium and hence may be hypomagnesemic (Priori et al., 2001); the Canadian Cardiovascular Society shares this recommendation. The ESC recommends normalizing $\mathrm{Mg}$ levels in patents with heart failure experiencing supraventricular tachycardia, especially if ventricular arrhythmias are present. $\mathrm{Mg}$ is thought to be effective in supraventricular tachycardia by prolonging atrioventricular nodal conduction time and refractory period, and suppressing conduction in accessory pathways (Viskin et al., 1992). 


\section{References}

1. Abad, C.; Teppa-Garran, A.; Proverbio, T.; Pinero, S.; Proverbio, F.;

Marin, R., Effect of magnesium sulfate on the calcium-stimulated adenosine triphosphatase activity and lipid peroxidation of red blood cell membranes from preeclamptic women. Biochemical Pharmacology 2005, 70 (11), 1634-1641.

2. Abad, C.; Carrasco, M.J.; Pinero, S.; et al., Effect of magnesium sulfate on the osmotic fragility and lipid peroxidation of intact red blood cells from pregnant women with severe preeclampsia. Hypertension in Pregnancy 2010, 29 (1), 3853.

3. Abbott, L.; Nadler, J.; Rude, R.K., Magnesium deficiency in alcoholismpossible contribution to osteoporosis and cardiovascular disease in alcoholics. Alcoholism-Clinical and Experimental Research 1994, 18 (5), 1076-1082. 4. Abrams, S.A.; Grusak, M.A.; Stuff, J.; O'Brien, K.O., Calcium and magnesium balance in 9-14 yr old children. American Journal of Clinical Nutrition 1997, 66, 1172-1177.

5. Alberti, K.G.M.M.; Ecklel, R.H.; Grundy, S.M.; et al., Harmonizing the Metabolic Syndrome. Circulation 2009, 120, 1640-1645.

6. Alghamdi, S.M.G.; Cameron, E.C.; Sutton, R.A.L., Magnesium deficiency- pathophysiologic and clinical overview. American Journal of Kidney Diseases 1994, 24 (5), 737-752.

7. Almoznino-Sarafian, D.; Berman, S.; Mor, A.; et al., Magnesium and Creactive protein in heart failure: an anti-inflammatory effect of magnesium administration? European Journal of Nutrition 2007, 46 (4), 230-237. 
8. Altura, B.M.; Kostellow, A.B.; Zhang, A.M.; et al., Expression of the nuclear factor-kappa B and proto-oncogenes c-fos and c-jun are induced by low extracellular $\mathrm{Mg} 2+$ in aortic and cerebral vascular smooth muscle cells: Possible links to hypertension, atherogenesis, and stroke. American Journal of Hypertension 2003, 16 (9), 701-707.

9. Altura, B.T.; Brust, M.; Bloom, S.; Barbour, R.L.; Stempak, J.G.; Altura, B.M., Magnesium dietary intake modulates blood lipid levels and atherogenesis. Proceedings of the National Academy of Sciences of the United States of America 1990, 87 (5), 1840-1844.

10. Antman, E.; Cooper, H.; Domanski, M.; et al., Early administration of intravenous magnesium to high-risk patients with acute myocardial infarction in the Magnesium in Coronaries (MAGIC) Trial: a randomised controlled trial. Lancet 2002, 360 (9341), 1189-1196.

11. Arsenault, B.J.; Boekholdt S.M.; Kastelein J.J.P., Lipid parameters for measuring risk of cardiovascular disease. Nature Reviews Cardiology 2011, 8, 197-206.

12. Ascherio, A.; Hennekens, C.; Willett, W.C.; et al., Prospective study of nutritional factors, blood pressure, and hypertension among US women. Hypertension 1996, 27 (5), 1065-1072.

13. Ascherio, A.; Rimm, E.B.; Giovannucci, E.L.; et al., Prospective study of nutritional factors and hypertension among United States men. Circulation 1992, $86(5), 1475-1484$.

14. Balon, T.W.; Gu, J.L.; Tokuyama, Y.; Jasman, A.P.; Nadler, J.L., Magnesium supplementation reduces development of diabetes in a rat model of 
spontaneous NIDDM. American Journal of Physiology-Endocrinology and Metabolism 1995, 269 (4), E745-E752.

15. Bo, S.; Durazzo, M.; Guidi, S.; et al., Dietary magnesium and fiber intakes and inflammatory and metabolic indicators in middle-aged subjects from a population-based cohort. American Journal of Clinical Nutrition 2006, 84 (5), 1062-1069.

16. Bo, S. \& Pisu, E., Role of dietary magnesium in cardiovascular disease prevention, insulin sensitivity and diabetes. Current Opinion in Lipidology 2008, $19(1), 50-56$.

17. Bots, M.L.; Hoes, A.W.; Koudstaal, P.J.; Hofman, A.; Grobbee, D.E., Common carotid intima-media thickness and risk of stroke and myocardial infarction: the Rotterdam Study. Circulation 1997, 96, 1432-1437.

18. Bussiere, F.I.; Gueux, E.; Rock, E.; Mazur, A.; Rayssiguier, Y., Protective effect of calcium deficiency on the inflammatory response in magnesiumdeficient rats. European Journal of Nutrition 2002, 41 (5), 197-202.

19. Cao, G.; Lee, K.P.; van der Wijst, J.; et al., Methionine Sulfoxide Reductase B1 (MsrB1) Recovers TRPM6 Channel Activity during Oxidative Stress. Journal of Biological Chemistry 2010, 285 (34), 26081-26087.

20. Cappuccio, F.P.; Markandu, N.D.; Beynon, G.W.; Shore, A.C.; Sampson, B.; Macgregor, G.A., Lack of effect of oral magnesium on high blood pressure- a double-blind study. British Medical Journal 1985, 291 (6490), 235-238.

21. Catling, L.A.; Abubakar, I.; Lake, I.R.; Swift, L.; Hunter, P.R., A systematic review of analytical observational studies investigating the association 
between cardiovascular disease and drinking water hardness. Journal of Water and Health 2008, 6 (4), 433-442.

22. Ceriello, A.; Giugliano, D.; Dello, R.P.; Passariello, N., Hypomagnesemia in relation to diabetic retinopathy. Diabetes Care 1982, 5, 558-559.

23. Chaudhary, D.P.; Boparai, R.K.; Bansal, D.D., Effect of a low magnesium diet on in vitro glucose uptake in sucrose fed rats. Magnesium Research 2007, 20 (3), 187-195.

24. Chiuve, S.E.; Korngold, E.C.; Januzzi, J.L.; Gantzer, M.L.; Albert, C.M., Plasma and dietary magnesium and risk of sudden cardiac death in women. American Journal of Clinical Nutrition 2011, 93 (2), 253-260.

25. Chubanov, V.; Schlingmann, K.P.; Waering, J.; et al., Hypomagnesemia with secondary hypocalcemia due to a missense mutation in the putative poreforming region of TRPM6. Journal of Biological Chemistry 2007, 282 (10), 76567667.

26. Cohen, H.; Sherer, Y.; Shaish, A.; et al., Atherogenesis inhibition induced by magnesium-chloride fortification of drinking water. Biological Trace Element Research 2002, 90 (1-3), 251-259.

27. Collins, R.; Peto, R.; Flather, M.; et al., ISIS-4 - A randomized factorial trial assessing early oral captopril, oral mononitrate, and intravenous magnesium sulphate in 58,050 patients with suspected acute myocardial infarction. Lancet 1995, 345 (8951), 669-685.

28. Corica, F.; Allegra, A.; Ientile, R.; et al., Changes in plasma, erythrocyte, and platelet magnesium levels in normotensive and hypertensive obese subjects 
during oral glucose tolerance test. American Journal of Hypertension 1999, 12 (2), 128-136.

29. Danesh J., Fibrinogen Studies Collaboration. Plasma fibrinogen level and the risk of major cardiovascular diseases and nonvascular mortality: an individual participant meta-analysis, JAMA 2005, 294, 1799-1809.

30. de Valk, H.W.; Verkaaik, R.; van Rijn, H.J.M.; Geerdink, R.A.;

Struyvenberg, A., Oral magnesium supplementation in insulin-requiring Type 2 diabetic patients. Diabetic Medicine 1998, 15 (6), 503-507.

31. de Valk H.W., Magnesium in diabetes mellitus. Netherlands Journal of Medicine 1999, 54, 139-146.

32. Dickinson, H.O.; Nicolson, D.J.; Campbell, F.; et al., Magnesium supplementation for the management of essential hypertension in adults. Cochrane Database of Systematic Reviews 2006, DOI:

10.1002/14651858.CD004640.pub2.

33. Dorup, I., Magnesium and potassium deficiency- its diagnosis, occurrence and treatment in diuretic therapy and its consequences for growth, protein synthesis and growth factors. Acta Physiologica Scandinavica 1994, 618, 1-55.

34. Dyckner, T.; Hallberg, D.; Hultman, E.; Wester, P.O., Magnesium deficiency following jejunoileal bypass operations for obesity. Journal of the American College of Nutrition 1982, 1 (3), 239-246.

35. Dyckner, T. \& Wester, P.O., Effect of magnesium on blood pressure. British Medical Journal 1983, 286 (6381), 1847-1849. 
36. Eibl, N.L.; Kopp, H.P.; Nowak, H.R.; Schnack, C.J.; Hopmeier, P.G.;

Schernthaner, G., Hypomagnesaemia in type 2 diabetes- effect of a 3 month replacement therapy. Diabetes Care 1995, 18 (2), 188-192.

37. Elin, R.J. \& Tan, H.T., Erythrocyte membrane plaques from rats with magnesium deficiency. Blood 1977, 49, 657-664.

38. Elin, R.J., Magnesium- the 5th but forgotten electrolyte. American Journal of Clinical Pathology 1994; 102 (5), 616-622.

39. Emerging Risk Factors Collaboration (ERFC). C-reactive protein concentration and risk of coronary heart disease, stroke, and mortality: an individual participant meta-analysis. Lancet 2010, 375, 132-140.

40. Eriksson, J. \& Kohvakka, A., Magnesium and ascorbic acid supplementation in diabetes mellitus. Annals of Nutrition and Metabolism 1995, $39(4), 217-223$.

41. Evangelopoulos, A.A.; Vallianou, N.G.; Panagiotakos, D.B.; et al., An inverse relationship between cumulating components of the metabolic syndrome and serum magnesium levels. Nutrition Research 2008, 28 (10), 659-663.

42. Ferrara, L.A.; Iannuzzi, R.; Castaldo, A.; et al., Long-term magnesium supplementation in essential hypertension. Cardiology 1992, 81, 25-33.

43. Forbes, G.B., Human body composition: growth, aging, nutrition and activity. 1987, Springer-Verlag: New York, NY.

44. Frisch, L.S. \& Mimouni, F., Hypomagnesaemia following correction of metabolic acidosis- a case of hungry bones. Journal of the American College of Nutrition 1993, 12 (6), 710-713. 
45. Fung, T.T.; Manson, J.E.; Solomon, C.G.; Liu, S.M.; Willett, W.C.; Hu,

F.B., The association between magnesium intake and fasting insulin concentration in healthy middle-aged women. Journal of the American College of Nutrition 2003, 22 (6), 533-538.

46. Galan, P.; Arnaud, M.J.; Czernichow, S.; et al., Contribution of mineral waters to dietary calcium and magnesium intake in a French adult population. Journal of the American Dietetic Association 2002, 102 (11), 1658-1662.

47. Galland, L., Magnesium and inflammatory bowel disease. Magnesium 1988, 7 (2), 78-83.

48. Gilleran, G.; Oleary, M.; Bartlett, W.A.; Vinall, H.; Jones, A.F.; Dodson, P.M., Effects of dietary sodium substitution with potassium and magnesium in hypertensive Type II diabetics: A randomised blind controlled parallel study. Journal of Human Hypertension 1996, 10 (8), 517-521.

49. Graham, L.A.; Caesar, J.J.; Burgen, A.S.V., Gastrointestinal absorption and excretion of Mg-28 in man. Metabolism-Clinical and Experimental 1960, 9 (7), 646-659.

50. Guerrero-Romero, F. \& Rodriguez-Moran, M., Low serum magnesium levels and metabolic syndrome. Acta Diabetologica 2002, 39 (4), 209-213. 51. Guerrero-Romero, F. \& Rodriguez-Moran, M., Relationship between serum magnesium levels and C-reactive protein concentration, in non-diabetic, non-hypertensive obese subjects. International Journal of Obesity 2002, 26 (4), 469-474. 
52. Guerrero-Romero, F. \& Rodriguez-Moran, M., Complementary therapies for diabetes: The case for chromium, magnesium, and antioxidants. Archives of Medical Research 2005, 36 (3), 250-257.

53. Guerrero-Romero, F. \& Rodriguez-Moran, M., Magnesium improves the beta-cell function to compensate variation of insulin sensitivity: double-blind, randomized clinical trial. European Journal of Clinical Investigation 2011, 41 (4), 405-410.

54. Gueux, E.; Rayssiguier, Y.; Piot, M.C.; Alcindor, L., Reduction of plasma lecitin cholesterol acytransferase activity by acute magnesium deficiency in the rat. Journal of Nutrition 1984, 114 (8), 1479-1483.

55. Gunther, T., Functional compartmentation of intracellular magnesium. Magnesium 1986, 5 (2), 53-59.

56. Hasebe, N. \& Kikuchi, K., Cardiovascular disease and magnesium. In: New Perspectives in Magnesium Research: Nutrition and Health. 2007, SpringerVerlag: London, England.

57. Hashimoto, T.; Hara, A.; Ohkubo, T.; et al., Serum magnesium, ambulatory blood pressure, and carotid artery alteration: The Ohasama Study. American Journal of Hypertension 2010, 23 (12), 1292-1298.

58. Hatwal, A.; Gujral, A.S.; Bhatia, R.P.S.; Agrawal, J.K.; Bajpai, H.S., Association between hypomagnesemia and diabetic retinopathy. Acta Ophtalmology 1989, 67, 714-716.

59. Hatzistavri, L.S.; Sarafidis, P.A.; Georgianos, P.I.; et al., Oral magnesium supplementation reduces ambulatory blood pressure in patients with mild hypertension. American Journal of Hypertension 2009, 22 (10), 1070-1075. 
60. He, K.; Liu, K.; Daviglus, M.L.; et al., Magnesium intake and incidence of metabolic syndrome among young adults. Circulation 2006, 113 (13), 1675-1682.

61. Ho, K.M.; Sheridan, D.J.; Paterson, T., Use of intravenous magnesium to treat acute onset atrial fibrillation: a meta-analysis. Heart 2007, 93, 1433-1440.

62. Huerta, M.G.; Roemmich, J.N.; Kington, M.L.; et al., Magnesium deficiency is associated with insulin resistance in obese children. Diabetes Care 2005, 28 (5), 1175-1181.

63. Jee, S.H.; Miller, E.R.; Guallar, E.; et al. The effect of magnesium supplementation on blood pressure: a meta-analysis of randomized clinical trials. American Journal of Hypertension 2002, 15, 691-696.

64. Joffres, M.R.; Reed, D.M.; Yano, K., Relationship of magnesium and other dietary factors to blood pressure- the Honolulu heart study. American Journal of Clinical Nutrition 1987, 45 (2), 469-475.

65. Kalaitzidis, R.; Tismihodimos, V.; Bairaktari, E.; Siamopoulos, K.; Elisaf, M. Disturbances of phosphate metabolism: another feature of the metabolic syndrome. Journal of Kidney Diseases 2005, 45, 851-858.

66. Kandeel, F.R.; Balon, E.; Scott, S.; Nadler, J.L., Magnesium deficiency and glucose metabolism in rat adipocytes. Metabolism-Clinical and Experimental 1996, 45 (7), 838-843.

67. Kao, W.H.L.; Folsom, A.R.; Nieto, F.J.; Mo, J.P.; Watson, R.L.; Brancati, F.L., Serum and dietary magnesium and the risk for type 2 diabetes mellitus - The atherosclerosis risk in communities study. Archives of Internal Medicine 1999, 159 (18), 2151-2159. 
68. Katcher, H.I.; Legro, R.S.; Kunselman, A.R.; et al., The effects of a whole grain-enriched hypocaloric diet on cardiovascular disease risk factors in men and women with metabolic syndrome. American Journal of Clinical Nutrition 2008, 87 (1), 79-90.

69. Kazaks, A.G. \& Stern, J.S., Overweight and obesity are associated with decreased magnesium intake in people with asthma. California Agriculture 2007, $61(3), 119-123$.

70. King, D.E.; Mainous, A.G.; Geesey, M.E.; Woolson, R.F., Dietary magnesium and C-reactive protein levels. Journal of the American College of Nutrition 2005, 24 (3), 166-171.

71. Kishimoto, Y.; Tani, M.; Uto-Kondo, H.; et al., Effects of magnesium on postprandial serum lipid responses in healthy human subjects. British Journal of Nutrition 2010, 103 (4), 469-472.

72. Klevay, L.M. \& Milne, D.B., Low dietary magnesium increases supraventricular ectopy. American Journal of Clinical Nutrition 2002, 75 (3), $550-554$.

73. Knuiman, M.W.; Hung, J.; Divitini, M.L.; Davis, T.M.; Beilby, J.P., Utility of the metabolic syndrome and its components in the prediction of incident cardiovascular disease: a prospective cohort study. European Journal of Cardiovascular Prevention \& Rehabilitation 2009, 16 (2), 235-241.

74. Koh-Banerjee, P.; Franz, M.V.; Sampson, L.; et al., Changes in wholegrain, bran, and cereal fiber consumption in relation to 8-y weight gain among men. American Journal of Clinical Nutrition 2004, 80 (5), 1237-1245. 
75. Kuipers, M.T.; Thang, H.D.; Arntzenius, A.B., Hypomagnesaemia due to use of proton pump inhibitors - a review. Netherlands Journal of Medicine 2009, $67(5), 169-172$.

76. Kurokawa, J.; Suzuki, T.; Furukawa, T., Acute Effects of Female Hormones on Cardiac Ion Channels and Cardiac Repolarization. Journal of Pharmacological Sciences 2009, 109 (3), 334-340.

77. Laires, M.J. \& Monteiro, C., Exercise and magnesium. New Perspectives in Magnesium Research: Nutrition and Health 2007, 18, 173-185.

78. Laires, M.J.; Moreira, H.; Monteiro, C.P.; et al., Magnesium, insulin resistance and body composition in healthy postmenopausal women. Journal of the American College of Nutrition 2004, 23 (5), 510S-513S.

79. Li, J.; Zhang, Q.; Zhang, M.; Egger, M., Intravenous magnesium for acute myocardial infarction. Cochrane Database of Systematic Reviews 2007, DOI: 10.1002/14651858.CD002755.pub2.

80. Lima, M.D.L.; Cruz, T.; Pousada, J.C.; Rodrigues, L.E.; Barbosa, K.; Cangucu, V., The effect of magnesium supplementation in increasing doses on the control of type 2 diabetes. Diabetes Care 1998, 21 (5), 682-686.

81. Lima, M.D.; Cruz, T.; Rodrigues, L.E.; et al., Serum and intracellular magnesium deficiency in patients with metabolic syndrome-Evidences for its relation to insulin resistance. Diabetes Research and Clinical Practice 2009, 83 (2), 257-262.

82. Lopez-Ridaura, R.; Willett, W.C.; Rimm, E.B.; et al., Magnesium intake and risk of type 2 diabetes in men and women. Diabetes Care 2004, 27 (1), 134140. 
83. Ma, J.; Folsom, A.R.; Melnick, S.L.; et al., Associations of serum and dietary magnesium with cardiovascular disease, hypertension, diabetes, insulin and carotid arterial-wall thickness- the ARIC study. Journal of Clinical Epidemiology 1995, 48 (7), 927-940.

84. Macintyre, I. \& Davidsson, D., Production of secondary potassium depletion, sodium retention, nephrocalcinosis and hypercalcaemia by magnesium deficiency. Biochemical Journal 1958, 70, 456-462.

85. Mak, I.T.; Kramer, J.H.; Chmielinska, J.J.; Khalid, M.H.; Landgraf, K.M.; Weglicki, W.B., Inhibition of neutral endopeptidase potentiates neutrophil activation during Mg-deficiency in the rat. Inflammation Research 2008, 57 (7), 300-305.

86. Mak, I.T.; Kramer, J.H.; Weglicki, W.B., Suppression of neutrophil and endothelial activation by substance $\mathrm{P}$ receptor blockade in the $\mathrm{Mg}$-deficient rat. Magnesium Research 2003, 16 (2), 91-97.

87. Malpuech-Brugere, C.; Kuryszko, J.; Nowacki, W.; Rock, E.; Rayssiguier, Y.; Mazur, A., Early morphological and immunological alterations in the spleen during magnesium deficiency in the rat. Magnesium Research 1998, 11 (3), 161169.

88. Manolio, T.A.; Savage, P.J.; Burke, G.L.; et al., Correlates of fasting insulin levels in young adults- The Cardia Study. Journal of Clinical Epidemiology 1991, 44 (6), 571-578.

89. Marchioli, R.; Barzi, F.; Bomba, E.; et al., Early protection against sudden death by n-3 polyunsaturated fatty acids after myocardial infarction - Time-course analysis of the results of the Gruppo Italiano per lo Studio della Sopravvivenza 
nell'Infarto Miocardico (GISSI)-Prevenzione. Circulation 2002, 105 (16), 1897 1903.

90. Marken, P.A.; Weart, C.W.; Carson, D.S.; Gums, J.G.; Lopesvirella, M. F., Effects of magnesium oxide on the lipid profile of healthy volunteers. Atherosclerosis 1989, 77 (1), 37-42.

91. Martin, H.; Uring-Lambert, B.; Adrian, M.; et al., Effects of long-term dietary intake of magnesium on oxidative stress, apoptosis and ageing in rat liver. Magnesium Research 2008, 21 (2), 124-130.

92. Massing, M.W.; Simpson, R.J.; Rautaharju, P.M.; Schreiner, P.J.; Crow, R.; Heiss, G., Usefulness of ventricular premature complexes to predict coronary heart disease events and mortality (from the Atherosclerosis Risk in Communities cohort). American Journal of Cardiology 2006, 98 (12), 1609-1612.

93. Mather, H.M.; Nisbet, J.A.; Burton, G.H.; et al., Hypomagnesaemia in diabetes. Clinica Chimica Acta 1979, 95 (2), 235-242.

94. Matsuda, H., Effects of external and internal $\mathrm{K}+$ ions on magnesium block of inwardly rectifying $\mathrm{K}+$ channels in guinea-pig heart cells. Journal of Physiology-London 1991, 435, 83-99.

95. Mazur, A.; Maier, J.A.M.; Rock, E.; Gueux, E.; Nowacki, W.; Rayssiguier, Y., Magnesium and the inflammatory response: Potential physiopathological implications. Archives of Biochemistry and Biophysics 2007, $458(1), 48-56$.

96. McKeown, N.M.; Jacques, P.F.; Zhang, X.L.L.; Juan, W.Y.; Sahyoun, N. R., Dietary magnesium intake is related to metabolic syndrome in older Americans. European Journal of Nutrition 2008, 47 (4), 210-216. 
97. McNair, P.; Christiansen, C.; Madsbad, S.; et al., Hypomagnesemia, a risk factor in diabetic retinopathy. Diabetes 1978, 27, 1075-1077.

98. Meissner, G. \& Henderson, J.S., Rapid calcium release from cardiac sarcoplasmic reticulum vesicles is dependent on $\mathrm{Ca} 2+$ and is modulated by $\mathrm{Mg} 2+$, adenine nucleotide, and calmodulin. Journal of Biological Chemistry 1987, 262, 3065-3073.

99. Menaker, W., Cardiovascular disease and hardness of water. JamaJournal of the American Medical Association 1960, 174 (10), 1346-1347. 100. Miller, S.; Crystal, E.; Garfinkle, M.; Lau, C.; Lashevsky, I.; Connolly, S. J., Effects of magnesium on atrial fibrillation after cardiac surgery: a metaanalysis. Heart 2005, 91 (5), 618-623.

101. Minnich, V.; Smith, M.B.; Brauner, M.J.; Majews, P.W. Glutathione biosythesis in human erythrocytes. Journal of Clinical Investigation 1971, 50, 507-513.

102. Mizushima, S.; Cappuccio, F.P.; Nichols, R.; Elliott, P., Dietary magnesium intake and blood pressure: a qualitative overview of the observational studies. Journal of Human Hypertension 1998, 12 (7), 447-453.

103. Mooren, F.C.; Kruger, K.; Volker, K.; Golf, S.W.; Wadepuhl, M.; Kraus, A., Oral magnesium supplementation reduces insulin resistance in non-diabetic subjects - a double-blind, placebo-controlled, randomized trial. Diabetes Obesity \& Metabolism 2011, 13 (3), 281-284.

104. Motoyama, T.; Sano, H.; Fukuzaki, H., Oral magnesium supplementation in patients with essential hypertension. Hypertension 1989, 13 (3), 227-232. 
105. Mozaffarian, D.; Shi, P.; Morris, J.S.; et al., Mercury Exposure and Risk of Cardiovascular Disease in Two U.S. Cohorts. New England Journal of Medicine 2011, 364 (12), 1116-1125.

106. Nassir, F.; Mazur, A.; Giannoni, F.; Gueux, E.; Davidson, N. O.; Rayssiguier, Y., Magnesium deficiency modulates hepatic lipogenesis and apolipoprotein gene expression in the rat. Biochimica Et Biophysica Acta-Lipids and Lipid Metabolism 1995, 1257 (2), 125-132.

107. Ness, A.R.; Hughes, J.; Elwood, P.C.; Whitley, E.; Smith, G.D.; Burr, M. L., The long-term effect of dietary advice in men with coronary disease: followup of the Diet and Reinfarction trial (DART). European Journal of Clinical Nutrition 2002, 56 (6), 512-518.

108. Nielsen, F.H.; Johnson, L.K.; Zeng, H.W., Magnesium supplementation improves indicators of low magnesium status and inflammatory stress in adults older than 51 years with poor quality sleep. Magnesium Research 2010, 23 (4), $158-168$.

109. Nielsen, F.H.; Milne, D.B.; Klevay, L.M.; Gallagher, S.; Johnson, L., Dietary magnesium deficiency induces heart rhythm changes, impairs glucose tolerance, and decreases serum cholesterol in post menopausal women. Journal of the American College of Nutrition 2007, 26 (2), 121-132.

110. O'Leary, D.H.; Polak, J.F.; Kronmal, R.A.; Manolio, T.A.; Burke, G.L.; Wolfson, S.K., Carotid-artery intima and media thickness as a risk factor for myocardial infarction and stroke in older adults. Cardiovascular Health Study Collaborative Research Group. New England Journal of Medicine 1999, 340, 14 22. 
111. Onalan, O.; Crystal, E.; Daoulah, A.; Lau, C.; Crystal, A.; Lashevsky, I., Meta-analysis of magnesium therapy for the acute management of rapid atrial fibrillation. American Journal of Cardiology 2007, 99 (12), 1726-1732.

112. Paolisso, G.; Sgambato, S.; Gambardella, A.; et al., Daily magnesium supplements improve glucose handling in elderly subjects. American Journal of Clinical Nutrition 1992, 55 (6), 1161-1167.

113. Paolisso, G.; Scheen, A.; Cozzolino, D.; et al., Changes in glucose turnover parameters and improvement of glucose oxidation after 4 week magnesium administration in elderly noninsulin dependent (type 2) diabetic patients. Journal of Clinical Endocrinology and Metabolism 1994, 78 (6), 15101514.

114. Peacock, J.M.; Folsom, A.R.; Arnett, D.K.; et al., Relationship of serum and dietary magnesium to incident hypertension: The Atherosclerosis Risk in Communities (ARIC) study. Annals of Epidemiology 1999, 9 (3), 159-165. 115. Peacock, J.M.; Ohira, T.; Post, W.; Sotoodehnia, N.; Rosamond, W.; Folsom, A.R., Serum magnesium and risk of sudden cardiac death in the Atherosclerosis Risk in Communities (ARIC) Study. American Heart Journal 2010, 160 (3), 464-470.

116. Pham, P.C.T.; Pham, P.M.T.; Pham, S.V.; Miller, J.M.; Pham, P.T.T., Hypomagnesemia in patients with type 2 diabetes. Clinical Journal of the American Society of Nephrology 2007, 2 (2), 366-373.

117. Pittas, A.G.; Dawson-Hughes, B.; Li, T.; et al., Vitamin D and calcium intake in relation to type 2 diabetes in women. Diabetes Care 2006, 29 (3), 650656. 
118. Pittas, A.G.; Harris, S.S.; Stark, P.C.; Dawson-Hughes, B., The effects of calcium and vitamin D supplementation on blood glucose and markers of inflammation in nondiabetic adults. Diabetes Care 2007, 30 (4), 980-986. 119. Priori, S.G.; Aliot, E.; Blomstrom-Lundqvist, C.; et al., Task force on sudden cardiac death of the European Society of Cardiology. European Heart Journal 2001, 22 (16), 1374-1450.

120. Purvis, J.R.; Cummings, D.M.; Landsman, P. et al. Effect of oral magnesium supplementation on selected cardiovascular risk factors in noninsulin-dependent diabetics. Archives of Family Medicine, 1994, 3 (6), 503-508. 121. Randell, E.W.; Mathews, M.; Gadag, V.; Zhang, H.W.; Sun, G., Relationship between serum magnesium values, lipids and anthropometric risk factors. Atherosclerosis 2008, 196 (1), 413-419.

122. Rayssiguier, Y.; Gueux, E.; Bussiere, L.; Durlach, J.; Mazur, A., Dietary magnesium affects susceptibility of lipoproteins and tissues to peroxidation in rats. Journal of the American College of Nutrition 1993, 12 (2), 133-137.

123. Rock, E.; Astier, C.; Lab, C.; et al., Dietary magnesium deficiency in rats enhances free radical production in skeletal muscle. Journal of Nutrition 1995, $125(5), 1205-1210$.

124. Rodriguez-Moran, M. \& Guerrero-Romero, F., Low serum magnesium levels and foot ulcers in subjects with type 2 diabetes. Archives of Medical Research 2001, 32 (4), 300-303.

125. Rodriguez-Moran, M. \& Guerrero-Romero, F., Oral magnesium supplementation improves insulin sensitivity and metabolic control in type 2 
diabetic subjects - A randomized double-blind controlled trial. Diabetes Care 2003, 26 (4), 1147-1152.

126. Rodriguez-Moran, M. \& Guerrero-Romero, F., Serum magnesium and Creactive protein levels. Archives of Disease in Childhood 2008, 93 (8), 676-680.

127. Rosolova, H.; Mayer, O.; Reaven, G., Effect of variations in plasma magnesium concentration on resistance to insulin-mediated glucose disposal in nondiabetic subjects. Journal of Clinical Endocrinology \& Metabolism 1997, 82 (11), 3783-3785.

128. Rubenowitz, E.; Axelsson, G.; Rylander, R., Magnesium in drinking water and body magnesium status measured using an oral loading test. Scandinavian Journal of Clinical \& Laboratory Investigation 1998, 58 (5), 423-428.

129. Rude, R.K. \& Shils, M.E. Magnesium. In: Modern nutrition in health and disease, $10^{\text {th }}$ edition. 2006, Lippincott Williams \& Wilkins: Baltimore, MD. 130. Russo, G.L., Dietary n-6 and n-3 polyunsaturated fatty acids: From biochemistry to clinical implications in cardiovascular prevention. Biochemical Pharmacology 2009, 77 (6), 937-946.

131. Rylander, R. \& Arnaud, M.J., Mineral water intake reduces blood pressure among subjects with low urinary magnesium and calcium levels. BMC Public Health 2004, DOI: 10.1186/1471-2458-4-56.

132. Sabatier, M.; Grandvuillemin, A.; Kastenmayer, P.; et al., Influence of the consumption pattern of magnesium from magnesium-rich mineral water on magnesium bioavailability. British Journal of Nutrition 2011, 106 (3), 331-334. 133. Schlingmann, K.P.; Sassen, M.C.; Weber, S.; et al. Novel TRPM6 mutations in 21 families with primary hypomagnesemia and secondary 
hypocalcemia. Journal of the American Society of Nephrology 2005, 16 (10), 3061-3069.

134. Schlingmann, K.P.; Waldegger, S.; Konrad, M.; Chubanov, V.;

Gudermann, T., TRPM6 and TRPM7 - Gatekeepers of human magnesium metabolism. Biochimica et Biophysica Acta-Molecular Basis of Disease 2007, $1772(8), 813-821$.

135. Schmitz, C.; Perraud, A.L.; Johnson, C.O.; et al., Regulation of vertebrate cellular Mg2+ homeostasis by TRPM7. Cell 2003, 114 (2), 191-200.

136. Schoppen, S.; Perez-Granados, A.M.; Carbajal, A.; et al., Sodium bicarbonated mineral water decreases postprandial lipaemia in postmenopausal women compared to a low mineral water. British Journal of Nutrition 2005, 94 (4), 582-587.

137. Schroeder, H.A.; Relation Between Mortality From Cardiovascular Disease and Treated Water Supplies. JAMA 1960, 172, 1902-1908.

138. Schuitemaker, G.E.; van der Pol, G.A.; Aretz C.P.; G.J. Dinant, G.J., A placebo-controlled, double-blind, randomised trial of magnesium-pyridoxal-5'phosphate-glutamate for hypercholesterolaemia and other clinical-chemical risk factors of cardiovascular disease in a primary care setting, European Journal of Clinical Pharmacology 2001, 56, 857-863.

139. Schwartz, R.; Walker, G.; Linz, M.D.; Mackella. I, Metabolic responses of adolescent boys to two levels of dietary magnesium and protein. 1. Magnesium and nitrogen retention. American Journal of Clinical Nutrition 1973, 26 (5), 510518. 
140. Seelig, M.S., ISIS-4 - Clinical controversy regarding magnesium infusion, thrombolytic therapy, and acute myocardial infarction. Nutrition Reviews 1995, $53(9), 261-264$.

141. Shah, T.; Casas, J.P.; Cooper, J.A. et al., Critical appraisal of CRP measurement for the prediction of coronary heart disease events: new data and systematic review of 31 prospective cohorts, International Journal of Epidemiology 2009, 38, 217-231.

142. Shepherd, J.; Jones, J.; Frampton, G.K.; Tanajewski, L.; Turner, D.; Price, A., Intravenous magnesium sulphate and sotalol for prevention of atrial fibrillation after coronary artery bypass surgery: a systematic review and economic evaluation. Health Technology Assessment 2008, DOI:

$10.3310 /$ hta12280

143. Sherer, Y.; Shaish, A.; Levkovitz, H.; et al., Magnesium fortification of drinking water suppresses atherogenesis in male LDL-receptor-deficient mice. Pathobiology 1999, 67 (4), 207-213.

144. Sherer, Y.; Shoenfeld, Y.; Shaish, A.; Levkovitz, H.; Bitzur, R.; Harats, D., Suppression of atherogenesis in female low-density lipoprotein receptor knockout mice following magnesium fortification of drinking water: The importance of diet. Pathobiology 2000, 68 (2), 93-98.

145. Simmons, D.; Joshi, S.; Shaw, J., Hypomagnesaemia is associated with diabetes: Not pre-diabetes, obesity or the metabolic syndrome. Diabetes Research and Clinical Practice 2010, 87 (2), 261-266. 
146. Slavin, J.L. \& Marlett, J.A., Influence of refined cellulose on human bowel function and calcium and magnesium balance. American Journal of Clinical Nutrition 1980, 33 (9), 1932-1939.

147. Snyder, W., Report of the task group on reference man. 1975, Pergamon Press: Oxford, England.

148. Song, Y.Q.; Li, T.Y.; van Dam, R.M.; Manson, J.E.; Hu, F.B., Magnesium intake and plasma concentrations of markers of systemic inflammation and endothelial dysfunction in women. American Journal of Clinical Nutrition 2007, 85 (4), 1068-1074.

149. Song, Y.Q.; Manson, J.E.; Buring, J.E.; Liu, S.M., Dietary magnesium intake in relation to plasma insulin levels and risk of type 2 diabetes in women. Diabetes Care 2004, 27 (1), 59-65.

150. Song, Y.Q.; Manson, J E.; Tinker, L.; et al., Insulin sensitivity and insulin secretion determined by homeostasis model assessment and risk of diabetes in a multiethnic cohort of women - The Women's Health Initiative Observational Study. Diabetes Care 2007, 30 (7), 1747-1752.

151. Song, Y.Q. \& Ridker, P.M.; Manson, J.E.; Cook, N.R.; Buring, J.E.; Liu, S.M., Magnesium intake, C-reactive protein, and the prevalence of metabolic syndrome in middle-aged and older US women. Diabetes Care 2005, 28 (6), 1438-1444.

152. Song, Y.Q.; Sesso, H.D.; Manson, J.E.; Cook, N.R.; Buring, J.E.; Liu, S. M., Dietary magnesium intake and risk of incident hypertension among middleaged and older US women in a 10-year follow-up study. American Journal of Cardiology 2006, 98 (12), 1616-1621. 
153. Song, Y.; He, K.; Levitan, E.B.; Manson, J.E.; Liu, S., Effects of oral magnesium supplementation on glycaemic control in Type 2 diabetes: a metaanalysis of randomized double-blind controlled trials. Diabetic Medicine 2006, 23 (10), 1050-1056.

154. Spencer, H.; Norris, C.; Williams, D., Inhibitory effects of zinc on magnesium balance and magnesium absorption in man. Journal of the American College of Nutrition 1994, 13 (5), 479-484.

155. Stein, P.K.; Barzilay, J.I.; Chaves, P.H.M.; et al., Novel Measures of Heart Rate Variability Predict Cardiovascular Mortality in Older Adults Independent of Traditional Cardiovascular Risk Factors: The Cardiovascular Health Study (CHS). Journal of Cardiovascular Electrophysiology 2008, 19 (11), 1169-1174.

156. Suarez, A.; Pulido, N.; Casla, A.; Casanova, B.; Arrieta, F.J.; Rovira, A., Impaired tyrosine kinase activity of muscle insulin receptors from hypomagnesemic rats. Diabetologia 1995, 38 (11), 1262-1270.

157. Tejero-Taldo, M.I.; Chmielinska, J.J.; Gonzalez, G.; Mak, I.T.; Weglicki, W.B., N-methyl-D-aspartate receptor blockade inhibits cardiac inflammation in the Mg2+-deficient rat. Journal of Pharmacology and Experimental Therapeutics 2004, $311(1), 8-13$.

158. Tejero-Taldo, M.I.; Kramer, J.H.; Mak, I.T.; Komarov, A.M.; Weglicki, W.B., The nerve-heart connection in the pro-oxidant response to $\mathrm{Mg}$-deficiency. Heart Failure Reviews 2006, 11 (1), 35-44.

159. Teo, K.K. \& Yusuf, S., Role of magnesium in reducing mortality in acute myocardial infarction- A review of the evidence. Drugs 1993, 46 (3), 347-359. 
160. Turnlund, J.R.; Betschart, A.A.; Liebman, M.; Kretsch, M.J.; Sauberlich, H.E., Vitamin B6 depletion followed by repletion with animal source or plant sources diets and calcium and magnesium metabolism in young women. American Journal of Clinical Nutrition 1992, 56 (5), 905-910.

161. Valera, B.; Dewailly, E.; Poirier, P., Cardiac autonomic activity and blood pressure among Nunavik Inuit adults exposed to environmental mercury: a crosssectional study. Environmental Health 2008, DOI: 10.1186/1476-069X-7-29. 162. van den Heuvel, E.; Muijs, T.; Brouns, F.; Hendriks, H.F.J., Short-chain fructo-oligosaccharides improve magnesium absorption in adolescent girls with a low calcium intake. Nutrition Research 2009, 29 (4), 229-237.

163. Vangaal, L.; Delvigne, C.; Vandewoude, M.; et al., Evaluation of magnesium before and after jejunoileal gastric bypass surgery for morbid obesity. Journal of the American College of Nutrition 1987, 6 (5), 397-400.

164. Viskin, S.; Belhassen, B.; Laniado, S., Deterioration of ventricular tachycardia to ventricular fibrillation after rapid intravenous administration of magnesium sulphate. Chest 1992, 101 (5), 1445-1447.

165. Viskin, S.; Belhassen, B.; Sheps, D.; Laniado, S., Clinical and electrophysiologic effects of magnesium sulphate on paroxysmal supraventricular tachycardia and comparison with adenosine triphosphate. American Journal of Cardiology 1992, 70 (9), 879-885.

166. Vormann, J.; Blumenthal, A.; Merker, H. J.; Gunther, T., Reduced glucosuria by oral magnesium supplementation and decreased lipid peroxidation by increased vitamin E supply in obese Zucker rats. Magnesium-Bulletin 1997, 19 (3), 81-91. 
167. Warburton, D.E.R.; Welsh, R.C.; Haykowsky, M.J.; Taylor, D.A.; Humen, D.P., Biochemical changes as a result of prolonged strenuous exercise. British Journal of Sports Medicine 2002, 36 (4), 301-303.

168. Weglicki, W.B.; Mak, I.T.; Stafford, R.E.; Dickens, B.F.; Cassidy, M.M.; Phillip, T.M., Neurogenic peptides and the cardiomyopathy of magnesium deficiency- effects of substance $\mathrm{P}$ receptor inhibition. Molecular and Cellular Biochemistry 1994, 130 (2), 103-109.

169. Weglicki, W.B. \& Phillips, T.M., Pathobiology of magnesium deficiencyA cytokine neurogenic inflammation hypothesis. American Journal of Physiology 1992, 263 (3), R734-R737.

170. Widdowson, E.M.; McCance, R.A.; Spray, C.M., The chemical composition of the human body. Clinical Science 1951, 10, 113-125.

171. Wilson, P.W.F.; D'Agostino, R.B.; Sullivan, L.; Parise, H.; Kannel, W.B., Overweight and obesity as determinants of cardiovascular risk - The Framingham experience. Archives of Internal Medicine 2002, 162 (16), 1867-1872.

172. Wisker, E.; Nagel, R.; Tanudjaja, T.K.; Feldheim, W., Calcium, magnesium, zine and iron balances in young women- Effects of a low-phytate barley fiber concentrate. American Journal of Clinical Nutrition 1991, 54 (3), 553-559.

173. Woods, K.L.; Fletcher, S.; Roffe, C.; Haider, Y., Intravenous magnesium sulphate in suspected acute myocardial infarction- Results of the $2^{\text {nd }}$ Leicester intravenous magnesium intervention trial (LIMIT 2). Lancet 1992, 339 (8809), 1553-1558. 
174. Yogi, A.; Callera, G.E.; Antunes, T.T.; Tostes, R.C.; Touyz, R.M., Transient Receptor Potential Melastatin 7 (TRPM7) Cation Channels, Magnesium and the Vascular System in Hypertension. Circulation Journal 2011, 75 (2), 237245.

175. Zerwekh, J.E., Blood biomarkers of vitamin D status. American Journal of Clinical Nutrition 2008, 87 (4), 1087S-1091S.

176. Zipes, D.P.; Camm, A.J.; Borggrefe, M.; et al. ACC/AHA/ESC 2006 guidelines for management of patients with ventricular arrhythmias and the prevention of sudden cardiac death. Europace 2006, 8 (9), 746-837. 


\section{BRIDGE 1}

As discussed in the preceding chapter, hyperinsulinemia increases fractional Mg excretion (Kalaitzidis et al., 2005) and T2DM is associated with $\mathrm{Mg}$ depletion (Pham et al., 2007) as Mg wasting occurs via osmotic diuresis during glucosuria (de Valk et al., 1999). However, the long-term impact of transient impairments in glucose regulation on $\mathrm{Mg}$ biomarkers, such as those occurring during gestational diabetes, is unknown for affected mothers and offspring. Gestational diabetic pregnancy exposes the fetus to high concentrations of glucose, necessitating the fetus to increase its own insulin production (Weintrob et al., 1996). These adverse intrauterine conditions are associated with epigenetically induced downregulation of genes controlling $\beta$-cell growth, differentiation, and function (Pinney \& Simmons, 2010; Raychaudhuri et al., 2008).

Since GDM is associated with increased glycemic risk in mothers and offspring (Egeland \& Meltzer, 2010) and Mg homeostasis appears to be altered in offspring born of diabetic pregnancies, GDM history may influence potential associations between $\mathrm{Mg}$ biomarkers and glycemic endpoints. Therefore, we sought to determine if GDM history modifies associations between $\mathrm{Mg}$ and glycemic variables in mothers and offspring in the following investigation. 


\section{References}

1. de Valk, H.W., Magnesium in diabetes mellitus. Netherlands Journal of Medicine 1999, 54, 139-146.

2. Egeland, G.M. \& Meltzer, S.J., Following in mother's footsteps? Motherdaughter risks for insulin resistance and cardiovascular disease 15 years after gestational diabetes. Diabetic Medicine 2010, 27, 257-265.

3. Kalaitzidis, R.; Tismihodimos, V.; Bairaktari, E.; Siamopoulos, K.; Elisaf, M. Disturbances of phosphate metabolism: another feature of the metabolic syndrome. Journal of Kidney Diseases 2005, 45, 851-858.

4. Pham, P.C.T.; Pham, P.M.T.; Pham, S.V.; Miller, J.M.; Pham, P.T.T., Hypomagnesemia in patients with type 2 diabetes. Clinical Journal of the American Society of Nephrology 2007, 2 (2), 366-373.

5. Pinney S.E. \& Simmons, R.A., Epigenetic mechanisms in the development of type 2 diabetes, Trends in Endocrinology \& Metabolism 2010, 21, 223-229. 6. Raychaudhuri, N.; Raychaudhuri, S.; Thamotharan, M.; Devaskar, S.U., Histone code modifications repress glucose transporter 4 expression in the intrauterine growth-restricted offspring, Journal of Biological Chemistry 2008, 283 (20), 13611-13626.

7. Weintrob, N.; Karp, M.; Hod, M., Short- and long-range complications in offspring of diabetic mothers, Journal of Diabetes and its Complications 1996, 10(5), 294-301. 


\section{CHAPTER 3. MANUSCRIPT 1}

Gestational glucose intolerance modifies the association between magnesium concentrations and glycemic measures in mothers and daughters

\section{5 years post-partum}

Short title: Magnesium, gestational diabetic history \& glycemic parameters

L.C. Del Gobbo ${ }^{1}$, Y. Song ${ }^{2}$, R.J. Elin ${ }^{3}$, S.J. Meltzer ${ }^{4}$, G.M. Egeland ${ }^{1}$

${ }^{1}$ School of Dietetics \& Human Nutrition, McGill University, Ste Anne De

Bellevue, PQ, Canada

${ }^{2}$ Division of Preventive Medicine, Brigham and Women's Hospital, Harvard

Medical School, Boston, MA, USA

${ }^{3}$ Department of Pathology and Laboratory Medicine, University of Louisville, Louisville, KY, USA

${ }^{4}$ McGill University, Obstetrics and Gynecology, Montreal, QC, Canada

Corresponding author: Grace M. Egeland (grace.egeland@mcgill.ca)

School of Dietetics and Human Nutrition

Room MS2-039, Macdonald Stewart Building, 21111 Lakeshore Road

Ste. Anne de Bellevue, Quebec H9X 3V9

Tel.: 514-398-8642

Fax: 514-398-1020 


\section{Abstract}

Introduction: Poor $\mathrm{Mg}$ intake and status are associated with increased risk of T2DM. However, both Mg homeostasis and risk of T2DM are modified by gestational glucose intolerance. We sought to determine if GDM history modifies associations between $\mathrm{Mg}$ and glycemic measures in mothers and their offspring. Methods: $\mathrm{pMg}, \mathrm{dMg}$, anthropometric and lifestyle variables were assessed at a 15-year follow-up evaluation of mothers affected by GDM during 1989-1990, mothers with normoglycemic pregnancies who delivered during the same time, and the nondiabetic teenage daughters of affected and unaffected pregnancies $(\mathrm{n}=332)$. Multivariate regression analyses evaluated the associations between $\mathrm{pMg}$ and $\mathrm{dMg}$ with glycemic variables in mothers and daughters.

Results: pMg was lower among GDM mothers in comparison to control mothers after adjustment for current T2DM, race and BMI $(0.90 \pm 0.01$ vs. $0.96 \pm 0.01 \mathrm{mmol} / \mathrm{L} ; p=0.002)$. GDM-born daughters had higher mean $\mathrm{pMg}$ than non-GDM daughters $(0.92 \pm 0.11$ vs. $0.88 \pm 0.05 \mathrm{mmol} / 1 ; p=0.002)$. pMg was significantly $(p<0.05)$ associated with fasting insulin and insulin sensitivity in GDM mothers only. pMg and $\mathrm{dMg}$ were significantly inversely associated with glycated haemoglobin and fasting glucose, respectively, among nondiabetic 15year old daughters. The inverse association between $\mathrm{pMg}$ and fasting glucose in daughters was significantly ( $p=0.04)$ modified by GDM history.

Conclusions: Associations between pMg and some glycemic variables may be stronger in mothers and offspring with GDM history.

Keywords: magnesium, gestational diabetes, insulin resistance, pregnancy, diabetes 


\section{Introduction}

Women with a history of gestational diabetes mellitus (GDM) or glucose intolerance during pregnancy are characterized by a greatly elevated risk of developing type 2 diabetes (T2DM) (Egeland \& Meltzer, 2010). While modifiable risk factors for worsening glycemic parameters and incident T2DM, such as adiposity and physical activity, have been well established (Haffner, 1995), micronutrient intake or status may also influence these outcomes. Magnesium $(\mathrm{Mg})$ is part of the activated $\mathrm{Mg}$-ATP complex required for all rate-limiting enzymes of glycolysis, playing a critical regulatory role in phosphorylation reactions, such as tyrosine-kinase phosphorylation of the insulin receptor (Barbagallo \& Dominguez, 2007). Significant inverse associations between serum Mg (sMg) (Kao et al., 1999) dietary Mg (dMg) (Kim et al., 2010; Song et al., 2004; Lopez-Riduara et al., 2004; Kirii et al., 2010) and incidence of diabetes have been reported in many, but not all (Nanri et al., 2010) large prospective studies adjusted for covariates related to cardiometabolic risk. Oral Mg supplementation improves glycemic control in T2DM (Song et al., 2006), a condition associated with hypomagnesaemia, and supplementation resulted in a significant reduction in fasting glucose and increased insulin sensitivity compared to placebo in a small recent trial in normomagnesemic, overweight, non-diabetic subjects (Mooren et al., 2011).

While both GDM and $\mathrm{Mg}$ are associated with glycemic outcomes, $\mathrm{Mg}$ homeostasis may be modified by GDM. Intracellular Mg concentrations are significantly different in GDM women during their final trimester of pregnancy compared to non-GDM pregnant women (Ertbeg et al., 2004). However, no 
known study has examined the potential effect modification of GDM pregnancy on associations between $\mathrm{Mg}$ and glycemic measures in women.

We hypothesized that GDM history may modify the strength of associations between $\mathrm{Mg}$ and glycemic parameters. Since adolescent offspring born of GDM or gestational impaired glucose tolerant pregnancies are more insulin resistant than offspring of normoglycemic pregnancies (Egeland \& Meltzer), and $\mathrm{Mg}$ homeostasis is altered in offspring of diabetic mothers (Mughal et al., 2005), we further hypothesized that GDM history might also modify potential associations between $\mathrm{Mg}$ and glycemic variables in offspring 15-years postpartum.

\section{Methods}

A comprehensive health evaluation was conducted in 2005 on a sample of mothers (aged 36-61yrs at time of evaluation) affected by GDM or gestational impaired glucose tolerance during singleton pregnancies between 1989-1990, women with normoglycemic pregnancies delivering during the same time, and the teenage daughters born of affected and unaffected pregnancies $(n=332)$. All pregnancies resulted in term deliveries (37-42 weeks' gestation) between 1989 and 1990 at the Royal Victoria Hospital (Montreal, Canada). GDM and gestational impaired glucose tolerance mothers were stratified by age and socioeconomic categories derived from local census data and frequency matched to normoglycemic mothers. All women underwent a $50 \mathrm{~g}$ glucose screen during week 24-28 of gestation, or earlier if assessed as higher risk; those with a glucose value between 7.8 and $11.1 \mathrm{mmol} / \mathrm{L}$ went on to a $100 \mathrm{~g} 3-\mathrm{hr}$ oral glucose tolerance test (OGTT). GDM was diagnosed if the glucose screen exceeded $11 \mathrm{mmol} / \mathrm{L}$ or if 
women had two abnormal OGTT values. Gestational impaired glucose intolerance was diagnosed if one OGTT value was abnormal based on National Diabetes Data Group Criteria (1979). As gestational impaired glucose intolerant subjects were grouped with GDM subjects in study design, for simplicity, GDM and gestational impaired glucose intolerance are together abbreviated GDM. Ethics approval was obtained by the Commission d'acces à l'information du Québec, the Québec Registry of Medical Services, and the McGill Research Ethics Review Board. In 2005, plasma $\mathrm{Mg}(\mathrm{pMg})$ concentrations, dietary $\mathrm{Mg}(\mathrm{dMg})$, anthropometric measurements, lifestyle variables and a full medical history were assessed in all mothers and their adolescent ( $15 \mathrm{yr}$ old $)$ daughters. No record of serious gastrointestinal disease (Crohn's disease, ulcerative colitis, Whipple's disease or celiac sprue), kidney disease nor alcoholism was indicated in any participant. From the original cohort consisting of 189 mother-daughter pairs, $\mathrm{pMg}$ and $\mathrm{dMg}$, anthropometric and glycemic variables were available for 166 pairs $(n=332)$. All daughters had begun to menstruate and in this subset no daughter had type 1 diabetes or T2DM.

Anthropometric, lifestyle and clinical variable assessment

Weight was assessed by bioelectrical impedance equipment with a weight scale (Tania Corporation, Arlington Heights, IL) and height was measured to calculate body mass index (BMI). BMI for mothers was interpreted according to 1998 designations from the National Heart, Lung, and Blood Institute (BMI 18.524.9 considered normal weight, 25-29.9 considered overweight, $\geq 30$ considered obese). For daughters, BMI was interpreted according to 2000 CDC BMI-for-age growth charts. At risk of overweight was defined as $85^{\text {th }}-95^{\text {th }}$ percentile and 
overweight at $>95^{\text {th }}$ percentile based on age and gender-specific CDC growth charts. Waist circumference was measured at the midpoint between the bottom of the rib cage and the highest point on the iliac crest. High waist circumference in mothers was considered $\geq 80 \mathrm{~cm}$ based on International Diabetes Federation (IDF) metabolic syndrome criteria (IDF, 2005). For daughters, IDF high waist circumference from pediatric metabolic syndrome criteria was considered $\left(\geq 90^{\text {th }}\right.$ waist circumference percentile or adult threshold if lower) (IDF, 2007) and the lower adult threshold was used.

Race was self-reported as were lifestyle variables such as current smoking (yes or no), alcohol consumption and physical activity. Heavy alcohol consumption results in renal $\mathrm{Mg}$ wasting (Romani et al., 2008), thus, evidence of events of heavy consumption (the individual consumed $\geq 5$ drinks in one sitting on at least one occasion in the past month) was noted. An individual was considered to exercise if she reported engaging in physical activity sufficiently rigorous to induce hard breathing for at least a 20 minute duration for $\geq 3$ times per week.

All participants underwent a fasting blood draw for glucose, insulin, and glycated haemoglobin $\left(\mathrm{HbA}_{1 \mathrm{c}}\right)$. After a $75 \mathrm{~g}$ glucose load, venipuncture for serum glucose and insulin values was repeated at 30 and 120min. Glucose was analyzed using the glucose oxidase technique on the Beckman-Coulter LX20 analyzer (Beckman Instruments, Fullerton, CA). Insulin was assessed using an immunometric assay with chemiluminescent detection on an Immulyte immunoanalyzer (Diagnostic Products Corp., Los Angeles, CA). Glycated haemoglobin was measured using an immunoturbidometric method on a Cobas 
Mira analyzer (Roche, Stockholm, Sweden) with the reagent Roche Unimate 3 hemoglobin $\mathrm{A}_{1 \mathrm{c}}$.

For $\mathrm{pMg}$ analysis, samples were centrifuged prior to freezing at $-80 \mathrm{C}$ in BD lavender-top vacutainers (containing anti-coagulant). $500 \mu 1$ aliquots were withdrawn for shipment to Nutrasource Diagnostics contractor at the Trace Elements Laboratory of the London Laboratory Services group. At the Trace Elements Laboratory, samples were thawed and diluted with tetramethyl ammonium hydroxide and analyzed for Mg (Finnigan MAT element high resolution inductively coupled plasma mass spectrometer, ICP-MS).

T2DM was determined if fasting glucose $\geq 7 \mathrm{mmol} / \mathrm{L}, 2 \mathrm{hr}$ glucose $\geq$ $11.1 \mathrm{mmol} / \mathrm{L}$, or by physician's diagnosis. Insulin sensitivity was assessed using homeostasis model assessment of insulin resistance (HOMA-IR) (Matthews et al., 1985) and the whole body insulin sensitivity index using reduced time points (ISI composite) (Defronzo \& Matsuda, 2010).

Dietary assessment

$\mathrm{dMg}$ and caloric intake were derived from a 73-item, semiquantitative, self-administered food frequency questionnaire (FFQ), adapted in French and English from the Block National Cancer Institute Health Habits and History Questionnaire. The FFQ was initially tested in 248 Montreal-area adults and validated in a subsample of adults $(\mathrm{n}=94)$ using four non-consecutive food records (Shatenstein et al., 2005). dMg was adjusted for calories for subsequent modelling according to Willett \& Stampfer's (1986) residual approach.

\section{Statistical methods}


Arithmetic means and standard deviations were reported for normally distributed lifestyle and demographic characteristics and plasma $\mathrm{Mg}$ means were compared using two-tailed $t$-tests or ANOVA. Depending on their distributions, Pearson's or Spearman's bivariate correlations between $\mathrm{pMg}$ and $\mathrm{dMg}$ in mothers and daughters were determined. For multivariable linear regression analyses, we were interested in identifying the significant covariates of each glycemic outcome variable in addition to the associations with $\mathrm{pMg}$ and $\mathrm{dMg}$ in mothers and daughters. Dependent variables included fasting glucose, fasting insulin, HOMAIR, $\mathrm{HbA}_{1 \mathrm{c}}$, and ISI composite. Their distributions were skewed and log transformed prior to linear regression. For the cross-sectional analyses, four separate multivariate regressions were run for the following independent variables of interest: 1.) mothers' pMg 2.) mothers' dMg 3.) daughters' $\mathrm{pMg}$, and 4.) daughters' dMg. pMg and dMg were entered in models as a continuous variables. Unstandardized beta coefficient $(B)$ values, standard errors, and $p$ were recorded for each variable of the model. No adjustment was made for multiple comparisons. For $\mathrm{dMg}$ in mothers and daughters, estimates were recorded per 100mg increase in $\mathrm{dMg}$. Collinearity statistics (variance inflation factors, VIFs) were checked in all multivariable models and VIFs did not exceed 1.5 for any variable in any model. Additional adjustment for exercise, smoking and alcohol consumption did not appreciably alter any of the coefficients for $\mathrm{Mg}$ associations with outcome variables ( $\beta$ change in $\mathrm{Mg}<0.02$ ).

To examine whether the associations of $\mathrm{pMg}$ and $\mathrm{dMg}$ with glycemic dependent variables differed by GDM status or current maternal T2DM status, we entered interaction terms into multivariate adjusted models separately to test their 
significance. GDM status and maternal T2DM status were binary coded and multiplied by $\mathrm{Mg}$ ( $\mathrm{pMg}$ or $\mathrm{dMg}$ ) to create the interaction terms. The Wald test was used to assess the significance of multiplicative interaction terms. If the interaction term was significant in the model for a given dependent variable, we conducted subgroup analyses stratified by GDM and/or T2DM for that dependent variable. All $p$ values were two-tailed. All analyses were performed using SPSS version 18.0 (SPSS Inc., Chicago, IL).

\section{Results}

Age (32.4 \pm 4.5 vs. $32.1 \pm 5.3$ years $)$, parity $(0.88 \pm 1.07$ vs. $0.88 \pm 1.15)$, daughters' birthweight (3.36 \pm 0.61 vs. $3.35 \pm 0.49 \mathrm{~kg})$ and pregnancy weight gain $(14.3 \pm 6.71$ vs. $13.8 \pm 5.04 \mathrm{~kg})$ did not significantly differ between GDM and nonGDM mothers $(\mathrm{p}>0.05)$. Mothers with GDM history had a significantly greater mean pre-pregnancy BMI $(25.5 \pm 5.0$ vs. $23.1 \pm 3.81 \mathrm{~kg} / \mathrm{m} 2 ; \mathrm{p}<0.01)$ and earlier gestational age at delivery $(271 \pm 13.9$ vs. $274 \pm 11.2$ days; $\mathrm{p}<0.05)$ than nonGDM mothers. No other differences in obstetric or neonatal characteristics were observed.

Plasma Mg concentrations did not differ between mothers taking proton pump inhibitors, thiazide or loop diuretics, or aminoglycosides (plasma Mg: 0.96 $\pm 0.12 \mathrm{mmol} / \mathrm{L} ; \mathrm{n}=8)$ and women not taking these medications $(\mathrm{Mg}$ : $0.94 \pm 0.12 \mathrm{mmol} / \mathrm{L} ; \mathrm{n}=158)(\mathrm{t}-$ test, $\mathrm{p}=0.62)$. Twenty-eight women $(17 \%)$ took a multivitamin and $14(8 \%)$ indicated explicit use of $\mathrm{Mg}$ supplements, but plasma Mg concentrations did not differ among those who used supplements $(0.94 \pm 0.11 \mathrm{mmol} / \mathrm{L})$ and those who $\operatorname{did}$ not $(0.93 \pm 0.12 \mathrm{mmol} / \mathrm{L} ;$ t-test, $\mathrm{p}=0.63)$ results did not materially differ when GDM or T2DM status were adjusted for. 
pMg concentrations were significantly associated with race, GDM history, and current T2DM status in mothers. Caucasian mothers, nonGDM mothers, and mothers without current T2DM were more likely to have higher pMg concentrations (Table 3.1). pMg in GDM mothers was lower in comparison to nonGDM mothers after adjustment for current T2DM, race and BMI $(0.90 \pm 0.01$ vs. $0.96 \pm 0.01 \mathrm{mmol} / \mathrm{L} ; p=0.002)$. Among mothers without current T2DM, unadjusted $\mathrm{pMg}$ concentrations were $0.92 \pm 0.10 \mathrm{mmol} / \mathrm{L}$ for GDM mothers and $0.97 \pm 0.12 \mathrm{mmol} / \mathrm{L}$ for control mothers $(p=0.02)$. Total dietary $\mathrm{Mg}$ intake did not significantly differ between GDM (336.7 $\pm 152.0 \mathrm{mg})$ and nonGDM mothers (303.9 $\pm 125.0 \mathrm{mg})(p=0.19)$ nor did calorie-adjusted $\mathrm{Mg}$ intake $(325.2 \pm 67.4 \mathrm{mg}$ vs. $312.8 \pm 65.9 \mathrm{mg} ; p=0.24)$.

Six daughters took a multivitamin and 1 took $\mathrm{Mg}$ supplements, but $\mathrm{pMg}$ concentrations did not differ among supplement users $(0.84 \pm 0.04)$ and non-users

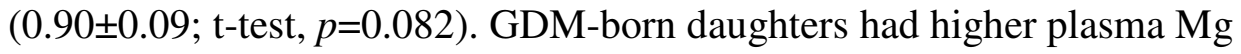
concentrations than nonGDM daughters $(0.92 \pm 0.11$ vs. $0.88 \pm 0.05 \mathrm{mmol} / \mathrm{L}$; $p=0.002$ ). Total dietary intake did not differ significantly between GDM-born daughters $(264.3 \pm 120.9 \mathrm{mg})$ and nonGDM daughters $(247.5 \pm 99.9 \mathrm{mg})(p=0.33)$ nor did calorie-adjusted $\mathrm{Mg}$ intake $(259.2 \pm 66.7 \mathrm{mg}$ vs. $251.5 \pm 54.3 \mathrm{mg} ; p=0.41)$. $\mathrm{pMg}$ and $\mathrm{dMg}$ were not significantly correlated in mothers (spearman's rho $=-0.110 ; p=0.16)$ nor in daughters $(-0.033 ; p=0.67)$.

Plasma Mg, dietary $\mathrm{Mg}$ and glycemic parameters in mothers

Mothers' GDM status 15-yrs prior, current BMI, and T2DM status were significantly associated with glycemic variables (Table 3.2). Interactions between pMg and GDM history were significant in models for fasting insulin, HOMA IR, 
and ISI composite, indicating that the associations between $\mathrm{pMg}$ and those glycemic variables differed between mothers with and without GDM history. Subgroup analyses showed that $\mathrm{pMg}$ was significantly inversely associated with fasting insulin, HOMA IR and ISI composite in GDM mothers only. For subgroup analysis of GDM vs. nonGDM mothers, regression coefficients $(\beta \pm \mathrm{SE}, p)$ for fasting insulin were $-2.36 \pm 0.73, p=0.002$ vs. $0.08 \pm 0.43, p=0.85$, for HOMA IR: $-2.24 \pm 0.78 ; p=0.006$ vs. $0.05 \pm 0.45, p=0.91$, and for whole-body insulin sensitivity (ISI composite) $(1.92 \pm 0.85, p=0.03$ vs. $-0.58 \pm 0.48 ; p=0.23)$. T2DM status modified the association of $\mathrm{pMg}$ and $\mathrm{HbA}_{1 \mathrm{c}}$ in mothers (Table 3.2); $\mathrm{pMg}$ was associated with $\mathrm{HbA}_{1 \mathrm{c}}$ in mothers without current T2DM $(-0.18 \pm 0.05 ; p<0.001)$ but not in mothers with T2DM $(-0.25 \pm 0.57 ; p=0.67)$.

T2DM status appeared to alter the association between $\mathrm{dMg}$ and outcome variables fasting glucose and $\mathrm{HbA}_{1 \mathrm{c}}$ (Table 3.2). Subgroup multivariate regression analyses showed that $\mathrm{dMg}$ was nonetheless neither significantly associated with these glycemic parameters in mothers with T2DM nor in mothers without T2DM. Plasma Mg, dietary Mg and glycemic parameters in 15-year old daughters

Daughters’ BMI was significantly associated with fasting insulin, HOMA IR, and ISI composite; neither their mothers' GDM status during the pregnancy nor current maternal T2DM status was significantly associated with any of daughters' glycemic variables. Daughters' pMg was inversely associated with $\mathrm{HbA}_{1 \mathrm{c}}$ in adjusted models ( $\beta \pm \mathrm{SE}, p$ for $\mathrm{pMg}$ : $\left.-0.10 \pm 0.05 ; p=0.05\right)$ (Table 3.2). Mothers' GDM history modified the association between daughters' pMg and fasting glucose; fasting glucose estimates per 1 unit pMg increase were - 
$0.03 \pm 0.01(p=0.06)$ for GDM-born daughters and 0.02 $\pm 0.01(p=0.13)$ for nonGDM daughters.

Daughters' dMg was significantly inversely associated with fasting glucose in adjusted models ( $\beta \pm \mathrm{SE}, p$ for $\mathrm{dMg}$ : $-0.02 \pm 0.01 ; p=0.03)$. No significant interactions with $\mathrm{dMg}$ were detected (Table 3.3).

\section{Discussion}

In this cross-sectional study including 332 mothers and daughters, we found that mothers with GDM history were more likely to have lower $\mathrm{pMg}$ concentrations 15 years later in comparison to mothers without GDM history. pMg was significantly associated with glycemic parameters (fasting insulin, HOMA IR, ISI composite) only in mothers with GDM history. $\mathrm{pMg}$ and $\mathrm{dMg}$ were significantly and inversely associated with $\mathrm{HbA}_{1 \mathrm{c}}$ and fasting glucose, respectively, in the total population of healthy, nondiabetic, 15-year old girls. Mothers' GDM history modified the association between daughters' pMg and fasting glucose.

The novel finding that $\mathrm{pMg}$ concentrations assessed at 15 years postpartum were significantly lower in mothers with GDM history in comparison to mothers without, independent of current maternal diabetic status, race, BMI, and $\mathrm{dMg}$ intake, cannot be entirely explained. While glycosuria can result in renal $\mathrm{Mg}$ wasting secondary to osmotic diuresis (de Valk, 1999) when blood glucose concentrations exceed $\sim 11 \mathrm{mmol} / \mathrm{L}$, there was no significant difference between the number of GDM mothers reaching a blood glucose value of $11 \mathrm{mmol} / \mathrm{L}$ thirty minutes into the OGTT at follow-up and nonGDM mothers ( $x^{2}$ test: $\left.p=0.22\right)$. Variables related to glycemic control in GDM history mothers without T2DM 
were not worse than nonGDM mothers without T2DM $(p=0.10$ for mean difference in glucose $120 ; p=0.33$ for mean difference in $\mathrm{HbA}_{1 \mathrm{c}}$ ); results were similar when comparing the whole population of mothers.

Gestational diabetic pregnancy itself may be associated with changes in $\mathrm{Mg}$ homeostasis, contributing to other potential mechanisms leading to altered $\mathrm{Mg}$ biomarkers among GDM history women. During the third trimester of pregnancy, intracellular free $\mathrm{Mg}$ concentrations in GDM women differ from non-GDM pregnant women (Ertberg et al., 2004; Bardiceff et al., 1995), but this difference is not reflected in total pMg concentrations (Bardiceff et al., 1995), nor is it expected that altered Mg biomarkers associated with pregnancy should persist over time. However, among mothers without T2DM, insulin sensitivity was significantly worse among GDM in comparison to nonGDM mothers ( $p=0.05$ for mean difference in ISI composite; $p=0.01$ for mean difference in HOMA IR), and insulin sensitivity was associated with higher $\mathrm{pMg}$ concentrations in GDM mothers. Fractional excretion of $\mathrm{Mg}$ has been shown to increase as a function of insulin concentration after adjustment for age, sex and BMI among nondiabetics (Kalaitzidis et al., 2005) and may be the most likely explanation for the observed difference in $\mathrm{pMg}$ between GDM and nonGDM mothers.

To our knowledge, the finding that $\mathrm{Mg}$ concentrations are significantly higher in offspring who developed during gestational diabetic or glucose impaired pregnancies in comparison to offspring born of normal pregnancies has never been reported in humans. Although this finding could be caused by chance, tubular reabsorptive mechanisms for $\mathrm{Mg}$ are increased markedly in rat offspring born of diabetic pregnancies in comparison to rats born of normal pregnancies 
(Bond et al., 2005) and Mg excretion is reduced in children and adolescents born of diabetic pregnancy (Mughal et al., 2005). GDM-born 15-year old daughters currently at the $\geq 75^{\text {th }}$ percentile of insulin resistance (HOMA IR) among all daughters do not have significantly different $\mathrm{pMg}$ concentrations than the total study population of nonGDM daughters $(0.89 \pm 0.09 \mathrm{mmol} / \mathrm{L}$ vs. $0.88 \pm 0.05 \mathrm{mmol} / \mathrm{L}$; $p=0.47$ ), but the mean $\mathrm{pMg}$ concentration in GDM-born daughters currently at $\leq 25^{\text {th }}$ percentile HOMA IR is $0.94 \pm 0.19 \mathrm{mmol} / \mathrm{L}$. We speculate that potential in utero programming of enhanced tubular reabsorption of $\mathrm{Mg}$ due to diabetic pregnancy may result in increased Mg markers in GDM-born offspring in the absence of a hyperglycaemic/insulin resistant external (post-utero) environment.

GDM history may be an important effect modifier of associations between $\mathrm{Mg}$ status and glycemic variables in affected mothers and affected offspring. Nonetheless, even if the finding that GDM history interacts with Mg-glycemic outcomes is replicated in other studies, low prevalence of GDM in general populations suggest that overall model estimates for $\mathrm{pMg}$ and glycemic measures would not be affected for large epidemiological cohorts.

Since lack of baseline $\mathrm{Mg}$ concentrations is a limitation of our study design, future studies elucidating the temporal relation between the observed differences between $\mathrm{pMg}$ concentrations in GDM and nonGDM mothers and daughters are required. Other limitations include lack of data on GDM status in subsequent pregnancies and the possibility that GDM history could be a proxy for unmeasured glycemic risk factors or other underlying factors in affected mothers and daughters. pMg is associated with blood concentrations of other nutrients and similarly, dietary $\mathrm{Mg}$ is strongly correlated with dietary fiber, potassium, and folic 
acid and therefore the effect of $\mathrm{Mg}$ per se cannot be entirely separated from other nutrients or dietary patters in observational studies. Another limitation of this study is use of pMg instead of ionized Mg as a biomarker (Altura et al., 1992); free intracellular $\mathrm{Mg}$ is the fraction regulating enzyme pathways (Nadler et al., 1993). Since extracellular Mg concentrations are under tight homeostatic regulation in the human body, normal levels of $\mathrm{pMg}$ are within a narrow range and may not be a sensitive marker in reflecting mild $\mathrm{Mg}$ inadequacy or the intracellular $\mathrm{Mg}$ pool. However, $\mathrm{pMg}$ correlates well with intracellular free $\mathrm{Mg}$ as measured by nuclear magnetic resonance spectroscopy (Ryzen et al., 1989). Grouping of GDM with gestational impaired glucose intolerant cases is also a limitation, but segregating GDM mothers and daughters from gestational impaired glucose intolerant mothers and daughters would result in inappropriately small sample sizes for our analyses.

GDM predisposes women to increased risk of adverse glycemic variables, which may represent potential pathophysiological mechanisms for the eventual development of T2DM. It remains to be elucidated if Mg biomarkers and homeostasis are altered previous to, during and/or as a result of gestational diabetic pregnancies in humans and whether or not $\mathrm{pMg}$ is related to longitudinal changes in glycemic variables. Clinical trials are warranted to unravel possible causal effects of $\mathrm{Mg}$ supplementation on glycemic status.

\section{Acknowledgments}

The gestational diabetes study was supported by a grant from the Canadian Institutes of Health Research. 


\section{Tables}

Table 3.1. Plasma magnesium $(\mathrm{mmol} / \mathrm{L})^{1}$ in relation to demographic and lifestyle characteristics in mothers $(n=166)$ and their 15 -year old daughters $(n=166)$

\begin{tabular}{|c|c|c|c|c|c|c|}
\hline \multirow[t]{2}{*}{ Characteristic } & \multicolumn{2}{|c|}{ Mothers } & \multirow[b]{2}{*}{$P$} & \multicolumn{2}{|c|}{ Daughters } & \multirow[b]{2}{*}{$p$} \\
\hline & Frequency & Plasma Mg & & Frequency & Plasma Mg & \\
\hline $\begin{array}{l}\text { Age } \\
<45 \mathrm{yrs} \\
\geq 45 \mathrm{yrs}\end{array}$ & $\begin{array}{l}54(32.5 \%) \\
112(67.5 \%)\end{array}$ & $\begin{array}{l}0.93 \pm 0.13 \\
0.94 \pm 0.12\end{array}$ & 0.625 & $\begin{array}{l}- \\
-\end{array}$ & $\begin{array}{l}- \\
-\end{array}$ & \\
\hline Race & & & & & & \\
\hline Caucasian & $133(80.1 \%)$ & $0.95 \pm 0.12$ & & $133(80.1 \%)$ & $0.90 \pm 0.09$ & \\
\hline Non-caucasian & $33(19.9 \%)$ & $0.89 \pm 0.12$ & 0.011 & $33(19.9 \%)$ & $0.89 \pm 0.09$ & 0.569 \\
\hline $\begin{array}{l}\text { Current } \text { BMI }^{2} \\
<25 \\
25-29.9 \\
\geq 30\end{array}$ & $\begin{array}{l}60(36.1 \%) \\
50(30.1 \%) \\
56(33.7 \%)\end{array}$ & $\begin{array}{l}0.95 \pm 0.11 \\
0.95 \pm 0.13 \\
0.92 \pm 0.12\end{array}$ & 0.314 & $\begin{array}{l}136(81.9 \%) \\
20(12.0 \%) \\
10(6.0 \%)\end{array}$ & $\begin{array}{l}0.90 \pm 0.09 \\
0.89 \pm 0.08 \\
0.86 \pm 0.07\end{array}$ & 0.361 \\
\hline $\begin{array}{l}\text { Waist } \\
\text { circumference } \\
\leq 80 \mathrm{~cm} \\
>80 \mathrm{~cm}\end{array}$ & $\begin{array}{l}42(25.3 \%) \\
124(74.7 \%)\end{array}$ & $\begin{array}{l}0.96 \pm 0.13 \\
0.93 \pm 0.12\end{array}$ & 0.172 & $\begin{array}{l}115(69.3 \%) \\
51(30.7 \%)\end{array}$ & $\begin{array}{l}0.89 \pm 0.07 \\
0.90 \pm 0.12\end{array}$ & 0.502 \\
\hline $\begin{array}{l}\text { Smoking } \\
\text { Yes } \\
\text { No }\end{array}$ & $\begin{array}{l}23(13.9 \%) \\
143(86.1 \%)\end{array}$ & $\begin{array}{l}0.95 \pm 0.12 \\
0.93 \pm 0.12\end{array}$ & 0.459 & $\begin{array}{l}6(3.6 \%) \\
160(96.4 \%)\end{array}$ & $\begin{array}{l}0.91 \pm 0.09 \\
0.89 \pm 0.09\end{array}$ & 0.594 \\
\hline $\begin{array}{l}\text { Alcohol/sitting }{ }^{3} \\
<5 \text { drinks } \\
\geq 5 \text { drinks }\end{array}$ & $\begin{array}{l}141(84.9 \%) \\
25(15.1 \%)\end{array}$ & $\begin{array}{l}0.94 \pm 0.12 \\
0.95 \pm 0.12\end{array}$ & 0.702 & $\begin{array}{l}152(91.6 \%) \\
14(8.4 \%)\end{array}$ & $\begin{array}{l}0.89 \pm 0.12 \\
0.94 \pm 0.18\end{array}$ & 0.157 \\
\hline $\begin{array}{l}\text { Exercise } 4 \\
<3 \text { times/wk } \\
\geq 3 \text { times/wk }\end{array}$ & $\begin{array}{l}136(81.9 \%) \\
30(18.1 \%)\end{array}$ & $\begin{array}{l}0.94 \pm 0.12 \\
0.94 \pm 0.13\end{array}$ & 1.000 & $\begin{array}{l}56(33.7 \%) \\
110(66.3 \%)\end{array}$ & $\begin{array}{l}0.89 \pm 0.07 \\
0.89 \pm 0.09\end{array}$ & 1.000 \\
\hline $\begin{array}{l}\text { GDM/GIGT } \\
\text { history } \\
\text { Yes } \\
\text { No }\end{array}$ & $\begin{array}{l}72(43.4 \%) \\
94(56.6 \%)\end{array}$ & $\begin{array}{l}0.90 \pm 0.11 \\
0.97 \pm 0.12\end{array}$ & 0.002 & $\begin{array}{l}72(43.4 \%) \\
94(56.6 \%)\end{array}$ & $\begin{array}{l}0.92 \pm 0.11 \\
0.88 \pm 0.05\end{array}$ & 0.002 \\
\hline $\begin{array}{l}\text { Mother T2DM } \\
\text { Yes } \\
\text { No }\end{array}$ & $\begin{array}{l}29(17.5 \%) \\
137(82.5 \%)\end{array}$ & $\begin{array}{l}0.88 \pm 0.13 \\
0.95 \pm 0.11\end{array}$ & 0.003 & $\begin{array}{l}29(17.5 \%) \\
137(82.5 \%)\end{array}$ & $\begin{array}{l}0.88 \pm 0.07 \\
0.90 \pm 0.09\end{array}$ & 0.262 \\
\hline
\end{tabular}

Arithmetic means and standard deviations are presented

${ }^{2}$ For daughters, three BMI groupings were considered: $<85^{\text {th }}$ percentile, $85^{\text {th }}-95^{\text {th }}$ percentile ('at risk of overweight') and $>95$ th percentile ('overweight') based on gender-specific BMI-for-age growth charts (CDC, 2000)

${ }^{3}$ Alcohol/sitting indicates if the individual consumed 5 or more drinks in one sitting on at least one occasion in the past month

${ }^{4}$ Exercise indicates if the individual engages in light or heavy exercise for at least 20 minutes in duration at least 3 times per week

${ }^{5}$ Type 2 diabetes (T2DM) was defined as physician's diagnosis, fasting glucose $\geq 7 \mathrm{mmol} / \mathrm{L}$, or $2 \mathrm{hr}$ OGTT glucose $\geq 11.1 \mathrm{mmol} / \mathrm{L}$ 
Table 3.2. Linear regression results $(\beta \pm \mathrm{SE} ; p)$ for plasma $\mathrm{Mg}(\mathrm{pMg})$ and dietary $\mathrm{Mg}^{1}(\mathrm{dMg})$, covariates and glycemic dependent variables in mothers $(\mathrm{n}=166)$

\begin{tabular}{|c|c|c|c|c|c|}
\hline $\begin{array}{c}\text { Model } \\
\text { variables }\end{array}$ & Fasting glucose & Fasting insulin & HOMA IR & HBA1c & ISI composite \\
\hline Intercept & $1.64 \pm 1.13 ;<0.01$ & $4.26 \pm 0.39 ;<0.01$ & $0.82 \pm 0.41 ; 0.05$ & $1.57 \pm 0.10 ;<0.01$ & $2.93 \pm 0.45 ;<0.01$ \\
\hline Plasma Mg & $-0.08 \pm 0.13 ; 0.52$ & $-0.70 \pm 0.39 ; 0.08$ & $-0.75 \pm 0.41 ; 0.07$ & $0.06 \pm 0.10 ; 0.57$ & $0.28 \pm 0.45 ; 0.54$ \\
\hline Age & $0.05 \pm 0.03 ; 0.13$ & $-0.01 \pm 0.09 ; 0.96$ & $0.05 \pm 0.10 ; 0.63$ & $0.01 \pm 0.02 ; 0.81$ & $-0.08 \pm 0.11 ; 0.44$ \\
\hline Race & $0.04 \pm 0.04 ; 0.31$ & $-0.08 \pm 0.12 ; 0.46$ & $-0.03 \pm 0.12 ; 0.78$ & $0.08 \pm 0.03 ;<0.01$ & $-0.12 \pm 0.13 ; 0.36$ \\
\hline BMI & $0.05 \pm 0.03 ; 0.15$ & $0.34 \pm 0.10<0.01$ & $0.38 \pm 0.10 ;<0.01$ & $0.03 \pm 0.02 ; 0.16$ & $-0.41 \pm 0.11 ;<0.01$ \\
\hline GDM & $0.07 \pm 0.03 ; 0.03$ & $0.16 \pm 0.10 ; 0.10$ & $0.24 \pm 0.10 ; 0.02$ & $0.04 \pm 0.02 ; 0.12$ & $-0.30 \pm 0.11 ; 0.01$ \\
\hline T2DM & $0.38 \pm 0.04 ;<0.01$ & $0.23 \pm 0.13 ; 0.08$ & $0.62 \pm 0.14 ;<0.01$ & $0.27 \pm 0.03 ;<0.01$ & $-0.52 \pm 0.15 ;<0.01$ \\
\hline pMg xGDM & $0.04 \pm 0.27 ; 0.88$ & $-2.12 \pm 0.79 ; 0.01$ & $-2.04 \pm 0.84 ; 0.02$ & $-0.24 \pm 0.20 ; 0.23$ & $2.34 \pm 0.91 ; 0.02$ \\
\hline pMg x T2DM & $-0.39 \pm 0.30 ; 0.19$ & $-0.02 \pm 0.90 ; 0.98$ & $-1.01 \pm 0.86 ; 0.24$ & $-0.72 \pm 0.22 ;<0.01$ & $-0.87 \pm 1.03 ; 0.40$ \\
\hline Intercept & $1.48 \pm 0.07 ;<0.01$ & $3.73 \pm 0.23 ;<0.01$ & $0.16 \pm 0.24 ; 0.49$ & $1.52 \pm 0.06 ;<0.01$ & $3.82 \pm 0.25 ;<0.01$ \\
\hline Dietary Mg & $0.02 \pm 0.02 ; 0.28$ & $-0.05 \pm 0.07 ; 0.46$ & $-0.03 \pm 0.07 ; 0.67$ & $0.03 \pm 0.03 ; 0.07$ & $0.12 \pm 0.08 ; 0.13$ \\
\hline Age & $0.04 \pm 0.03 ; 0.19$ & $-0.01 \pm 0.10 ; 0.98$ & $0.05 \pm 0.10 ; 0.64$ & $0.01 \pm 0.02 ; 0.99$ & $-0.11 \pm 0.11 ; 0.32$ \\
\hline Race & $0.04 \pm 0.04 ; 0.23$ & $-0.05 \pm 0.11 ; 0.66$ & $0.01 \pm 0.12 ; 0.95$ & $0.08 \pm 0.03 ;<0.01$ & $-0.12 \pm 0.13 ; 0.36$ \\
\hline BMI & $0.05 \pm 0.03 ; 0.13$ & $0.34 \pm 0.10 ;<0.01$ & $0.38 \pm 0.10 ;<0.01$ & $0.04 \pm 0.02 ; 0.14$ & $-0.40 \pm 0.11 ;<0.01$ \\
\hline GDM & $0.07 \pm 0.03 ; 0.02$ & $0.21 \pm 0.10 ; 0.03$ & $0.29 \pm 0.10 ;<0.01$ & $0.03 \pm 0.02 ; 0.17$ & $-0.33 \pm 0.11 ;<0.01$ \\
\hline T2DM & $0.38 \pm 0.04 ;<0.01$ & $0.26 \pm 0.13 ; 0.05$ & $0.65 \pm 0.14 ;<0.01$ & $0.26 \pm 0.03 ;<0.01$ & $-0.56 \pm 0.15 ;<0.01$ \\
\hline $\mathrm{dMg} \times \mathrm{xDM}$ & $0.06 \pm 0.04 ; 0.15$ & $-0.18 \pm 0.14 ; 0.18$ & $-0.13 \pm 0.14 ; 0.38$ & $0.05 \pm 0.03 ; 0.17$ & $0.25 \pm 0.15 ; 0.11$ \\
\hline $\mathrm{dMg} \times \mathrm{T} 2 \mathrm{DM}$ & $0.20 \pm 0.06 ;<0.01$ & $-0.06 \pm 0.19 ; 0.74$ & $0.13 \pm 0.20 ; 0.53$ & $0.22 \pm 0.04 ;<0.01$ & $-0.15 \pm 0.21 ; 0.49$ \\
\hline
\end{tabular}

${ }^{1}$ per 100mg increase in calorie-adjusted dietary $\mathrm{Mg}$

2 Mothers' plasma Mg was entered as a continuous variable; all other mothers' variables were binary coded [age $(<45 \mathrm{yrs}=0$, $\geq 45 \mathrm{yrs}=1)$, race (caucasian=0, non-caucasian=1), BMI (BMI <30=0, BMI $\geq 30=1)$, GDM/GIGT history (no GDM/GIGT=0, GDM/GIGT =1), current type 2 diabetes $(\mathrm{T} 2 \mathrm{DM})($ no T2DM =0, T2DM =1)]. Estimates are provided for interaction terms when added separately into the fully adjusted model. Analyses were repeated replacing mothers' plasma $\mathrm{Mg}$ with mothers' dietary $\mathrm{Mg}$ 
Table 3.3. Linear regression results $(\beta \pm \mathrm{SE} ; p)$ for plasma $\mathrm{Mg}(\mathrm{pMg})$ and dietary $\mathrm{Mg}^{1}(\mathrm{dMg})$, covariates and glycemic dependent variables in daughters $(\mathrm{n}=166)$

\begin{tabular}{|c|c|c|c|c|c|}
\hline Model variables $^{2}$ & Fasting glucose & Fasting insulin & HOMA IR & HBA1c & ISI composite \\
\hline $\begin{array}{c}\text { Intercept } \\
\text { Plasma Mg } \\
\text { Race } \\
\text { BMI } \\
\text { GDM } \\
\text { T2DM }\end{array}$ & $\begin{array}{r}1.67 \pm 0.06 ;<0.01 \\
-0.11 \pm 0.07 ; 0.14 \\
0.01 \pm 0.03 ; 0.83 \\
0.02 \pm 0.02 ; 0.17 \\
-0.01 \pm 0.01 ; 0.28 \\
0.02 \pm 0.02 ; 0.24\end{array}$ & $\begin{array}{l}4.32 \pm 0.43 ;<0.01 \\
-0.53 \pm 0.48 ; 0.28 \\
0.04 \pm 0.10 ; 0.74 \\
0.48 \pm 0.11 ;<0.01 \\
0.15 \pm 0.09 ; 0.10 \\
-0.11 \pm 0.12 ; 0.38\end{array}$ & $\begin{array}{l}0.96 \pm 0.44 ; 0.03 \\
-0.66 \pm 0.50 ; 0.19 \\
0.04 \pm 0.11 ; 0.72 \\
0.49 \pm 0.11 ;<0.01 \\
0.14 \pm 0.09 ; 0.14 \\
-0.08 \pm 0.13 ; 0.53\end{array}$ & $\begin{array}{l}1.72 \pm 0.06 ;<0.01 \\
\mathbf{- 0 . 1 0} \pm \mathbf{0 . 0 5} ; \mathbf{0 . 0 5} \\
0.01 \pm 0.01 ; 0.35 \\
0.01 \pm 0.02 ; 0.78 \\
-0.01 \pm 0.01 ; 0.35 \\
0.01 \pm 0.02 ; 0.74\end{array}$ & $\begin{array}{l}2.73 \pm 0.44 ;<0.01 \\
0.27 \pm 0.49 ; 0.58 \\
-0.04 \pm 0.11 ; 0.74 \\
-0.41 \pm 0.11 ;<0.01 \\
-0.05 \pm 0.09 ; 0.63 \\
-0.05 \pm 0.13 ; 0.69\end{array}$ \\
\hline pMg x GDM & $-0.35 \pm 0.17 ; 0.04$ & $1.74 \pm 1.17 ; 0.14$ & $1.38 \pm 1.22 ; 0.26$ & $0.17 \pm 0.12 ; 0.18$ & $-1.69 \pm 1.21 ; 0.17$ \\
\hline $\mathrm{pMg} \times \mathrm{T} 2 \mathrm{DM}$ & $0.20 \pm 0.21 ; 0.36$ & $-0.11 \pm 1.40 ; 0.94$ & $0.05 \pm 1.45 ; 0.97$ & $0.11 \pm 0.15 ; 0.44$ & $0.45 \pm 1.48 ; 0.76$ \\
\hline $\begin{array}{c}\text { Intercept } \\
\text { Dietary Mg } \\
\text { Race } \\
\text { BMI } \\
\text { GDM } \\
\text { T2DM }\end{array}$ & $\begin{array}{l}1.63 \pm 0.03 ;<0.01 \\
\mathbf{- 0 . 0 2} \pm \mathbf{0 . 0 1} ; \mathbf{0 . 0 3} \\
0.01 \pm 0.03 ; 0.98 \\
0.03 \pm 0.02 ; 0.11 \\
-0.02 \pm 0.01 ; 0.15 \\
0.03 \pm 0.02 ; 0.13\end{array}$ & $\begin{array}{l}3.92 \pm 0.18 ;<0.01 \\
-0.03 \pm 0.07 ; 0.68 \\
0.03 \pm 0.11 ; 0.75 \\
0.50 \pm 0.11 ;<0.01 \\
0.12 \pm 0.09 ; 0.16 \\
-0.09 \pm 0.12 ; 0.46\end{array}$ & $\begin{array}{l}0.50 \pm 0.19 ; 0.01 \\
-0.05 \pm 0.07 ; 0.48 \\
0.04 \pm 0.11 ; 0.75 \\
0.52 \pm 0.11 ;<0.01 \\
0.10 \pm 0.09 ; 0.25 \\
-0.06 \pm 0.13 ; 0.65\end{array}$ & $\begin{array}{l}1.66 \pm 0.02 ;<0.01 \\
-0.01 \pm 0.01 ; 0.24 \\
0.01 \pm 0.01 ; 0.38 \\
0.01 \pm 0.01 ; 0.51 \\
-0.01 \pm 0.01 ; 0.27 \\
0.01 \pm 0.01 ; 0.53\end{array}$ & $\begin{array}{l}2.83 \pm 0.19 ;<0.01 \\
0.06 \pm 0.07 ; 0.42 \\
-0.02 \pm 0.11 ; 0.83 \\
-0.43 \pm 0.11 ;<0.01 \\
-0.03 \pm 0.09 ; 0.75 \\
-0.07 \pm 0.13 ; 0.60\end{array}$ \\
\hline $\mathrm{dMg} \times \mathrm{GDM}$ & $-0.01 \pm 0.02 ; 0.61$ & $0.02 \pm 0.14 ; 0.87$ & $0.02 \pm 0.14 ; 0.92$ & $-0.01 \pm 0.02 ; 0.46$ & $-0.03 \pm 0.14 ; 0.83$ \\
\hline dMg x T2DM & $-0.02 \pm 0.02 ; 0.33$ & $-0.01 \pm 0.15 ; 0.93$ & $-0.04 \pm 0.15 ; 0.80$ & $-0.02 \pm 0.02 ; 0.13$ & $-0.09 \pm 0.16 ; 0.57$ \\
\hline
\end{tabular}

${ }^{1}$ per $100 \mathrm{mg}$ increase in calorie-adjusted dietary $\mathrm{Mg}$

2 Daughters' plasma Mg was entered as a continuous variable; all other daughters' variables were binary coded: race (caucasian=0, non-caucasian=1), BMI (BMI $<85^{\text {th }}$ percentile $=0, \mathrm{BMI} \geq 85^{\text {th }}$ percentile $=1$ ), mother had GDM/GIGT during pregnancy with the daughter (no GDM/GIGT=0, GDM/GIGT $=1$ ), mother currently has type 2 diabetes (T2DM) (no T2DM =0, T2DM =1)]. Estimates are provided for interaction terms when added separately into the fully adjusted model. Analyses were repeated replacing daughters' plasma Mg with daughters' dietary $\mathrm{Mg}$ 


\section{References}

1. Altura, B.T.; Shirey, T.L.; Young, C.C.; et al. A new method for the rapid determination of ionized $\mathrm{Mg}^{2+}$ in whole blood, serum and plasma. Methodological Findings in Experimental \& Clinical Pharmacology 1992, 14, 297-301.

2. Barbagallo, M. \& Dominguez, L.J.; Magnesium metabolism in type 2 diabetes mellitus, metabolic syndrome and insulin resistance. Archives of Biochemistry and Biophysics 2007, 458, 40-47.

3. Bardiceff, M.; Bardicef, O.; Sorokin, Y.; et al. Extracellular and intracellular magnesium depletion in pregnancy and gestational diabetes. American Journal of Obstetrics \& Gynecology 1995, 172, 1009-1013.

4. Bond, H.; Sibley, C.P.; Balment, R.J.; Ashton, N.; Increased renal tubular reabsorption of calcium and magnesium by the offspring of diabetic rat pregnancy. Pediatric Research 2005, 57, 890-895.

5. Defronzo, R.A. \& Matsuda, M., Reduced Time Points to Calculate the Composite Index. Diabetes Care 2010, 33, e93-e93 (abstract).

6. de Valk, H.W., Magnesium in diabetes mellitus. Netherlands Journal of Medicine 1999, 54, 139-146.

7. Egeland, G.M. \& Meltzer, S.J., Following in mother's footsteps? Motherdaughter risks for insulin resistance and cardiovascular disease 15 years after gestational diabetes. Diabetic Medicine 2010, 27, 257-265.

8. Ertbeg P, Norgaard P, Bang L, Nyholm H, Rudnicki M. Ionized magnesium in gestational diabetes. Magnesium Research 2004, 17, 35-38.

9. Haffner, S.M., Risk factors for non-insulin dependent diabetes mellitus. Journal of Hypertension 1995, 13, S73-S76 (abstract). 
10. International Diabetes Federation. A new worldwide definition of the metabolic syndrome. 2005. Available online:

http://www.idf.org/metabolic_syndrome. Last accessed: Aug 2011.

11. International Diabetes Federation. The IDF consensus definition of the metabolic syndrome in children and adolescents. 2007. Available online:

http://www.idf.org/webdata/docs/Mets_definition_children.pdf. Last accessed: Aug 2011.

12. Kalaitzidis, R.; Tismihodimos, V.; Bairaktari, E.; Siamopoulos, K.; Elisaf, M., Disturbances of phosphate metabolism: another feature of the metabolic syndrome. Journal of Kidney Diseases 2005, 45, 851-858.

13. Kao, W.H.L.; Folsom, A.R.; Nieto, F.J.; Mo, J.P.; Watson, R.L.; Brancati, F.L., Serum and dietary magnesium and the risk for type 2 diabetes mellitus - The atherosclerosis risk in communities study. Archives of Internal Medicine 1999, 159, 2151-2159.

14. Kim, D.J.; Xun, P.C.; Liu, K.A.; et al. Magnesium intake in relation to systemic inflammation, insulin resistance, and the incidence of diabetes. Diabetes Care 2010, 33, 2604-2610.

15. Kirii, K.; Iso, H.; Date, C.; et al., Magnesium intake and risk of selfreported type 2 diabetes among Japanese. Journal of the American College of Nutrition 2010, 29, 99-106.

16. Lopez-Ridaura, R.; Willett, W.C.; Rimm, E.B.; et al., Magnesium intake and risk of type 2 diabetes in men and women. Diabetes Care 2004, 27, 134-140. 17. Matthews, D.R.; Hosker, J.P.; Rudenski, A.S.; Naylor, B.A.; Treacher, D.F.; Turner, R.C., Homeostasis model assessment: insulin resistance and beta- 
cell function from fasting plasma glucose and insulin concentrations in man. Diabetology 1985, 28, 412-419.

18. Mooren, F.C.; Kruger, K.; Volker, K.; Golf, S.W.; Wadepuhl, M.; Kraus, A., Oral magnesium supplementation reduces insulin resistance in non-diabetic subjects - a double-blind, placebo-controlled, randomized trial. Diabetes, Obesity \& Metabolism 2011, 13, 281-284.

19. Mughal, M.Z.; Eelloo, J.A.; Roberts, S.A.; et al., Intrauterine programming of urinary calcium and magnesium excretion in children born to mothers with insulin dependent diabetes mellitus. Archives of Disease in Childhood- Fetal and Neonatal Edition 2005, 90, F332-F336.

20. Nadler, J.L.; Buchanan, T.; Natarajan, R.; Antonipillai, I.; Bergman, R.; Rude, R., Magnesium deficiency produces insulin resistance and increased thromboxane synthesis. Hypertension 1993, 21, 1024-1029.

21. Nanri, A.; Mizoue, T.; Noda, M.; et al., Magnesium intake and type II diabetes in Japanese men and women: the Japan Public Health Center-based Prospective Study. European Journal of Clinical Nutrition 2010, 64, 1244-1247.

22. National Diabetes Data Group, Classification and diagnosis of diabetes mellitus and other categories of glucose intolerance. Diabetes 1979, 28. 10391057.

23. Romani, A.M.P., Magnesium homeostasis and alcohol consumption. Magnesium Research 2008, 21, 197-204.

24. Ryzen, E., Servis, K.L.; DeRusso, P.; Kershaw, A.; Stephen, T.; Rude, K., Determination of intracellular free magnesium by nuclear magnetic resonance in 
human magnesium deficiency. Journal of the American College of Nutrition 1989, 8, 580-587.

25. Shatenstein, B.; Nadon, S.; Godin, C.; Ferland, G., Development and validation of a food frequency questionnaire. Canadian Journal of Dietetic Practice and Research 2005, 66, 67-75.

26. Song, Y.; He, K.; Levitan, E.B.; Manson, J.E.; Liu, S., Effects of oral magnesium supplementation on glycaemic control in type 2 diabetes: a metaanalysis of randomized double-blind controlled trials. Diabetic Medicine 2006, 23, 1050-1056.

27. Song, Y.Q.; Manson, J.E.; Buring, J.E.; Liu, S.M., Dietary magnesium intake in relation to plasma insulin levels and risk of type 2 diabetes in women. Diabetes Care 2004, 27, 59-65.

28. Willett, W.C. \& Stampfer, M.J., Total energy intake: implications for epidemiologic analyses. American Journal of Epidemiology 1986, 124, 17-27. 


\section{BRIDGE 2}

In the previous analysis, $\mathrm{pMg}$ was inversely associated with glycemic outcome variables among mothers and 15-year old nondiabetic daughters after multivariate adjustment. Although extracellular $\mathrm{Mg}$ measures, such as $\mathrm{pMg}$ and $\mathrm{sMg}$, remain the most commonly used biomarkers clinically and in the literature, they have not been validated as reliable biomarkers of Mg status (IOM, 1997). In 1985, Elin concluded that the determination of $\mathrm{Mg}$ status was riddled with challenges, and no simple, rapid and accurate test has emerged in subsequent decades.

Total $\mathrm{Mg}$ contents in erythrocytes ( $\mathrm{rMg}$ ) may be responsive to $\mathrm{Mg}$ depletion and repletion (Deutser et al., 1987; Nielsen et al., 2007) and represent long-term nutrient status. The correlation between $\mathrm{rMg}$ and the most commonly measured $\mathrm{Mg}$ biomarker, total $\mathrm{sMg}$, is unknown, as is the utility of $\mathrm{rMg}$ as a cardiometabolic risk biomarker.

The following analysis examines associations between $\mathrm{sMg}, \mathrm{rMg}$ and cardiovascular variables in two ethnically distinct, cross-sectional cohorts, evaluates whether the same cardiovascular associations observed for sMg hold for

$\mathrm{rMg}$, and comments on the utility of each as a cardiometabolic risk biomarker. Based on the sum of evidence presented, what these Mg biomarkers are actually capturing remains equivocal. 


\section{References}

1. Deutser, P.A.; Deuster, U.H.; Trostmann, L.L.; Bernier, E.; Dolev, E., Indirect vs direct measurement of magnesium and zinc in erythrocytes. Clinical Chemistry 1987, 33, 529-532.

2. Elin, R.J. Overview of problems in diagnosis of magnesium status. Journal of the American College of Nutrition 1985, 4 (3), 330 (abstract).

3. Institute of Medicine (IOM), Dietary Reference Intakes for Calcium, Phosphorus, Magnesium, Vitamin D, and Fluoride. 1997, National Academies Press: Washington, DC.

4. Nielsen, F.H.; Milne, D.B.; Klevay, L.M.; Gallagher, S.; Johnson, L., Dietary magnesium deficiency induces heart rhythm changes, impairs glucose tolerance, and decreases serum cholesterol in post menopausal women. Journal of the American College of Nutrition 2007, 26, 121-132. 


\section{CHAPTER 4. MANUSCRIPT 2}

Serum magnesium, erythrocyte magnesium and cardiovascular risk profiles in two ethnically distinct populations

Short title: Mg biomarkers and cardiovascular risk

L.C. Del Gobbo ${ }^{1}$, Y. Song ${ }^{2}$, R.J. Elin ${ }^{3}$, E. Dewailly ${ }^{4}$, M. Noel ${ }^{4}$, G.M. Egeland ${ }^{1}$

${ }^{1}$ School of Dietetics \& Human Nutrition, McGill University, Ste. Anne de Bellevue, Quebec, Canada

${ }^{2}$ Division of Preventive Medicine, Brigham and Women's Hospital, Harvard Medical School, Boston, MA, USA

${ }^{3}$ Department of Pathology and Laboratory Medicine, University of Louisville, Louisville, KY, USA

${ }^{4}$ Public Health Research Unit, CHUL Research Center, Centre Hospitalier, Universitaire de Quebec Sainte-Foy, Canada

Corresponding author: Grace M. Egeland (grace.egeland@mcgill.ca)

School of Dietetics and Human Nutrition

Room MS2-039, Macdonald Stewart Building, 21111 Lakeshore Road

Ste. Anne de Bellevue, Quebec H9X 3V9

Tel.: 514-398-8642

Fax: 514-398-1020 


\section{Abstract}

Introduction: $\mathrm{sMg}$ is associated with cardiometabolic endpoints, but remains an imperfect risk associate and marker of $\mathrm{Mg}$ status. The objective of this study is to provide a comprehensive evaluation of the utility of $\mathrm{rMg}$ as a potential cardiovascular risk biomarker in two distinct populations, determine if the same cardiovascular associations observed for total sMg hold for $\mathrm{rMg}$, and comment on each $\mathrm{Mg}$ measure as a marker for cardiovascular risk.

Methods: rMg was measured in 1327 participants derived from two aboriginal cross-sectional populations in Canada, James Bay Cree and Inuit; in the Cree population ( $\mathrm{n}=615), \mathrm{sMg}$ was also available. Associations between $\mathrm{Mg}$ biomarkers and adiposity measures, fasting glucose, fasting insulin, blood lipids, high sensitivity C-reactive protein (hsCRP), casual systolic and diastolic blood pressure, and carotid intima-media thickness were assessed in nondiabetic adults $>18 y$ rs using multivariate linear regression and ANCOVA.

Results: $\mathrm{rMg}$ is significantly associated with adiposity in both populations $(p<0.001)$, but no associations between $\mathrm{rMg}$ and fasting glucose, insulin, hsCRP, blood pressure, nor carotid intima-media thickness were observed in either ethnic population. Consistent with previous findings, $\mathrm{sMg}$ was positively associated with total cholesterol, LDL and ApoB in Cree $(p=0.001)$, but significantly inversely associated with fasting glucose $(p=0.001)$, hsCRP $(p=0.038)$, and carotid-intima media thickness $(p=0.044)$ within the same population.

Conclusions: This study provides no evidence that $\mathrm{rMg}$ is associated with a favourable cardiovascular risk profile or adds value to risk assessment. Further 
investigations and clinical trials evaluating the utility of $\mathrm{sMg}$ as a $\mathrm{Mg}$ biomarker predicting cardiometabolic risk are appropriate.

Keywords: magnesium, magnesium biomarkers, lipids, CRP, blood pressure, carotid intima media thickness, cardiovascular risk 


\section{Introduction}

Multiple lines of evidence support the role of magnesium $(\mathrm{Mg})$ in the maintenance of vascular tone, blood pressure, and cardiac function (Ueshima, 2000). Although total serum $\mathrm{Mg}$ ( $\mathrm{sMg}$ ) has not been validated as a reliable indicator of body Mg status (IOM, 1997), it remains the most commonly used $\mathrm{Mg}$ biomarker (Arnaud et al., 2008). Previous studies have reported significant inverse associations between $\mathrm{sMg}$ and cardiometabolic risk endpoints such as ambulatory blood pressure (Hashimoto et al, 2010), systolic blood pressure (Ma et al., 1995), incident hypertension (Peacock et al., 1999) C-reactive protein (CRP) (Guerrero-Romero \& Rodriguez-Moran, 2002), fasting glucose (Ma et al., 1995) and carotid intima-media thickness (IMT) (Hashimoto et al., 2010; Ma et al., 1995). Therefore, the counterintuitive finding that $\mathrm{sMg}$ increases with LDL, TG and total cholesterol in a general adult population (Randell et al., 2008) has been met with interest and debate (Corsonello et al., 2007). Indeed, positive associations between $\mathrm{sMg}$ and some atherogenic blood lipids, such as LDL, have been reported in the same surveys showing inverse associations between $\mathrm{sMg}$ and carotid wall thickness, a surrogate marker of atherosclerosis (Hashimoto et al., 2010; Ma et al., 1995). While speculation that a potential binding interaction between $\mathrm{sMg}$ and lipoproteins may reduce the utility of $\mathrm{sMg}$ as an indicator of $\mathrm{Mg}$ status (Randell et al., 2008; Corsonello et al., 2007), there are other limitations of $\mathrm{sMg}$ as a biomarker. The correlation between $\mathrm{sMg}$ and $\mathrm{Mg}$ intake in the ARIC cohort $(n=14,882)$ was less than 0.06 in all race and sex groups (Ma et al., 1995). $\mathrm{sMg}$ is maintained within a stable range of $0.75-0.95 \mathrm{mmol} / \mathrm{L}$ in healthy adults by kidney filtration and reabsorption, and normal range concentrations cannot rule 
out body deficit due to compensatory Mg loss from the bone pool (Arnaud et al., 2008).

Changes in rMg content have been observed after several weeks of low dietary intake (Deutser et al., 1987), as erythrocyte pools are reflective of longterm rather than current nutrient status. In a recent experimental $\mathrm{Mg}$ dietary depletion study in postmenopausal women, USDA scientists (Nielsen et al., 2007) confirmed that rMg significantly declined during $\mathrm{Mg}$ depletion; while $\mathrm{sMg}$ initially decreased, it rebounded to baseline values on day 40 and only slightly decreased thereafter. Unlike sMg, there are few reports associating rMg with various anthropometric variables and apparently no studies relating rMg to blood lipids, fasting glucose, blood pressure, hsCRP, nor carotid IMT.

We sought to determine the association of total $\mathrm{rMg}$ with these cardiovascular variables in two ethnically distinct, general adult populations. We also measured sMg in one population in order to corroborate the surprising finding that sMg increases with blood lipids (Randell et al., 2008), evaluate if the same cardiovascular associations observed for $\mathrm{sMg}$ hold for $\mathrm{rMg}$, and comment on the relative utility of each $\mathrm{Mg}$ measure as a marker for cardiovascular risk.

\section{Methods}

Participants were selected from a subset of two comprehensive aboriginal health surveys in Canada as preliminary findings indicate that both populations fall well below recommended intakes for $\mathrm{Mg}$ (Johnson-Down \& Egeland, in press; Egeland et al., 2011) and are at elevated cardiometabolic risk due to high prevalence of obesity and dietary transition (Egeland et al., 2011). The first survey, 'Nituuchischaayihitaau Aschii: A Multi-Community Environment and 
Health Longitudinal Study in Iiyiyiu Aschii' was an age-stratified random survey of James Bay Cree from communities in Quebec, Canada. This work included fasting participants for which $\mathrm{sMg}$, covariates and cardiovascular variables were available from seven communities sampled between 2005-2009. The second survey, the "Inuit Health Survey", collected data from a community-stratified random sample of Inuit adults; a subset of adults sampled in 2008 from Kitikmeot, Inuvialuit/Northwest territories, and Nunutsiavut were available for inclusion. Participants in both studies were interviewed using a series of questionnaires detailing lifestyle habits, dietary patterns, medical history and medication use. Anthropometric measurements and blood drawn in a fasted state for clinical analyses were conducted by nurses.

Adults ( $\geq 18$ yrs) with prior record of myocardial infarction, stroke, type 1 diabetes or T2DM, kidney disease or current cancer were excluded as these conditions are associated with derangements in $\mathrm{Mg}$ homeostasis, the lipid profile, and/or inflammatory markers. As a primary aim was to provide a comprehensive evaluation of the utility of $\mathrm{rMg}$ as a potential risk associate in individuals without history of cardiovascular events or metabolic derangements, we evaluated rMg associations with a wide spectrum of cardiovascular risk components in both ethnic populations. Outcome variables included adiposity measures [waist circumference (WC), body mass index (BMI), body fat \%)], glycemic variables (fasting glucose, fasting insulin), blood lipids [total cholesterol, triglycerides (TG), high and low density lipoprotein (HDL, LDL), apolipoprotein B (ApoB)], high sensitivity C-reactive protein (hsCRP), casual systolic and diastolic blood pressure (BP), and carotid intima-media thickness (IMT) measured in two ways 
(as 'common carotid IMT,' the mean intima-media thickness of the common segments of the near and far wall of the common carotid artery, and 'total carotid IMT,' representing the mean intima-media thickness as measured at 12 segments along the common carotid artery, bulb and internal parts of the carotid tree). All analyses for independent variables of interest $\mathrm{sMg}$ (Cree), $\mathrm{rMg}$ (Cree), $\mathrm{rMg}$ (Inuit) were conducted separately and analyses were made comparable by using identically coded covariates among Cree and Inuit models. Variable coding and a description of anthropometric, lifestyle and clinical variable assessment are detailed here (Supplement).

Due largely to high prevalence of T2DM in Cree, the original cohort of 834 was reduced to 615 adults for which variables of interest were available. The removal of nonfasting individuals and diabetics reduced the Inuit cohort of 767 to 712 adults. Biomarker associations between $\mathrm{Mg}$ and hsCRP were examined with and without restricting analysis to those with hsCRP $<10 \mathrm{mg} / \mathrm{L}$. Carotid IMT measurements were available in 718 individuals from both populations (Cree, $\mathrm{n}=447$; Inuit, $\mathrm{n}=271$ ). Since carotid variables were only measured in individuals $\geq 40 \mathrm{yrs}$ in the Inuit cohort but individuals $\geq 18 \mathrm{yrs}$ in Cree, for consistency, we present carotid measures in the $\geq 40 y r$ Cree subgroup in tables $(n=193)$ and separately describe carotid IMT results for the 18-40yr Cree subgroup. Metabolic syndrome (MetS) components were included in carotid IMT models based on the rationale that some individual components, such as HDL and TG, are confounders, potentially associated with intima-media thickness progression (Maki et al., 2011) and Mg biomarkers themselves.

\section{Ethics}


Ethics for the Cree health survey was obtained from the Cree Board of Health and Social Services of James Bay (CBHSSJB), Centre Hospitalier Universitaire de Québec (Laval), and McGill universities. A research agreement with communities was developed with the Cree Board of Health and all individual study participants provided informed written consent in Cree or English. Ethical approval for the Inuit Health Survey was obtained from McGill's Institutional Review Board; regional licenses were obtained and community-university agreements were signed prior to conducting research in accordance with participatory methods (WHO \& CINE, 2003). Serum $M g(s M g)$ and erythrocyte $M g(r M g)$ assessment in Cree and Inuit

Serum, available in Cree only, was tested for total Mg content at the Trace Elements Laboratory the London Laboratory Services group, London, ON using the colorimetric endpoint method with addition of xylidyl blue; the $\mathrm{Mg}$ concentration measured photometrically as a function of the decrease in xylidyl blue absorbance (laboratory reference range: 0.65-1.05 mmol/L).

For rMg determination in Cree and Inuit, blood collected in BD lavendertop vacutainers (containing $\mathrm{K}_{2}$ EDTA as anticoagulant) was centrifuged at $4 \mathrm{C}$. Plasma was removed and erythrocytes were stored frozen at -80C. Erythrocytes were thawed, gently stirred, kept on ice and $500 \mu \mathrm{l}$ aliquots were withdrawn for Mg determination. Samples were handled through Nutrasource Diagnostics and analyzed at the Trace Elements Laboratory. Samples were thawed on arrival, then diluted with tetramethyl ammonium hydroxide and analyzed for $\mathrm{Mg}$ content with 
a Finnigan MAT Element High Resolution Inductively Coupled Plasma Mass Spectrometer (laboratory reference range: 1.57-2.73mmol/L). Statistical analysis

Differences in underlying cardiovascular risk characteristics among Cree vs. Inuit were compared using t-tests or $x^{2}$ tests. As both $\mathrm{sMg}$ and $\mathrm{rMg}$ concentrations were available in Cree adults $(n=615)$, potential associations between biomarkers were examined using partial correlations. Unadjusted $\mathrm{sMg}$ and $\mathrm{rMg}$ means according to anthropometric and lifestyle variables were compared using t-tests or one-way ANOVA. Univariate curve fitting techniques were used to assess the association between $\mathrm{Mg}$ biomarkers ( $\mathrm{sMg}, \mathrm{rMg}$ ) and dependent variables. Since nonlinear functions were not a significantly better fit for $\mathrm{Mg}$ biomarkers and dependent variables than the linear model $(p>0.05)$, we initially explored associations between $\mathrm{sMg}$ and $\mathrm{rMg}$ and dependent variables using multivariate linear regression. Residuals plots and testing of regression assumptions indicated multivariate linear techniques were reasonable.

Potential interactions between $\mathrm{Mg}$ biomarkers and age, sex, or MetS were tested for all dependent variables. In spite of emerging evidence for heterogeneous cardiometabolic risk according to sex and ethnicity (Cree vs. Inuit) at similar degrees of abdominal obesity (Chateau-Degat et al., 2008), in the absence of a MetS definition and prospective risk data specific to these aboriginal populations, we used the International Diabetes Federation's MetS definition. Selected significant interactions were depicted graphically using adjusted $\mathrm{Mg}$ means estimated for each group of the interacting variable. Since a body of literature derived from numerous lines of evidence links $\mathrm{Mg}$ with most 
associations tested, we chose not to adjust for multiple comparisons; all $p$ values were thus considered significant at the $\leq 0.05$ level.

\section{Results}

\section{Cardiovascular risk characteristics in Cree vs. Inuit nondiabetic adults}

The population distribution of the Cree adult sample was comparable to that of the Inuit with respect to age (Cree mean: $36.4 \pm 14.3$ yrs; Inuit: $40.9 \pm 14.0$ yrs), gender balance (Cree 56\% female; Inuit: 65\%), current smoking (Cree 57\%; Inuit 67\%), participants engaging in vigorous physical activity less than four days

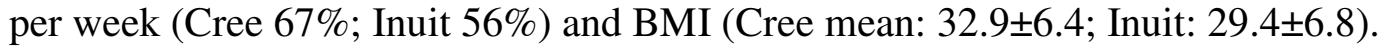
However, the proportion of participants meeting IDF-defined MetS component criteria was significantly higher in Cree for high WC (Cree: 92\%; Inuit 72\%, $p<0.001$ ), low HDL (Cree: 45\%; Inuit 31\%, $p<0.001$ ), and impaired fasting glucose (Cree: $40 \%$, Inuit $11 \%, \mathrm{p}<0.001$ ). The proportion of participants meeting MetS component criteria for high TG (Cree: 28\%; Inuit 32\%) and high BP (Cree $34 \%$; Inuit $31 \%$ ) did not significantly differ ( $p=0.208$ and $p=0.195$, respectively). A greater proportion of Cree had MetS overall (52\% vs. $27 \%$ in Inuit, $p<0.001)$, hsCRP $\geq 3(52 \%$ vs $27 \%, p<0.001)$ and higher carotid arterial thickness in adults 40yrs and older [total carotid IMT Cree: 0.76mm (95\% CI:0.74-0.79); Inuit:

0.71mm (95\% CI:0.69-0.74) and common carotid IMT Cree: $0.73 \mathrm{~mm}(95 \%$

CI:0.71-0.76); Inuit 0.68mm (95\% CI:0.67-0.70)].

Mg biomarkers in Cree and Inuit

$\mathrm{Mg}$ biomarkers were relatively normally distributed; mean $\mathrm{sMg}$ in Cree was $0.83 \pm 0.06 \mathrm{mmol} / \mathrm{L}$ (median $0.83 \mathrm{mmol} / \mathrm{L}$ ). Mean $\mathrm{rMg}$ in Cree was significantly higher than mean $\mathrm{rMg}$ in Inuit $(2.47 \pm 0.31 \mathrm{mmol} / \mathrm{L}$ vs. $2.13 \pm 0.36$ 
$\mathrm{mmol} / \mathrm{L}, p<0.001$, t-test). rMg concentrations in $7.3 \%$ of Inuit adults were below the lower limit of the reference range for $\mathrm{rMg}(1.57 \mathrm{mmol} / \mathrm{L})$, while no Cree had a rMg below the lower limit. sMg concentrations fell within the reference range (0.65-1.05mmol/L) for $99.8 \%$ of Cree.

The association between $\mathrm{sMg}$ and $\mathrm{rMg}$ significantly differed by age and sex (Figure 4.1). The unadjusted (Figure 4.4a,b,c) and adjusted correlation between $\mathrm{sMg}$ and $\mathrm{rMg}$ was stronger in females $(=0.278, p<0.001)$ than males $(=0.108, p=0.09)$ and in older individuals of both sexes. The magnitude of partial correlation coefficients between $\mathrm{sMg}$ and $\mathrm{rMg}$ did not differ between those with and without MetS or by degree of adiposity.

\section{Mg biomarkers and anthropometric characteristics}

Unadjusted mean sMg concentrations among Cree significantly differed by age, gender, region, education, physical activity, and multivitamin use, but not by adiposity (Table 4.1). By contrast, unadjusted rMg significantly increased with BMI in both Cree and Inuit (Figure 4.2) and also differed by region. In linear regression analyses adjusted for age, sex, region, education, exercise, smoking, alcohol, multivitamin use, $\mathrm{rMg}$ remained significantly associated with adiposity (WC, BMI, and body fat $\%)$ in both Cree and Inuit $(p<0.01)$, with strongest associations to body fat \% in both populations (Table 4.2). Mg biomarkers and blood lipids

Consistent with previous findings that $\mathrm{sMg}$ is positively associated with blood lipids in univariate analysis (Randell et al., 2008), with stronger associations reported for total cholesterol and LDL than HDL (Ma et al., 1995; Hashimoto et al., 2010; Randell et al., 2008) we found significant linear 
associations between sMg and total cholesterol, LDL and ApoB after multiple adjustment ( $p=0.001)$. The associations between $\mathrm{rMg}$ and lipid profile components were unclear, differing between Cree and Inuit (Table 4.2). Mg biomarkers and associations with other cardiovascular risk variables Although sMg was positively associated with blood lipids in Cree, we observed inverse linear associations between sMg and fasting glucose $(p=0.001)$, hsCRP ( $p=0.038$ ), and carotid IMT variables in Cree (Table 4.2), consistent with previous analyses (Ma et al., 1995; Guerrero-Romero \& Rodriguez-Morán, 2008; Hashimoto et al., 2010). We found no significant associations, however, between sMg and hsCRP when analysis was limited to individuals with concentrations $<10 \mathrm{mg} / \mathrm{L}(p=0.51) . \mathrm{sMg}$ was not associated with systolic nor diastolic blood pressure (Table 4.2).

Apart from positive associations between $\mathrm{rMg}$ and adiposity and $\mathrm{rMg}$ and some blood lipids, rMg concentrations were not associated with any other variables related to cardiometabolic risk in Cree nor Inuit (fasting glucose, insulin, hsCRP, hsCRP $<10 \mathrm{mg} / \mathrm{L}(p=0.18)$, blood pressure, total carotid IMT nor common carotid IMT) (Table 4.2).

Tests for sex and age interactions

Differences in the strength of associations in males vs. females were generally not significant, except for a stronger association between Cree rMg and body fat $\%$ in females $(p=0.002)$ than males $(p=0.15)$. The inverse association between $\mathrm{rMg}$ and HDL was present only in males $(p=0.018)$ and not females $(p=0.55)($ Table 4.3). 
Among Cree, associations between sMg and total cholesterol, LDL, total carotid IMT, and common carotid IMT were stronger in those $\geq 40 \mathrm{yrs}$; the same pattern was observed for Cree rMg (Table 4.4). In spite of the reasonably strong association between Cree $\mathrm{sMg}$ and $\mathrm{rMg}$ in those $>50 \mathrm{yrs}$ in both genders (Figure 4.1), and stronger inverse associations between $\mathrm{sMg}$ and carotid variables in this age group, $\mathrm{rMg}$ was not associated with total carotid IMT $(p=0.33)$ nor common carotid IMT ( $p=0.52)$ among the older subgroup. Exclusion of individuals on antihypertensive, cholesterol-lowering, and/or anticlotting drugs among the $\geq 40 \mathrm{yr}$ subgroups did not materially change results for Cree nor Inuit (data not shown). Tests for MetS interactions

Associations between $\mathrm{sMg}$ and fasting glucose, hsCRP $\leq 10 \mathrm{mg} / \mathrm{L}$, total carotid IMT and common carotid IMT were different in those with vs. without the metabolic syndrome. Fasting glucose varied significantly across the $\mathrm{sMg}$ concentration range in those with the MetS $(p=0.05)$, but not among those without the MetS $(p=0.76)$. Among individuals with MetS, adjusted mean fasting glucose was significantly lower in those with $\mathrm{sMg}$ of $0.85-0.90 \mathrm{mmol} / \mathrm{L}$ in comparison to those with a sMg concentration between $0.80-0.85 \mathrm{mmol} / \mathrm{L}$ (pairwise comparison ANCOVA, $p=0.016$ ) (Figure 4.3a). Among those with hsCRP $\leq 10 \mathrm{mg} / \mathrm{L}$, hsCRP was highest in those with MetS and $\mathrm{sMg}<0.75 \mathrm{mmol} / \mathrm{L}$; there was a significant difference in hsCRP between those with $\mathrm{sMg}<0.75 \mathrm{mmol} / \mathrm{L}$ and $0.75-0.80 \mathrm{mmol} / \mathrm{L}$ $(p=0.041)$ (Figure 4.3b). Total carotid IMT in those without MetS was higher in those with $\mathrm{sMg}<0.75 \mathrm{mmol} / \mathrm{L}$ than those with $\mathrm{sMg}$ of $85-90 \mathrm{mmol} / \mathrm{L}(p=0.001)$. Among those with MetS, total carotid IMT declined most steeply from the sMg $<0.75$ to the $0.75-0.80 \mathrm{mmol} / \mathrm{L}$ grouping $(p=0.045)$ (Figure 4.3c). Results for 
common carotid IMT mirrored those of total carotid IMT. rMg was not associated with any endpoint in subgroups with or without MetS in Cree nor Inuit.

\section{Discussion}

Our result of positive associations between sMg and blood lipids in Cree is consistent with previous findings in adult non-indigenous Canadian (Randell et al., 2008), American (Ma et al., 2005) and Japanese (Hashimoto et al., 2010) populations. We observe that the magnitude of associations between $\mathrm{sMg}$ and total cholesterol, and $\mathrm{sMg}$ and LDL, are stronger than the association between sMg and HDL, and review of previous data appears to corroborate this finding. The relations between sMg to TG and HDL are variable across studies. Based on the observation that sMg is more strongly associated with cholesterol-rich LDL and its primary apolipoprotein (ApoB) which deposit at peripheral tissues, we speculate that Mg may influx to serum for use as cofactor for lipoprotein lipase, requisite for receptor-mediated lipoprotein uptake at peripheral tissues, and/or other enzymes. Indeed, $\mathrm{Mg}$ is an essential cofactor for numerous reactions in lipid metabolism, and cholesterol feeding in rabbit models produces elevations in $\mathrm{sMg}$, irrespective of Mg content of the diet (Altura et al., 1990; King et al., 2009). We add to the literature that $\mathrm{rMg}$ is also positively associated with some blood lipid components, but associations are unclear as differences were observed between ethnicities, age groupings and gender. Some ethnic differences in associations between sMg and blood lipids between Caucasians and African Americans and by gender in the ARIC cohort were reported (Ma et al., 1995). Since methodology for measuring $\mathrm{Mg}$ and lipids was the same for all individuals within the ARIC 
sample and for Cree and Inuit in this work, metabolic or glycemic differences among subgroups within each study may explain divergent findings.

Individuals with $\mathrm{hsCRP} \geq 10 \mathrm{mg} / \mathrm{L}$ ( $\mathrm{n}=77$ ) were integrated into the main analysis as Ridker \& Cook (2004) suggest such elevated concentrations have prognostic value for cardiovascular risk. Inclusion of these individuals resulted in a significant inverse association between $\mathrm{sMg}$ and hsCRP $(p=0.038)$, but the association was not present when analysis was limited to individuals with concentrations $<10 \mathrm{mg} / \mathrm{L}(p=0.51)$. Participants with hsCRP $\geq 10 \mathrm{mg} / \mathrm{L}$ had a significantly lower mean $\mathrm{sMg}$ concentration $(0.81 \pm 0.05 \mathrm{mmol} / \mathrm{L})$ than those with hsCRP $<10 \mathrm{mg} / \mathrm{L}(0.84 \pm 0.06 \mathrm{mmol} / \mathrm{L} ; p<0.001)$ and a significantly higher percentage of individuals with hypomagnesaemia $(\mathrm{sMg}<0.70 \mathrm{mmol} / \mathrm{L})(4.9 \% \mathrm{vs}$. $0.6 \%, p=0.029)$. sMg depletion and elevated hsCRP has been previously documented (Rodriguez-Moran \& Guererro-Romero, 2008); underlying mechanisms by which $\mathrm{Mg}$ influences systemic inflammation are not well elucidated. In rodent models, $\mathrm{Mg}$ deficiency leads to the release of neuropeptide substance P and subsequent inflammatory cascade (Weglicki \& Phillips, 1992). However, it cannot be ruled out that individuals with acute infections, undiagnosed cancers, gastrointestinal disease or other conditions associated with inflammation and/or $\mathrm{Mg}$ derangements in the hsCRP $\geq 10 \mathrm{mg} / \mathrm{L}$ subgroup confound the reported association between sMg and hsCRP.

In spite of significant inverse associations between $\mathrm{sMg}$ and carotid intima-media thickness, fasting glucose and hsCRP reported here and in previous works, the usefulness of $\mathrm{sMg}$ as a biomarker of $\mathrm{Mg}$ status remains controversial (Arnaud et al., 2008). sMg may reflect renal handling of whole-body $\mathrm{Mg}$ rather 
than dietary intake, as it appears to be inappropriate for determining whether or not an individual is becoming $\mathrm{Mg}$ deficient due to dietary deprivation (Nielsen et al., 2007). rMg concentrations are also influenced by factors unrelated to dietary Mg intake, notably erythrocyte age, HLA phenotype, and activity of the erythrocyte sodium-Mg exchanger (Basso et al., 2000). Although early work indicated genetic heritability of rMg content may be stronger than extracellular Mg (Lalouel et al., 1985) sMg also has a significant heritable component with emerging polymorphism associations (Shuen et al., 2009).

Irrespective of the utility of $\mathrm{rMg}$ as a $\mathrm{Mg}$ biomarker, we report no associations between $\mathrm{rMg}$ and fasting glucose, insulin, hsCRP, blood pressure, nor carotid intima-media thickness in either ethnic population. The unexpected positive associations between $\mathrm{rMg}$ and adiposity in both populations may be explained the high correlation between $\mathrm{Mg}$ intake and total calories, with $\mathrm{Mg}$ stores possibly reflected in the erythrocyte pool. While we report a stronger association between $\mathrm{sMg}$ and $\mathrm{rMg}$ in older individuals (Figure 4.1), and inverse associations between $\mathrm{sMg}$ and carotid variables were stronger in the older subgroup, the lack of $\mathrm{rMg}$ associations with carotid variables persisted even when younger participants were excluded from rMg analyses.

Therefore, in the absence of prospective data evaluating the risk of cardiovascular events as a function of baseline $\mathrm{rMg}$ concentrations, there is no current evidence to suggest that total $\mathrm{rMg}$ concentrations are associated with a favorable cardiovascular risk profile or add value to the assessment of cardiovascular risk. Although questions remain regarding the utility of $\mathrm{sMg}$ as a marker of dietary $\mathrm{Mg}$, overall $\mathrm{Mg}$ status or physiologically active $\mathrm{Mg}$, elevated 
$\mathrm{sMg}$ is fairly consistently associated with a favourable cardiovascular risk profile in cross-sectional analyses, with the exception of blood lipids, is prospectively associated with reduced left ventricular mass independent of common cardiovascular risk factors (Reffelmann et al., 2010), and has recently been linked to a reduced risk of sudden cardiac death in the ARIC cohort (Peacock et al., 2010).

Limitations to this study include singleton measures of $\mathrm{Mg}$ and most dependent variables, with the exceptions of blood pressure and carotid intimamedia thickness, and assessment of $\mathrm{sMg}$ in only one of the populations (Cree). Measurement of ionized Mg remains of interest (Randell et al., 2008; Corsonello et al., 2007). While older individuals are at elevated risk of cardiovascular events, both population samples were relatively young, with $49 \%$ of the Cree and $51 \%$ of the Inuit sample between the ages of 30-50yrs. Further, the generalizability of this work is limited by the ethnic minorities sampled, with cardiovascular and diabetic risk distinct to each ethnicity, greatly elevated rates of overweight/ obesity in comparison to most other ethnic or general population surveys, and incomplete understanding of $\mathrm{Mg}$ intake changes over the past few decades, during which time both populations underwent nutrient transition to a more Westernized dietary pattern.

In sum, we conclude that there is little current evidence to support measurement of rMg as a cardiovascular risk biomarker. Mechanistic studies are required to elucidate the significance of epidemiological associations between $\mathrm{Mg}$ biomarkers and blood lipids, which have received scant attention. However, we agree with others (Randell et al., 2008); there is no evidence for a causal 
relationship between sMg and an atherogenic lipid profile (Hashimoto et al., 2010; Ma et al., 1995; Altura et al., 1990; King et al., 2009; Peacock et al., 2010). A $41 \%(15-58 \%)$ decreased risk of sudden cardiac death per $0.10 \mathrm{mmol} / \mathrm{L}$ increase in pMg (Chiuve et al., 2011) and a significantly decreased risk of sudden cardiac death in those in the highest vs. lowest quartile of $\mathrm{sMg}$ have been recently reported (Peacock et al., 2010). However, sMg may be only modestly altered by intervention in normomagnesemic individuals. In an experimental $\mathrm{Mg}$ dietary deprivation study of crossover design, the mean $\mathrm{sMg}$ concentration was only $3.5 \%$ different $(0.83 \pm 0.007 \mathrm{mmol} / \mathrm{L}$ vs. $0.86 \pm 0.007 \mathrm{mmol} / \mathrm{L})$ when postmenopausal women consumed a 130mg/day Mg diet for 81 days vs. a $411 \mathrm{mg} /$ day $\mathrm{Mg}$ diet for 81 days (Klevay et al., 2002). Similarly, sMg concentrations increased only modestly $(0.90 \pm 0.08$ to $0.92 \pm 0.07 \mathrm{mmol} / \mathrm{L})$ in obese nondiabetics after six months of $\mathrm{Mg}$ supplementation (365mg/day) (15mmol) (Mooren et al., 2011). If sMg is causally related to reduced cardiovascular risk, future work assessing the extent to which $\mathrm{sMg}$ is modifiable across the normal concentration range, and understanding inter-individual differences in response to intervention, appears important before devising specific recommendations.

\section{Acknowledgments}

The authors wish to thank lab managers Donna Leggee and Suzanne Cote. This scientific communication is a report from the Nituuchischaayihtitaau Aschii: Multi-Community Environment-and-Health Longitudinal Study in Iiyiyiu Aschii supported by the Cree people of northern Québec, the Cree First Nations and the Cree Board of Health and Social Services of James Bay. Funding and support for the Inuit health survey was provided by Canadian Federal Program for 
International Polar Year, Canadian Institutes for Health Research, Health Canada,

Indian and Northern Affairs Canada, and ArcticNet. L.D. is supported by the Nasivvik Center. 


\section{Tables}

Table 4.1. Participant characteristics according to serum and erythrocyte $\mathrm{Mg}$ concentrations $(\mathrm{mmol} / \mathrm{L})$ in nondiabetic Cree and Inuit adults $(\mathrm{n}=1327)^{1}$

\begin{tabular}{|c|c|c|c|c|c|c|}
\hline \multirow{2}{*}{ Variable } & \multicolumn{2}{|l|}{ Cree } & \multicolumn{2}{|l|}{ Cree } & \multicolumn{2}{|l|}{ Inuit } \\
\hline & Serum $\mathrm{Mg}$ & $p^{*}$ & $\begin{array}{l}\text { Erythrocyte } \\
\mathrm{Mg}\end{array}$ & $p$ & $\begin{array}{l}\text { Erythrocyte } \\
\mathrm{Mg}\end{array}$ & $P$ \\
\hline $\mathrm{N}$ & 615 & & 615 & & 712 & \\
\hline \multicolumn{7}{|l|}{ Age (yrs) } \\
\hline$<30$ & $0.82 \pm 0.06$ & & $2.46 \pm 0.30$ & & $2.12 \pm 0.36$ & \\
\hline $30-50$ & $0.84 \pm 0.06$ & & $2.48 \pm 0.33$ & & $2.12 \pm 0.36$ & \\
\hline$>50$ & $0.85 \pm 0.06$ & 0.012 & $2.51 \pm 0.29$ & 0.44 & $2.16 \pm 0.39$ & 0.30 \\
\hline \multicolumn{7}{|l|}{ Sex } \\
\hline Male & $0.85 \pm 0.06$ & & $2.50 \pm 0.28$ & & $2.10 \pm 0.38$ & \\
\hline Female & $0.82 \pm 0.06$ & $<0.001$ & $2.46 \pm 0.34$ & 0.12 & $2.14 \pm 0.36$ & 0.15 \\
\hline \multicolumn{7}{|l|}{ Region } \\
\hline 1 & $0.83 \pm 0.06$ & & $2.43 \pm 0.27$ & & $2.19 \pm 0.31$ & \\
\hline 2 & $0.86 \pm 0.06$ & & $2.41 \pm 0.29$ & & $2.25 \pm 0.36$ & \\
\hline 3 & $0.85 \pm 0.05$ & & $2.38 \pm 0.25$ & & $1.93 \pm 0.35$ & \\
\hline 4 & $0.81 \pm 0.05$ & & $2.51 \pm 0.37$ & & - & \\
\hline 5 & $0.81 \pm 0.05$ & & $2.46 \pm 0.33$ & & - & \\
\hline 6 & $0.86 \pm 0.06$ & & $2.62 \pm 0.36$ & & - & \\
\hline 7 & $0.83 \pm 0.06$ & $<0.001$ & $2.48 \pm 0.25$ & $<0.001$ & - & $<0.001$ \\
\hline \multicolumn{7}{|l|}{ Education } \\
\hline$\leq$ Elementary & $0.85 \pm 0.06$ & & $2.46 \pm 0.29$ & & $2.12 \pm 0.37$ & \\
\hline Secondary & $0.83 \pm 0.06$ & & $2.46 \pm 0.31$ & & $2.15 \pm 0.37$ & \\
\hline$\geq$ University & $0.83 \pm 0.05$ & 0.026 & $2.52 \pm 0.33$ & 0.15 & $2.07 \pm 0.36$ & 0.14 \\
\hline \multicolumn{7}{|l|}{ Exercise } \\
\hline Never & $0.82 \pm 0.06$ & & $2.49 \pm 0.31$ & & $2.18 \pm 0.39$ & \\
\hline$<4$ times $/ w k$ & $0.84 \pm 0.06$ & & $2.48 \pm 0.31$ & & $2.11 \pm 0.36$ & \\
\hline$\geq 4$ times $/ w k$ & $0.84 \pm 0.06$ & 0.038 & $2.46 \pm 0.34$ & 0.55 & $2.12 \pm 0.36$ & 0.14 \\
\hline \multicolumn{7}{|l|}{ Smoking } \\
\hline Current & $0.83 \pm 0.06$ & & $2.49 \pm 0.33$ & & $2.15 \pm 0.36$ & \\
\hline Former & $0.84 \pm 0.06$ & & $2.46 \pm 0.29$ & & $2.11 \pm 0.37$ & \\
\hline Never & $0.83 \pm 0.05$ & 0.33 & $2.47 \pm 0.28$ & 0.54 & $1.97 \pm 0.37$ & 0.003 \\
\hline \multicolumn{7}{|l|}{ Alcohol } \\
\hline Never & $0.83 \pm 0.06$ & & $2.46 \pm 0.30$ & & $2.14 \pm 0.37$ & \\
\hline$<1$ drink/d & $0.84 \pm 0.06$ & & $2.48 \pm 0.33$ & & $2.14 \pm 0.36$ & \\
\hline$\geq 1 \mathrm{drink} / \mathrm{d}$ & $0.84 \pm 0.06$ & 0.18 & $2.60 \pm 0.31$ & 0.06 & $2.11 \pm 0.37$ & 0.60 \\
\hline \multicolumn{7}{|l|}{ BMI $\left(\mathrm{kg} / \mathrm{m}^{2}\right)$} \\
\hline$<25$ & $0.83 \pm 0.06$ & & $2.37 \pm 0.28$ & & $2.06 \pm 0.39$ & \\
\hline $25-29.9$ & $0.83 \pm 0.06$ & & $2.46 \pm 0.32$ & & $2.14 \pm 0.35$ & \\
\hline$\geq 30$ & $0.84 \pm 0.06$ & 0.44 & $2.50 \pm 0.32$ & $<0.001$ & $2.17 \pm 0.36$ & 0.003 \\
\hline \multicolumn{7}{|l|}{ hsCRP } \\
\hline$<3 \mathrm{mg} / \mathrm{L}$ & $0.83 \pm 0.06$ & & $2.45 \pm 0.30$ & & $2.12 \pm 0.37$ & \\
\hline$\geq 3 \mathrm{mg} / \mathrm{L}$ & $0.83 \pm 0.06$ & 1.0 & $2.50 \pm 0.33$ & 0.051 & $2.15 \pm 0.36$ & 0.28 \\
\hline \multicolumn{7}{|l|}{ Mg intake } \\
\hline$<$ EAR & $0.83 \pm 0.05$ & & $2.48 \pm 0.31$ & & $2.12 \pm 0.37$ & \\
\hline EAR-RDA & $0.83 \pm 0.06$ & & $2.50 \pm 0.34$ & & $2.12 \pm 0.37$ & \\
\hline$\geq \mathrm{RDA}$ & $0.83 \pm 0.06$ & 0.88 & $2.45 \pm 0.30$ & 0.45 & $2.14 \pm 0.36$ & 0.86 \\
\hline \multicolumn{7}{|l|}{ Multivitamin } \\
\hline Yes & $0.80 \pm 0.05$ & & $2.41 \pm 0.35$ & & $2.17 \pm 0.33$ & \\
\hline No & $0.84 \pm 0.06$ & $<0.001$ & $2.48 \pm 0.31$ & 0.18 & $2.13 \pm 0.37$ & 0.53 \\
\hline
\end{tabular}


${ }^{1}$ Means were compared using the t-test or one way ANOVA; Levene's test for equality of variances $>0.05$ for all two-way comparisons, so equal variances were assumed in independent $t$ test output 
Table 4.2. Multivariate linear regression results for $\mathrm{Mg}$ biomarkers \& cardiovascular variables $(\mathrm{n}=1327)$

\begin{tabular}{|c|c|c|c|c|c|c|}
\hline $\begin{array}{l}\text { Outcome } \\
\text { variable }\end{array}$ & $\begin{array}{c}\text { Cree } \\
\text { Serum } \\
\mathrm{Mg} \\
\beta \pm \mathrm{SE}\end{array}$ & $p$ & $\begin{array}{c}\text { Cree } \\
\text { Erythrocyte } \\
\mathrm{Mg} \\
\beta \pm \mathrm{SE}\end{array}$ & $p$ & $\begin{array}{c}\text { Inuit } \\
\text { Erythrocyte } \\
\mathrm{Mg} \\
\beta \pm \mathrm{SE}\end{array}$ & $P$ \\
\hline $\mathrm{WC}^{1}$ & $0.11 \pm 0.10$ & 0.35 & $0.06 \pm 0.02$ & 0.001 & $0.07 \pm 0.02$ & $<0.001$ \\
\hline $\mathrm{BMI}^{1}$ & $-0.01 \pm 0.14$ & 0.95 & $0.07 \pm 0.03$ & 0.009 & $0.08 \pm 0.02$ & $<0.001$ \\
\hline Body fat $\%^{1}$ & $0.14 \pm 0.18$ & 0.44 & $0.10 \pm 0.03$ & 0.001 & $0.17 \pm 0.03$ & $<0.001$ \\
\hline Fasting glucose $^{2}$ & $-0.44 \pm 0.13$ & 0.001 & $-0.01 \pm 0.02$ & 0.61 & $0.01 \pm 0.01$ & 0.28 \\
\hline Fasting insulin ${ }^{2}$ & $-0.33 \pm 0.36$ & 0.36 & $0.08 \pm 0.06$ & 0.22 & $0.02 \pm 0.06$ & 0.69 \\
\hline $\begin{array}{l}\text { Total } \\
\text { cholesterol }^{3}\end{array}$ & $0.55 \pm 0.14$ & $<0.001$ & $0.08 \pm 0.02$ & 0.001 & $0.01 \pm 0.02$ & 0.64 \\
\hline $\mathrm{TG}^{3}$ & $0.60 \pm 0.34$ & 0.08 & $0.15 \pm 0.06$ & 0.013 & $0.09 \pm 0.05$ & 0.08 \\
\hline $\mathrm{HDL}^{3}$ & $0.21 \pm 0.16$ & 0.19 & $-0.01 \pm 0.02$ & 0.80 & $-0.06 \pm 0.03$ & 0.07 \\
\hline $\mathrm{LDL}^{3}$ & $0.68 \pm 0.20$ & 0.001 & $0.10 \pm 0.04$ & 0.007 & $0.03 \pm 0.03$ & 0.39 \\
\hline Apo $B^{3}$ & $0.58 \pm 0.18$ & 0.001 & $0.08 \pm 0.03$ & 0.009 & $0.02 \pm 0.06$ & 0.69 \\
\hline $\mathrm{hsCRP}^{4}$ & $-1.61 \pm 0.77$ & 0.038 & $0.17 \pm 0.14$ & 0.20 & $0.07 \pm 0.13$ & 0.60 \\
\hline Systolic BP ${ }^{5}$ & $0.08 \pm 0.08$ & 0.31 & $-0.01 \pm 0.01$ & 0.54 & $-0.01 \pm 0.01$ & 0.52 \\
\hline Diastolic $\mathrm{BP}^{5}$ & $0.05 \pm 0.12$ & 0.68 & $0.02 \pm 0.02$ & 0.32 & $-0.01 \pm 0.02$ & 0.62 \\
\hline $\begin{array}{l}\text { Common } \\
\text { carotid IMT }\end{array}$ & $-0.48 \pm 0.23$ & 0.044 & $-0.03 \pm 0.04$ & 0.52 & $0.01 \pm 0.02$ & 0.97 \\
\hline $\begin{array}{l}\text { Total carotid } \\
\text { IMT }^{6}\end{array}$ & $-0.40 \pm 0.22$ & 0.06 & $-0.04 \pm 0.04$ & 0.33 & $-0.03 \pm 0.02$ & 0.27 \\
\hline
\end{tabular}

\footnotetext{
${ }^{\mathrm{T}}$ Model (default): $\mathrm{Mg}$ (serum or RBC), age, sex, region, education, exercise, smoking, alcohol, multivitamin use

${ }^{2}$ Model (default) + adjustment for waist circumference

${ }^{3}$ Model (default) + adjustment for waist circumference, cholesterol lowering drug use

${ }^{4}$ Model (default) + adjustment for waist circumference, cholesterol lowering drug use, LDL

${ }^{5}$ Model (default) + adjustment for waist circumference, hypertension diagnosis, antihypertensive drug use

${ }^{6}$ Model (default) + adjustment for waist circumference, anticlotting medication use, LDL, and IDF defined components: high TG, low HDL, high BP, high FG (includes adjustment for cholesterollowering and antihypertensive drug use)
} 
Table 4.3. Linear regression coefficients for $\mathrm{Mg}$ x sex interaction terms*

\begin{tabular}{|c|c|c|c|c|c|c|}
\hline $\begin{array}{l}\text { Outcome } \\
\text { variable }\end{array}$ & $\begin{array}{c}\text { Cree } \\
\text { Serum Mg } \\
\beta \pm \mathrm{SE}\end{array}$ & $p$ & $\begin{array}{c}\text { Cree } \\
\text { RBC Mg } \\
\mathrm{B} \pm \mathrm{SE}\end{array}$ & $p$ & $\begin{array}{c}\text { Inuit } \\
\text { RBC Mg } \\
\mathrm{B} \pm \mathrm{SE}\end{array}$ & $p$ \\
\hline $\mathrm{WC}^{1}$ & $-0.24 \pm 0.20$ & 0.22 & $-0.01 \pm 0.04$ & 0.87 & $-0.01 \pm 0.03$ & 0.79 \\
\hline $\mathrm{BMI}^{1}$ & $-0.45 \pm 0.27$ & 0.09 & $0.02 \pm 0.05$ & 0.74 & $-0.02 \pm 0.04$ & 0.63 \\
\hline Body fat $\%^{1}$ & $-0.70 \pm 0.74$ & 0.037 & $-0.37 \pm 0.02$ & $<0.001$ & $-0.08 \pm 0.07$ & 0.22 \\
\hline Fasting glucose ${ }^{2}$ & $0.27 \pm 0.24$ & 0.26 & $-0.01 \pm 0.05$ & 0.78 & $0.01 \pm 0.02$ & 0.51 \\
\hline Fasting insulin ${ }^{2}$ & $-0.74 \pm 0.67$ & 0.27 & $-0.11 \pm 0.13$ & 0.42 & $-0.04 \pm 0.12$ & 0.75 \\
\hline $\begin{array}{l}\text { Total } \\
\text { cholesterol }^{3}\end{array}$ & $0.02 \pm 0.26$ & 0.94 & $-0.06 \pm 0.05$ & 0.26 & $-0.04 \pm 0.04$ & 0.29 \\
\hline $\mathrm{TG}^{3}$ & $-0.37 \pm 0.64$ & 0.56 & $-0.23 \pm 0.12$ & 0.07 & $0.07 \pm 0.09$ & 0.43 \\
\hline $\mathrm{HDL}^{3}$ & $0.38 \pm 0.30$ & 0.21 & $0.01 \pm 0.06$ & 0.81 & $0.13 \pm 0.06$ & 0.020 \\
\hline $\mathrm{LDL}^{3}$ & $-0.03 \pm 0.38$ & 0.94 & $-0.01 \pm 0.07$ & 0.95 & $-0.01 \pm 0.6$ & 0.95 \\
\hline Apo $B^{3}$ & $0.42 \pm 0.34$ & 0.21 & $-0.02 \pm 0.07$ & 0.76 & $-0.01 \pm 0.03$ & 0.71 \\
\hline $\begin{array}{l}\text { hsCRP }^{4} \\
\text { hsCRP }<\end{array}$ & $-0.56 \pm 1.4$ & 0.67 & $0.03 \pm 0.28$ & 0.92 & $-0.06 \pm 0.25$ & 0.80 \\
\hline $10 \mathrm{mg} / \mathrm{L}^{4}$ & $-0.20 \pm 1.3$ & 0.88 & $0.12 \pm 0.25$ & 0.64 & $-0.36 \pm 0.21$ & 0.09 \\
\hline Systolic BP ${ }^{5}$ & $0.03 \pm 0.15$ & 0.85 & $-0.02 \pm 0.03$ & 0.55 & $-0.01 \pm 0.03$ & 0.61 \\
\hline Diastolic $\mathrm{BP}^{5}$ & $0.21 \pm 0.23$ & 0.35 & $-0.05 \pm 0.04$ & 0.27 & $-0.01 \pm 0.03$ & 0.70 \\
\hline $\begin{array}{l}\text { Common } \\
\text { carotid IMT }\end{array}$ & $-0.06 \pm 0.22$ & 0.78 & $-0.18 \pm 0.17$ & 0.28 & $0.03 \pm 0.05$ & 0.50 \\
\hline $\begin{array}{l}\text { Total carotid } \\
\text { IMT }^{6}\end{array}$ & $0.04 \pm 0.20$ & 0.84 & $-0.18 \pm 0.15$ & 0.24 & $0.04 \pm 0.05$ & 0.46 \\
\hline
\end{tabular}

* serum or RBC Mg (continuous) $\mathrm{x}$ sex (binary coded 0 is male, 1 is female)

${ }^{1}$ Model (default): $\mathrm{Mg}$ (serum or RBC), age, sex, region, education, exercise, smoking, alcohol, multivitamin use

${ }^{2}$ Model (default) + adjustment for waist circumference

${ }^{3}$ Model (default) + adjustment for waist circumference, cholesterol lowering drug use

${ }^{4}$ Model (default) + adjustment for waist circumference, cholesterol lowering drug use, LDL

${ }^{5}$ Model (default) + adjustment for waist circumference, hypertension diagnosis, antihypertensive drug use

${ }^{6}$ Model (default) + adjustment for waist circumference, anticlotting medication use, LDL, and IDF defined components: high TG, low HDL, high BP, high FG (includes adjustment for cholesterollowering and antihypertensive drug use) 
Table 4.4. Linear regression coefficients for $\mathrm{Mg} \mathrm{x}$ age interaction terms*

\begin{tabular}{|c|c|c|c|c|c|c|}
\hline $\begin{array}{l}\text { Outcome } \\
\text { variable }\end{array}$ & $\begin{array}{c}\text { Cree } \\
\text { Serum Mg } \\
\mathrm{B} \pm \mathrm{SE}\end{array}$ & $p$ & $\begin{array}{c}\text { Cree } \\
\text { RBC Mg } \\
\beta \pm \mathrm{SE}\end{array}$ & $p$ & $\begin{array}{c}\text { Inuit } \\
\mathrm{RBC} \mathrm{Mg} \\
\mathrm{B} \pm \mathrm{SE}\end{array}$ & $P$ \\
\hline $\mathrm{WC}^{1}$ & $-0.08 \pm 0.02$ & 0.002 & $-0.02 \pm 0.01$ & 0.002 & $-0.01 \pm 0.01$ & 0.17 \\
\hline $\mathrm{BMI}^{1}$ & $-0.07 \pm 0.03$ & 0.036 & $-0.03 \pm 0.01$ & 0.021 & $-0.01 \pm 0.01$ & 0.36 \\
\hline Body fat $\%^{1}$ & $-0.08 \pm 0.04$ & 0.06 & $-0.03 \pm 0.01$ & 0.034 & $-0.01 \pm 0.02$ & 0.66 \\
\hline Fasting glucose ${ }^{2}$ & $0.02 \pm 0.03$ & 0.61 & $0.01 \pm 0.01$ & 0.62 & $0.01 \pm 0.01$ & 0.07 \\
\hline Fasting insulin ${ }^{2}$ & $0.02 \pm 0.08$ & 0.78 & $0.01 \pm 0.03$ & 0.76 & $-0.01 \pm 0.03$ & 0.69 \\
\hline $\begin{array}{l}\text { Total } \\
\text { cholesterol }^{3}\end{array}$ & $0.07 \pm 0.03$ & 0.024 & $0.02 \pm 0.01$ & 0.026 & $0.03 \pm 0.01$ & 0.018 \\
\hline $\mathrm{TG}^{3}$ & $0.02 \pm 0.08$ & 0.85 & $0.01 \pm 0.03$ & 0.74 & $0.10 \pm 0.06$ & 0.08 \\
\hline $\mathrm{HDL}^{3}$ & $0.02 \pm 0.04$ & 0.52 & $0.01 \pm 0.01$ & 0.40 & $0.01 \pm 0.02$ & 0.78 \\
\hline $\mathrm{LDL}^{3}$ & $0.11 \pm 0.05$ & 0.023 & $0.03 \pm 0.02$ & 0.040 & $0.06 \pm 0.04$ & 0.13 \\
\hline Apo $B^{3}$ & $0.06 \pm 0.04$ & 0.17 & $0.02 \pm 0.01$ & 0.19 & $0.03 \pm 0.04$ & 0.51 \\
\hline $\mathrm{hsCRP}^{4}$ & $0.06 \pm 0.18$ & 0.73 & $-0.01 \pm 0.06$ & 0.83 & $0.02 \pm 0.07$ & 0.77 \\
\hline hsCRP $<$ & & & & & & \\
\hline $10 \mathrm{mg} / \mathrm{L}^{4}$ & $-0.48 \pm 0.16$ & 0.77 & $-0.02 \pm 0.05$ & 0.65 & $-0.03 \pm 0.01$ & 0.64 \\
\hline Systolic BP ${ }^{5}$ & $0.01 \pm 0.02$ & 0.44 & $0.01 \pm 0.01$ & 0.78 & $0.01 \pm 0.01$ & 0.20 \\
\hline Diastolic $\mathrm{BP}^{5}$ & $0.03 \pm 0.03$ & 0.30 & $0.01 \pm 0.01$ & 0.53 & $0.02 \pm 0.01$ & 0.09 \\
\hline $\begin{array}{l}\text { Common } \\
\text { carotid IMT } \\
\text { Total carotid }\end{array}$ & $0.09 \pm 0.08$ & $<0.001$ & $0.09 \pm 0.03$ & $<0.001$ & $0.01 \pm 0.02$ & 0.80 \\
\hline $\mathrm{IMT}^{6}$ & $0.06 \pm 0.02$ & 0.022 & $0.05 \pm 0.02$ & 0.052 & $0.01 \pm 0.02$ & 0.93 \\
\hline
\end{tabular}

"serum or RBC Mg (continuous) $\mathrm{x}$ age (binary coded $\leq 40 \mathrm{yrs}$ is $0,>40 \mathrm{yrs}$ is 1 )

${ }^{1}$ Model (default): Mg (serum or RBC), age, sex, region, education, exercise, smoking, alcohol, multivitamin use

${ }^{2}$ Model (default) + adjustment for waist circumference

${ }^{3}$ Model (default) + adjustment for waist circumference, cholesterol lowering drug use

${ }^{4}$ Model (default) + adjustment for waist circumference, cholesterol lowering drug use, LDL

${ }^{5}$ Model (default) + adjustment for waist circumference, hypertension diagnosis, antihypertensive drug use

${ }^{6}$ Model (default) + adjustment for waist circumference, anticlotting medication use, LDL, and IDF defined components: high TG, low HDL, high BP, high FG (includes adjustment for cholesterollowering and antihypertensive drug use 


\section{Figures}

Figure 4.1. Partial correlation coefficients ${ }^{1}$ between serum $(\mathrm{sMg})$ and erythrocyte $(\mathrm{rMg})$ magnesium according to age and sex among nondiabetic adults $(\mathrm{n}=615)$

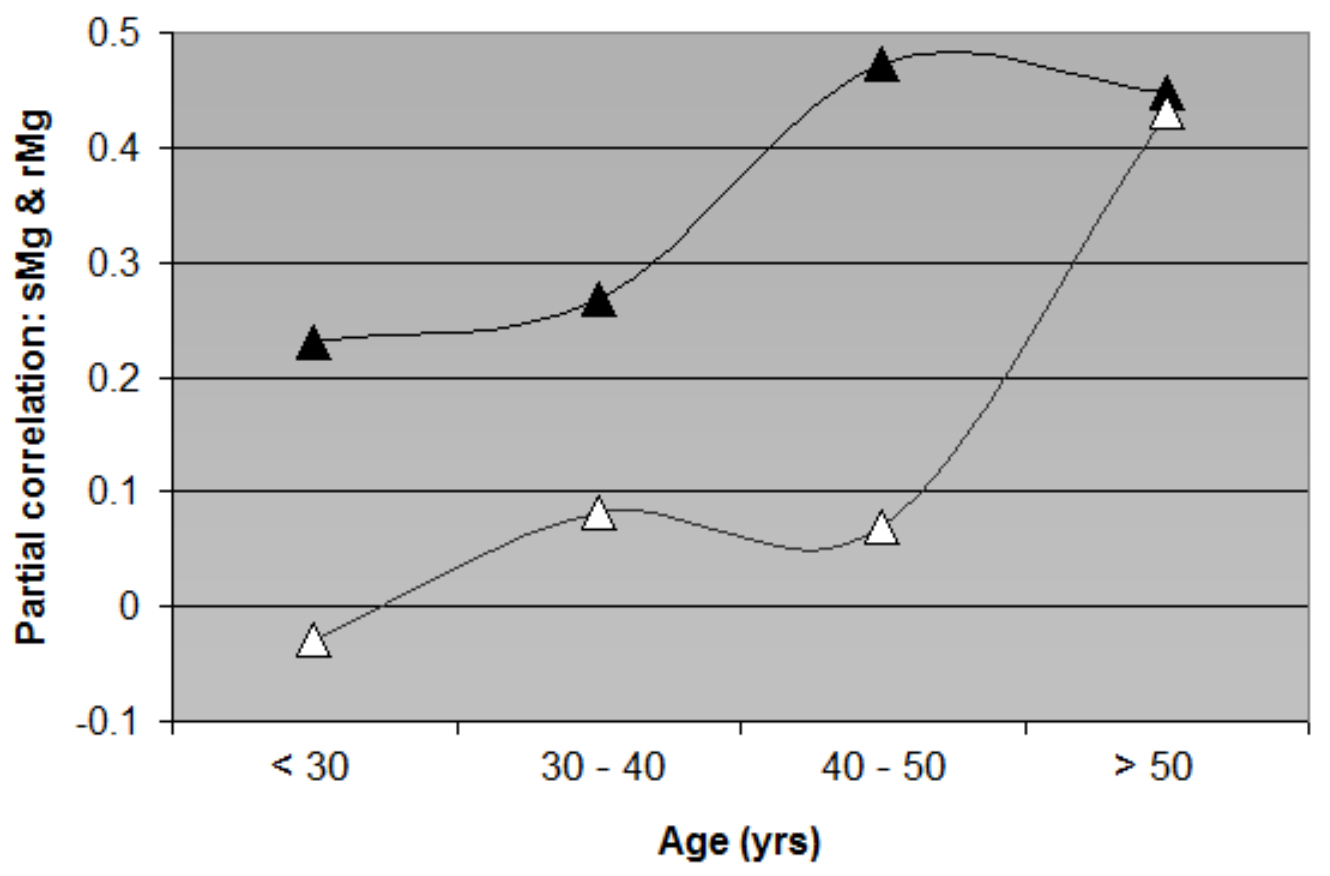

$\leftarrow$ Females $\triangle$ Males

${ }^{1}$ adjusted for age, region, waist circumference, BMI, education, exercise, smoking, alcohol, and multivitamin use

$p$ for coefficients in Cree females < 30yrs: 0.011; 30-40yrs: 0.012; 40-50yrs: 0.006; >50yrs: 0.013 $p$ for coefficients in Cree males <30yrs: 0.81; 30-40yrs: 0.63; 40-50yrs: 0.65; >50yrs: 0.011 
Figure 4.2. Total erythrocyte magnesium (rMg) and body mass index (BMI) in Inuit \& Cree adults $(\mathrm{n}=1327)$

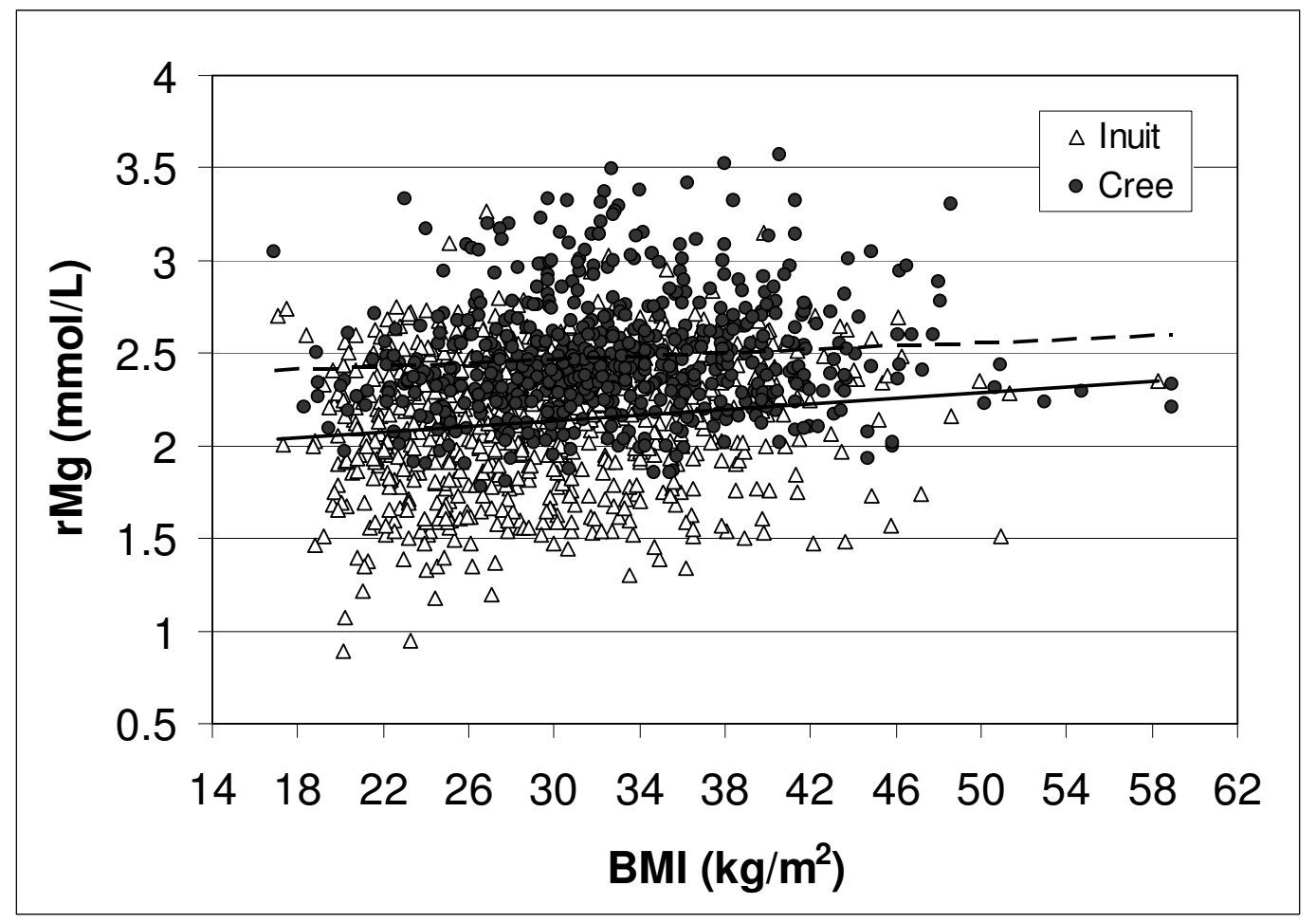

For Inuit (solid line): $\mathrm{rMg}=1.8993+0.0078(\mathrm{BMI}) ; p<0.001$; for Cree (dashed line): $\mathrm{rMg}=$ $2.3247+0.0046(\mathrm{BMI}) ; p=0.020$. 
Figure 4.3a. Adjusted* mean (a.) fasting glucose ${ }^{1}$ according to $\mathrm{sMg}$ concentrations $(\mathrm{mmol} / \mathrm{L})$ in participants with and without the metabolic syndrome (MetS)

a.)

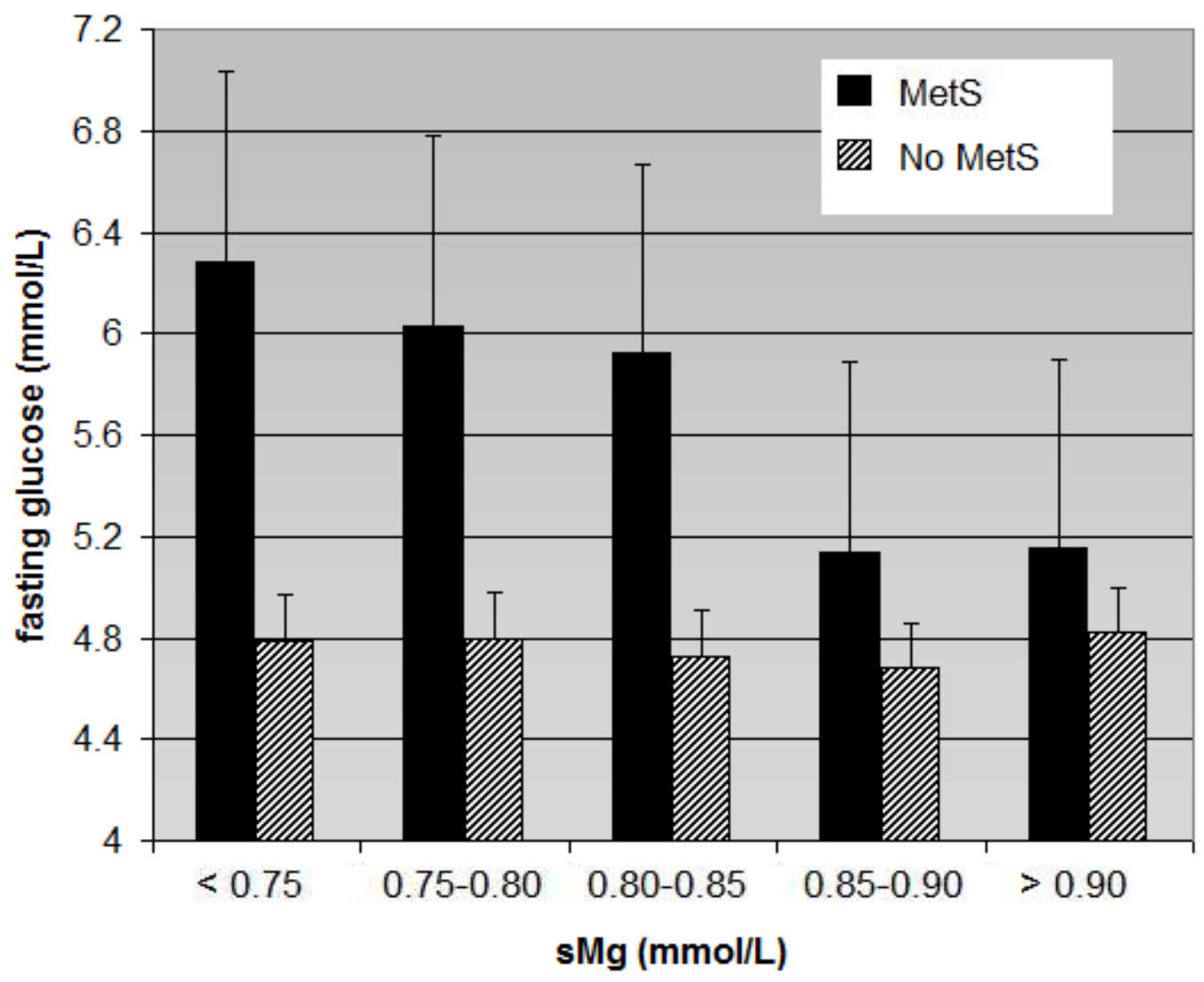

*Fasting glucose model: age, sex, region, education, exercise, smoking, alcohol, multivitamin use, waist circumference adjusted

${ }^{1}$ Fasting glucose varied significantly across the $\mathrm{sMg}$ concentration range in those with the MetS $(p=0.05)$, but not among those without the MetS $(p=0.76)$. Among individuals with MetS, adjusted mean fasting glucose was significantly lower in those with $\mathrm{sMg}$ of $0.85-0.90 \mathrm{mmol} / \mathrm{L}$ in comparison to those with a $\mathrm{sMg}$ concentration between $0.80-0.85 \mathrm{mmol} / \mathrm{L}$ (pairwise comparison ANCOVA, $p=0.016$ ). 
Figure 4.3b. Adjusted* mean (b.) hsCRP ${ }^{1}$ according to sMg concentrations $(\mathrm{mmol} / \mathrm{L})$ in participants with and without the metabolic syndrome (MetS)

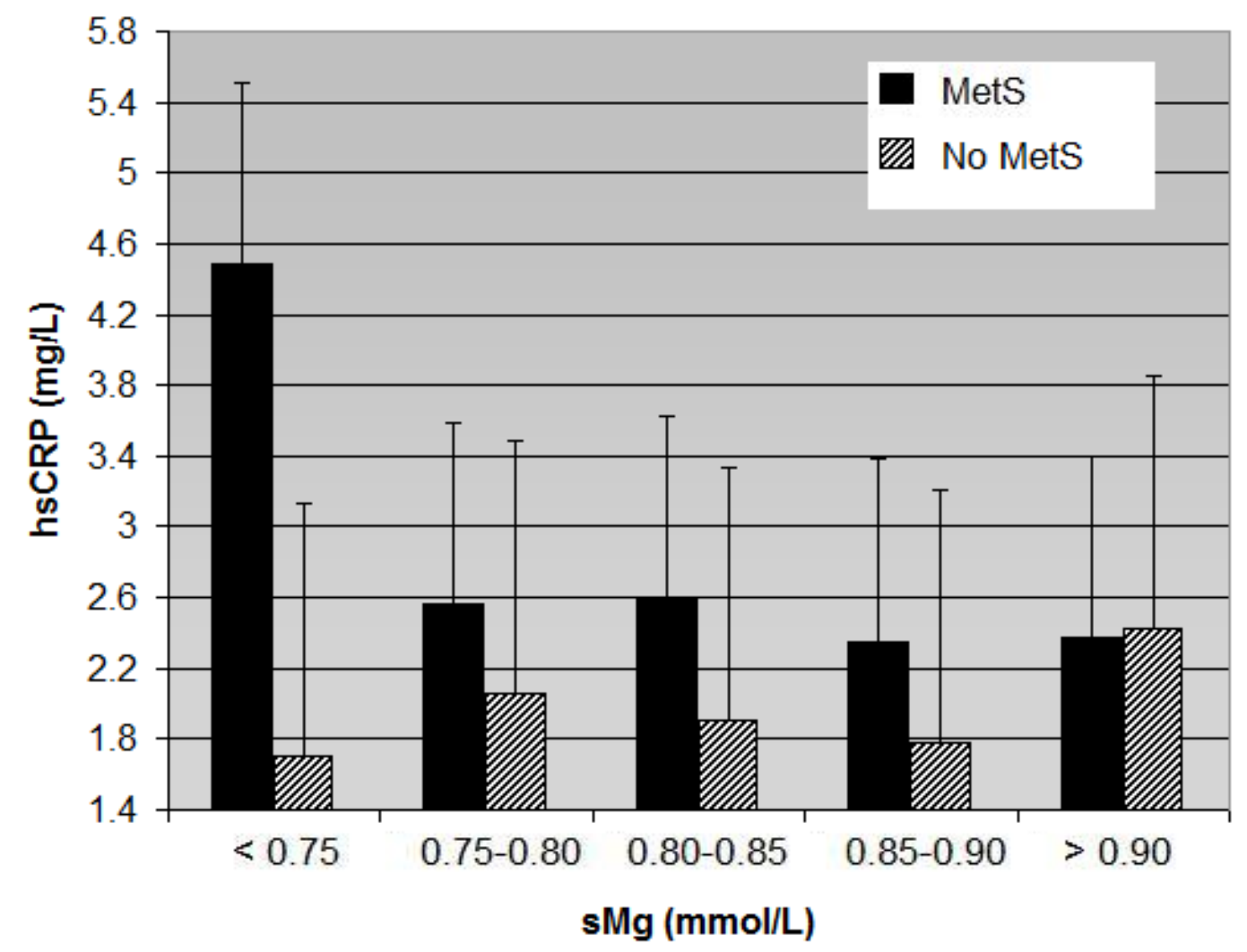

*hsCRP model: age, sex, region, education, exercise, smoking, alcohol, multivitamin use, waist circumference, cholesterol lowering drug use, LDL adjusted. Subgroup hsCRP $<10 \mathrm{mg} / \mathrm{L}$ is depicted.

${ }^{1}$ Among individuals with MetS, there was a significant difference in hsCRP between those with $\mathrm{sMg}<0.75 \mathrm{mmol} / \mathrm{L}$ and $0.75-0.80 \mathrm{mmol} / \mathrm{L}$ (pairwise comparison ANCOVA, $p=0.041$ ). 
Figure 4.3c. Adjusted* mean (c.) total carotid $\mathrm{IMT}^{1}$ according to $\mathrm{sMg}$ concentrations $(\mathrm{mmol} / \mathrm{L})$ in participants with and without the metabolic syndrome (MetS)

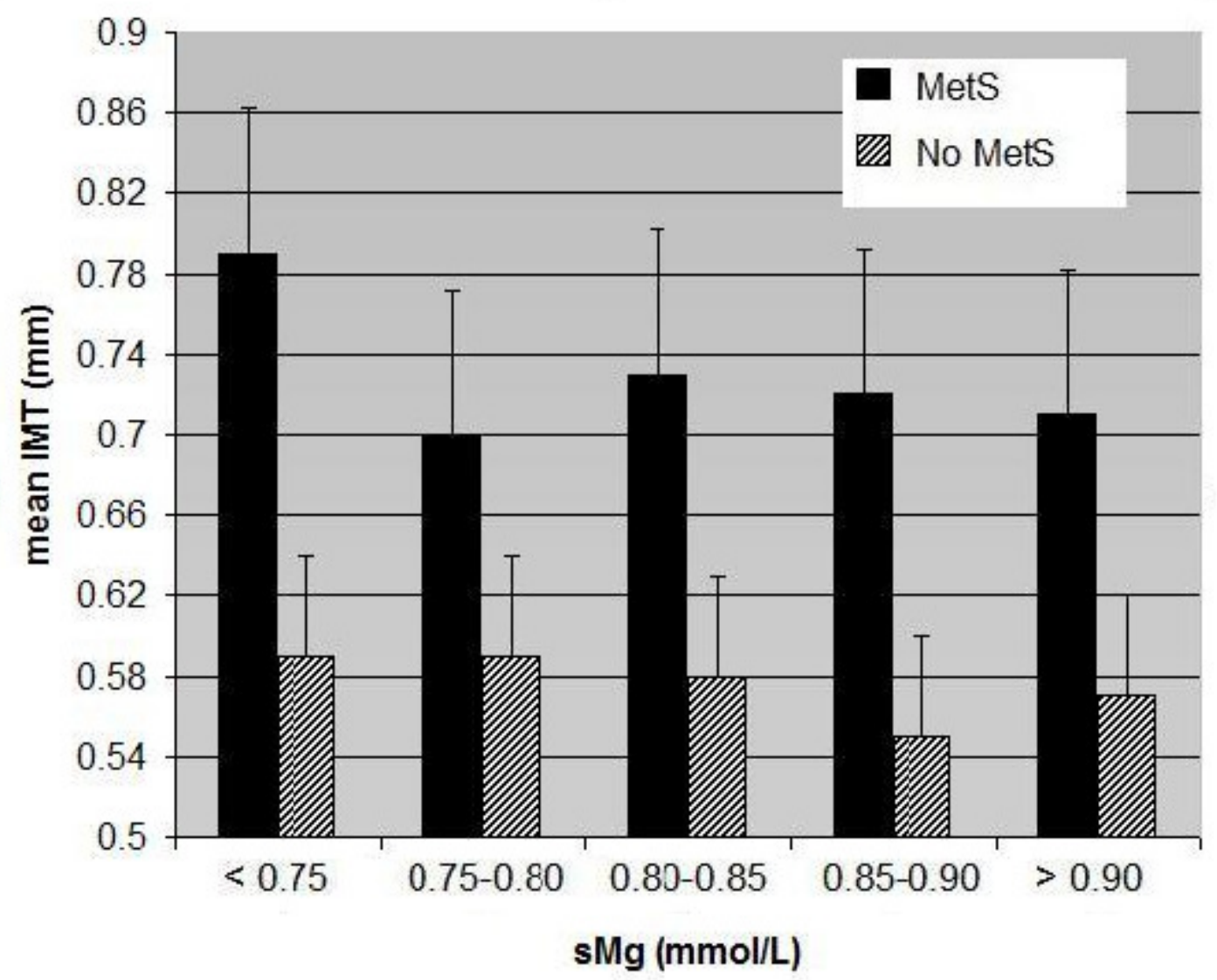

*Total carotid IMT model: age, sex, region, education, exercise, smoking, alcohol, multivitamin use, waist circumference adjusted

${ }^{1}$ Total carotid IMT in those without MetS was higher in those with $\mathrm{sMg}<0.75 \mathrm{mmol} / \mathrm{L}$ than those with $\mathrm{sMg}$ of $85-90 \mathrm{mmol} / \mathrm{L}$ (pairwise comparison ANCOVA, $p=0.001$ ). Among those with MetS, total carotid IMT declined most steeply from the $\mathrm{sMg}<0.75$ to the $0.75-0.80 \mathrm{mmol} / \mathrm{L}$ grouping (pairwise comparison ANCOVA, $p=0.045$ ). 
Figure 4.4. Unadjusted rMg means (ANOVA) by sMg concentration groupings among nondiabetic adults $(n=615)$

a.) all adults

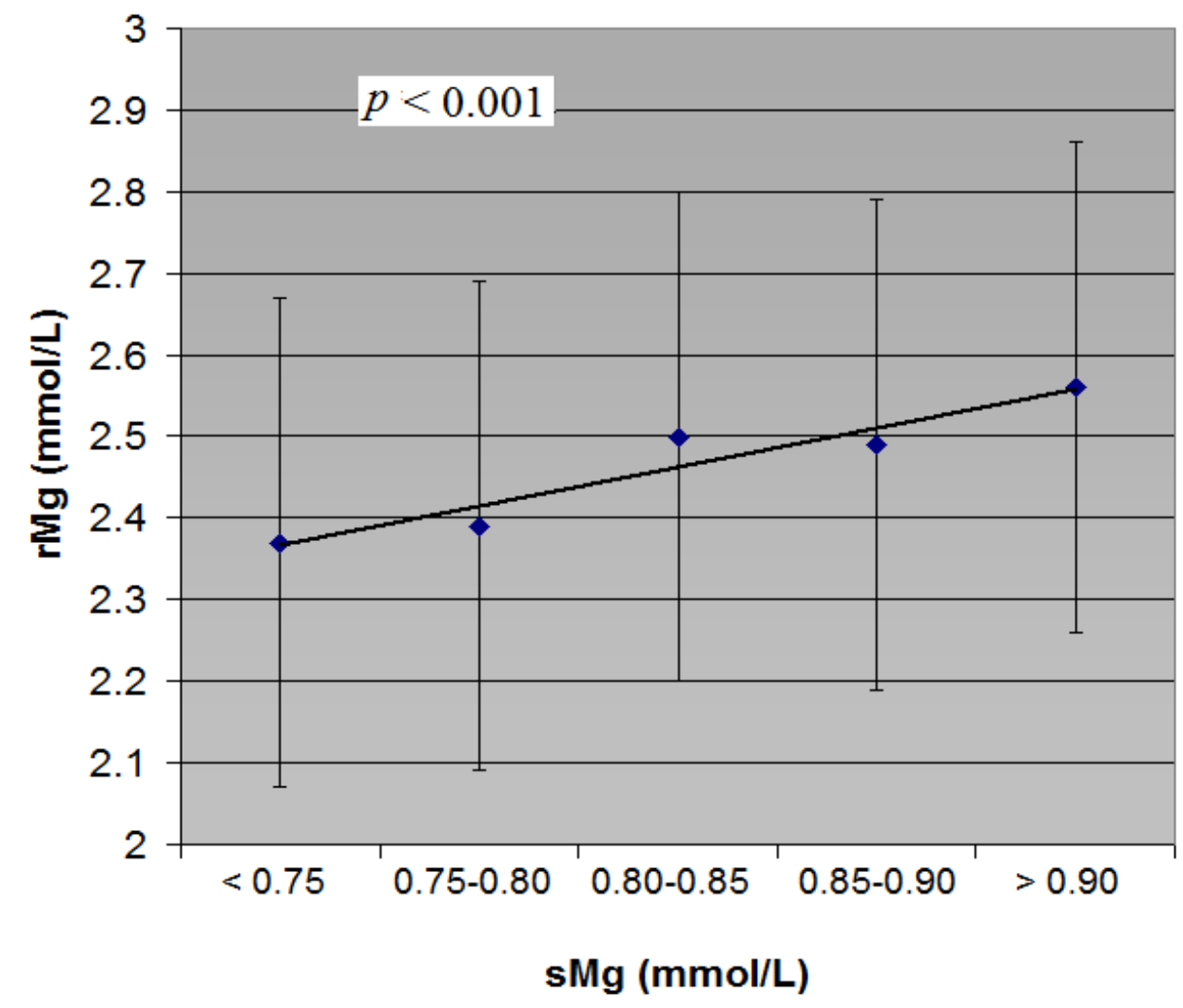


b.) men only ( $\mathrm{n}=271)$

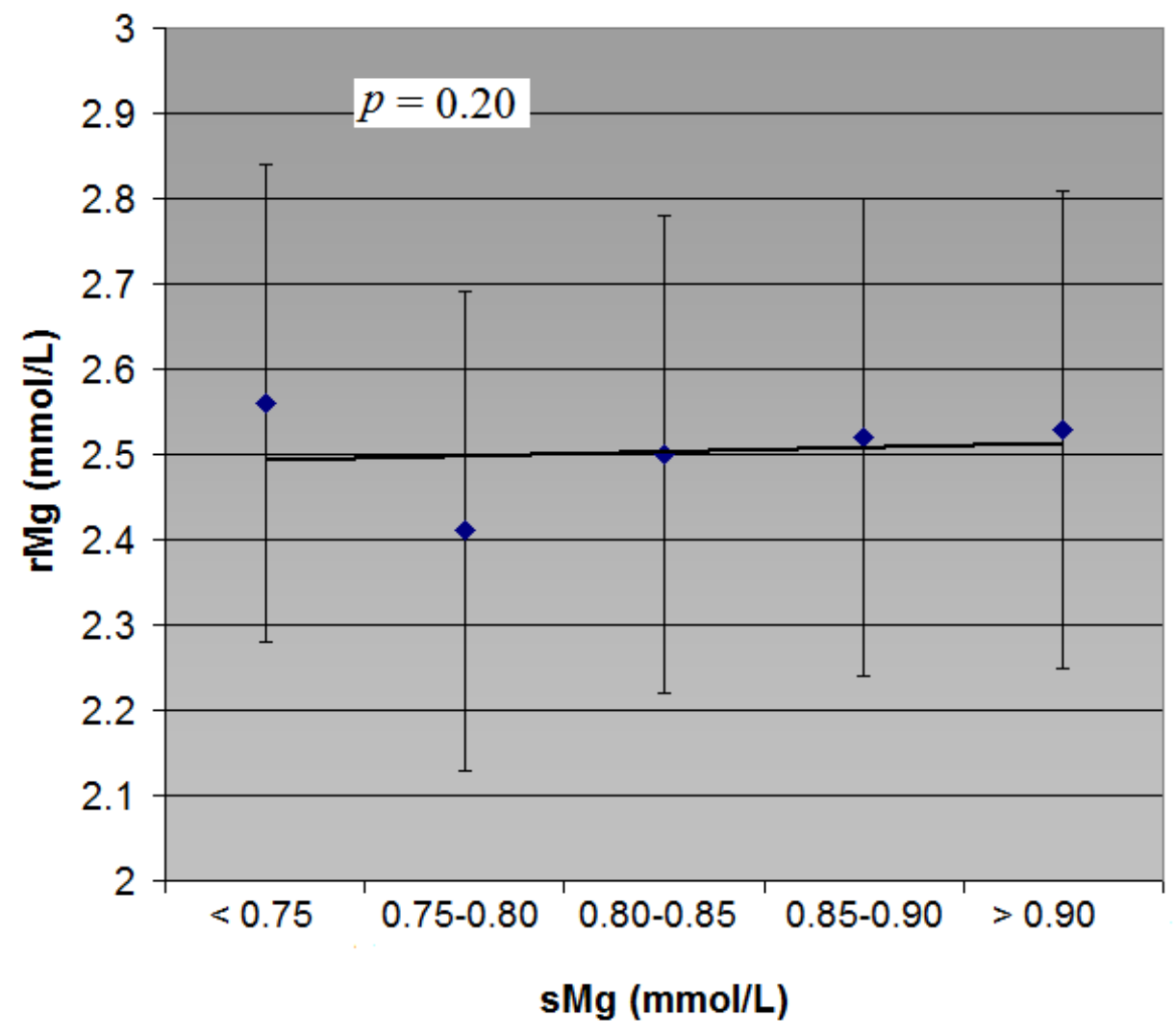


c.) women only $(n=344)$

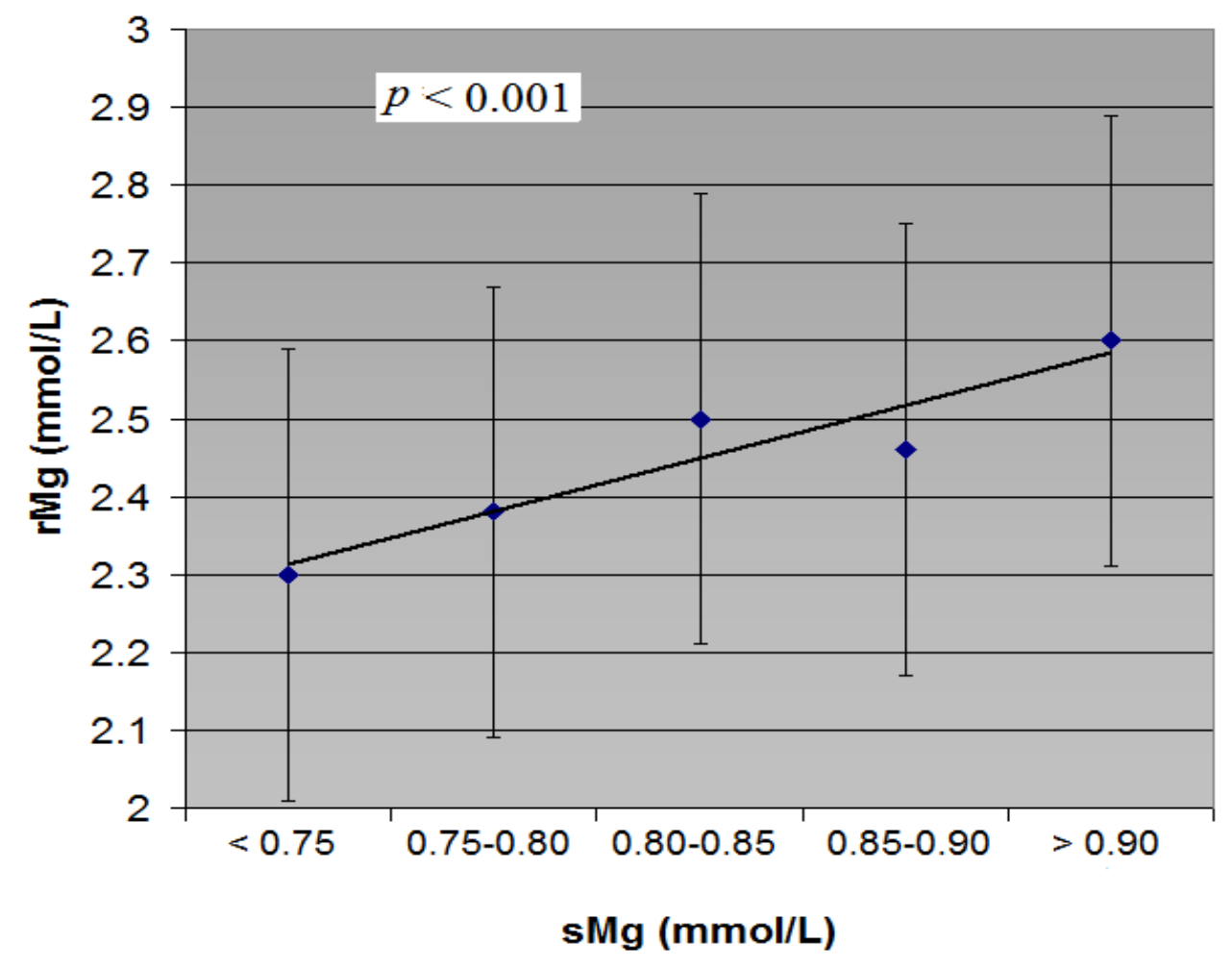




\section{Supplement}

\section{Variable coding}

Covariates included in the multivariate linear models for dependent variables related to adiposity (WC, BMI, body fat \%) included age (continuous), gender (binary), region (dummy coded, with region 1 as reference), smoking (dummy coded as current, former, never was reference), education (dummy coded as some or completed secondary or equivalent, some or completed college/university, elementary or less was reference), physical activity (dummy coded as moderate or vigorous physical activity for 20 min 1-3 times week, $\geq 4$ times week, never was reference), alcohol consumption (dummy coded as 1-6 drinks/ week, one or more drink per day, less than 1 drink/week was reference), multivitamin use (binary coded). This set of covariates was considered the 'default' model.

For glycemic dependent variables (fasting glucose and fasting insulin), waist circumference (continuous) was added to the default model. For blood lipid/lipoprotein dependent variables (total cholesterol, TG, HDL, LDL, Apo B), waist circumference and cholesterol lowering drug use (binary coded) was added to the default model. For dependent variable hsCRP, waist circumference, cholesterol lowering drug use, and LDL (continuous) was added to the default model. For dependent variables systolic and diastolic blood pressure, the variables waist circumference, hypertension diagnosis (binary), antihypertensive drug use (binary) were added to the default model. For carotid IMT thickness dependent variables (total carotid IMT, common carotid IMT), adjustment for waist circumference, anticlotting medication use (binary coded), LDL and MetS 
components high triglycerides (binary), low HDL (binary) high blood pressure (binary) and impaired fasting glucose (binary) were added to the default model. Anthropometric, lifestyle variable assessment for Cree \& Inuit

Height, as measured by a stadiometer, and weight, as measured on a beam scale, were used to calculate body mass index $(\mathrm{BMI})\left(\mathrm{kg} / \mathrm{m}^{2}\right)$. Body fat \% was obtained from bioelectrical impedence analysis (Tanita TBF-300, GHT Canada, Laval QC). Physical activity was assessed by a culturally adapted, short version of the International Physical Activity Questionnaire. Educational attainment was determined by participants indicating the highest level of education participants attended across three categories ('no formal or elementary,' 'some or completed high school,' 'some or completed college or university'). For smoking, frequency was recorded ('current,' 'ex-smoker' or 'never'). Multivitamin use and alcohol consumption were also self-reported; for alcohol consumption, participants indicated the frequency of drinks consumed by alcohol type (beer, liquor, wine, mixed drink) in a given week.

\section{Clinical variable assessment for Cree \& Inuit}

For Cree communities sampled in 2005, plasma glucose was measured by spectrophotometric assay (Vitros 950, Ortho-Clinical Diagnostics) and fasting insulin concentrations were measured with a commercial double-antibody radioimmunoassay (human-insulin-specific radioimmunoassay method, LINCO Research, St Louis, United States). For Cree communities sampled in 2006-2009 and Inuit communities, glucose was measured by a hexokinase II enzymatic assay and insulin by a chemiluminescent assay (Roche Modular system). Reference values for fasting glucose and insulin used were $3.6-5.8 \mathrm{mmol} / \mathrm{L}$ and 0 - 150 
$\mathrm{pmol} / \mathrm{L}$, respectively. Interassay coefficients of variation $(\mathrm{CV}) 1.4 \%$ for glucose at control values of 4.74 and $15.66 \mathrm{mmol} / \mathrm{L}$ and $2.9 \%$ and $2.3 \%$ for insulin at control values of 345 and $630 \mathrm{pmol} / \mathrm{L}$ for Inuit and Cree.

Cholesterol, triglyceride and HDL determination was performed using by enzymatic colorimetric methods on the Vitros 950 Chemistry Station (OrthoClinical Diagnostics, Raritan, NJ) using the manufacturer's reagents and calibrators. Multilayer film dry-slide chemistry was used to measure $11 \mathrm{uL}$ of cholesterol (CV 2.6\%, reference $<6.0 \mathrm{mmol} / \mathrm{L})$ and triglyceride (CV 1.4\%, reference $<1.7 \mathrm{mmol} / \mathrm{L}$ ) lipids. Intra-run $\mathrm{CV}$ for $\mathrm{HDL}$ was $2.20 \%$ and inter-run $\mathrm{CV}$ was $1.90 \%$. Calibration levels were determined using the VITROS Chemistry Prototype Calibrator Kit 2 (Ortho-Clinical Diagnostics) and verified using VITROS Performance Verifier fluids. LDL cholesterol was calculated based on the total cholesterol and HDL cholesterol measurements. ApoB concentrations were measured by nephelometry according to standardized clinical procedures using a BN Prospect station (Dade Berhing) with an inter-run CV of $4.03 \%$.

In Cree, plasma CRP levels were measured using the Behring LatexEnhanced (highly sensitive) CRP assay on the Behring Nephelometer BN-100 (Behring Diagnostic, Westwood, MA) and the calibrators (N Rheumatology Standards SL) provided by the manufacturer. The sensitivity of the assay ranged from 0.175 to $11 \mathrm{mg} / \mathrm{L}$. The mean interassay CVs for plasma CRP levels were < $1 \%$ at both low and high plasma CRP concentrations. In Inuit, CRP was measured by a highly sensitive Near Infrared Particle Immunoassay rate methodology with SYNCHRON Systems (Beckman Coulter, Mississauga, Canada) with interassay CV of less than $10 \%$. 
Systolic and diastolic blood pressure was taken according the WHO clinical guidelines for management of hypertension, using mercury sphygmomanometers, 15-inch stethoscopes, and cuffs sized to the subjects' arms. Prior to having their blood pressure taken, subjects must have rested for 5 minutes and not eaten or smoked for at least 30 minutes. Each subject had three blood pressure readings. The mean BP was calculated as the average of six measurements in a resting state.

Carotid artery measurements of intimal-to-medial arterial wall thickness of the carotid arteries was performed using a high-resolution B-mode ultrasound portable device (Model LogiqBook, GE Medical System, Milwaukee, WI) with and linear 4-10 MHz probe (Model 10LB-Rs, GE Medical System, Milwaukee, WI) by two well experienced sonographers. Prior to longitudinal scan, a transverse scan was performed to check for any hemodynamically relevant stenosis or the presence of significant plaque. Plaque was defined by either a focal structure that encroaches into the arterial lumen of at least $0.5 \mathrm{~mm}$, or $50 \%$ of the surrounding IMT value; or a thickness $>1.5 \mathrm{~mm}$ as measured from the mediaadventitia interface to the intima-lumen interface defined by a focal echogenic structure protruding into the lumen vessel.

Segments free of plaque in both common (left/right) carotids at the near and the far walls (common carotid: $1 \mathrm{~cm}$ below the bulb; bulb: $1 \mathrm{~cm}$ below the flow divider; internal: $1 \mathrm{~cm}$ above the flow divider) were digitally recorded and used to evaluate IMT. For the variable 'common carotid IMT,' segments of $1 \mathrm{~cm}$ of the near and far walls $(1 \mathrm{~cm}$ below the flow divider) of both common carotid arteries were used. For the variable 'total carotid IMT,' the mean intima-media 
thickness as measured at 12 segments of the common carotid artery, bulb and internal parts of the carotid tree was evaluated. Offline measurements were performed by a single reader blinded to the clinical data. Three non-consecutive frames were analyzed using a dedicated semi-automatic edge-detection software (Carotid Analyzer for Research v.5.5.6, Medical Imaging Application, Coraville, IA) providing the average of $1-\mathrm{cm}$ in length segmental means. The analyzer had the option in case of visual discrepancies to edit lines using fine-tuning detection algorithms measuring IMT every $10 \mu \mathrm{m}$ of length (100-150 successive points) along traced segments. The correlation coefficient of the ultrasound measurement assessed by two different readers for reproducibility was $0.78(\mathrm{p}<0.002)$. 


\section{References}

1. Altura B.T.; Brust, M.; Bloom, S.; Barbour, R.J.; Stempak, J.G.; Altura,

B.M., Magnesium dietary intake modulates blood lipid levels and atherogenesis. Proceedings of the National Academy of Science 1990, 87, 1840-1844.

2. Arnaud, M.J., Update on the assessment of magnesium status. British Journal of Nutrition 2008, 99, S24-S36.

3. Basso, L.E.; Ubbink, J.B.; Delport, R., Erythrocyte magnesium concentration as an index of magnesium status: a perspective from a magnesium supplementation study. Clinica Chemica Acta 2000, 291, 1-8.

4. Chateau-Degat, M.L.; Dewailly, E.; Poirier, P.; Gingras, S.; Egeland, G.M., Comparison of diagnostic criteria of the metabolic syndrome in 3 ethnic groups of Canada. Metabolism 2000, 57, 1526-1532.

5. Chiuve, S.E.; Korngold, E.C.; Januzzi J.L.; Gantzer, M.L.; Albert, C.M., Plasma and dietary magnesium and risk of sudden cardiac death in women. American Journal of Clinical Nutrition 2011, 93, 253-260.

6. Corsonello, A.; Perticone, F.; Ientile, R.; Barbagallo, M.; Corica, F., Serum magnesium and lipids: More clarity is needed. Atherosclerosis 2007, 192, 233-234.

7. Deuster, P.A.; Trostmann, U.H.; Bernier, L.L.; Dolev, E., Indirect vs direct measurement of magnesium and zinc in erythrocytes. Clinical Chemistry 1987, 33, 529-532.

8. Egeland, G.M.; Johnson-Down, L.; Cao, Z.R.; Sheikh, N.; Weiler, H., Food insecurity and nutrition transition combine to affect nutrient intakes in Canadian Arctic communities. Journal of Nutrition 2011, 141 (9), 1746-1753. 
9. Egeland, G.M.; Zhirong, C.; T. Young Kue. Hypertriglyceridemic-waist phenotype and glucose intolerance among Canadian Inuit: The International Polar Year Inuit Health Survey for Adults 2007-2008. Canadian Medical Association Journal 2011, 183, E553-E558.

10. Guerrero-Romero, F. \& Rodriguez-Morán, M. Relationship between serum magnesium levels and C-reactive protein concentration, in non-diabetic, non-hypertensive obese subjects. International Journal of Obesity Related Metabolic Disorders 2002, 26, 469-474.

11. Hashimoto, T.; Hara, A.; Ohkubo, T.; et al., Serum magnesium, ambulatory blood pressure, and carotid artery alteration: the Ohasama study. American Journal of Hypertension 2010, 23, 1292-1298.

12. Institute of Medicine (IOM). Dietary Reference Intakes for Calcium, Phosphorus, Magnesium, Vitamin D, and Fluoride, 1997, National Academies Press: Washington, DC.

13. Johnson-Down, L. \& Egeland, G.M. Effects of the Nutrition Transition on Dietary Adequacy in Eeyouch (Cree) Adults of Northern Quebec Canada (submitted).

14. King, J.L.; Miller, R.J.; Blue, J.P.; O'Brien, W.D.; Erdman, J.W., Inadequate dietary magnesium intake increases atherosclerotic plaque development in rabbits. Nutrition Research 2009, 29, 343-349.

15. Klevay, L.M. \& Milne, D.B., Low dietary magnesium increases supraventricular ectopy. American Journal of Clinical Nutrition 2002, 75, 550554. 
16. Lalouel, J.M.; Darlu, P.; Henrotte, J.G.; Rao, D.C., Genetic regulation of plasma and red blood cell magnesium concentration in man. II. Segregation analysis. American Journal of Human Genetics 1983, 35, 938-950.

17. Ma, J.; Folsom, A.R.; Melnick, S.L.; et al., Associations of serum and dietary magnesium with cardiovascular disease, hypertension, diabetes, insulin and carotid arterial wall thickness- the ARIC study. Journal of Clinical Epidemiology 1995, 48, 927-940.

18. Maki, K.C.; Davidson, M.H.; Dicklin, M.R.; Bell, M.; Witchger, M.; Feinstein, S.B., Predictors of anterior and posterior wall carotid intima media thickness progression in men and women at moderate risk of coronary heart disease. Journal of Clinical Lipidology 2011, 5, 141-153.

19. Mooren, F.C.; Kruger, K.; Volker, K.; Golf, S.W.; Wadepuhl, M.; Kraus, A., Oral magnesium supplementation reduces insulin resistance in non-diabetic subjects - a double-blind, placebo-controlled, randomized trial, Diabetes Obesity \& Metabolsm 2011, 13, 281-284.

20. Nielsen, F.H.; Milne, D.B.; Klevay, L.M.; Gallagher, S.; Johnson, L., Dietary magnesium deficiency induces heart rhythm changes, impairs glucose tolerance, and decreases serum cholesterol in post menopausal women. Journal of American College of Nutrition 2007, 26, 121-132.

21. Peacock, J.M.; Folsom, A.R.; Arnett, D.K.; et al., Relationship of serum and dietary magnesium to incident hypertension: the Atherosclerosis Risk in Communities (ARIC) study. Annals of Epidemiology 1999, 9, 159-165.

22. Peacock, J.M.; Ohira, T.; Post, W.; Sotoodehnia, N.; Rosamond, W.; Folsom, A.R., Serum magnesium and risk of sudden cardiac death in the 
Atherosclerosis Risk in Communities (ARIC) Study. American Heart Journal 2010, 160, 464-470.

23. Randell, E.W.; Mathews, M.; Gadag, V.; Zhang, H.W.; G. Sun, G., Relationship between serum magnesium values, lipids and anthropometric risk factors, Atherosclerosis 2008, 196, 413-419.

24. Randell E.W. \& Sun, G., Positive correlation between total serum magnesium and serum lipid levels in the general population is clear: Ionized magnesium remains to be examined. Atherosclerosis 2007, 192, 231-232.

25. Reffelmann, T.; Dorr, M.; Ittermann, T.; et al., Low serum magnesium concentrations predict increase in left ventricular mass over 5 years independently of common cardiovascular risk factors. Atherosclerosis 2010, 213, 563-569. 26. Ridker, R.M. \& Cook, N., Clinical usefulness of very high and very low levels of C-reactive protein across the full range of Framingham Risk Scores. Circulation 2004, 109, 1955-1959.

27. Rodríguez-Morán, M. \& Guerrero-Romero, F., Serum magnesium and Creactive protein levels. Archives of Diseases in Childhood 2008, 93, 676-680. 28. Shuen, A.Y.; Wong, B.Y.; Wei, C.; Liu, Z.; Li, M.; Cole, D.E., Genetic determinants of extracellular magnesium concentration: Analysis of multiple candidate genes, and evidence for association with the estrogen receptor alpha (ESR1) locus. Clinica Chimica Acta 2009, 409, 28-32.

29. Ueshima, K., Magnesium and ischemic heart disease: a review of epidemiological, experimental, and clinical evidences. Magnesium Research 2005, 18, 275-284. 
30. Weglicki, W.B. \& Phillips, T.M., Pathobiology of magnesium deficiency: a cytokine/ neurogenic inflammation hypothesis, AJP - Regulatory Physiology 1992, 263, R734-R737.

31. WHO \& Centre for Indigenous Peoples' Nutrition and Environment (CINE), Indigenous peoples and participatory health research. 2003. Available online: http://www.mcgill.ca/files/cine/partreresearch.english.pdf. Last accessed: Sept 2011. 


\section{BRIDGE 3}

The previous analysis showed that while there is no current evidence that total $\mathrm{rMg}$ is associated with a favourable cardiovascular risk profile or adds value to risk assessment, the association between $\mathrm{sMg}$ and cardiometabolic risk warrants further attention. Therefore, the following work explored associations between $\mathrm{sMg}$ and an emerging and controversial cardiovascular risk factor, ventricular ectopy (premature ventricular complexes or beats, PVC).

The association between $\mathrm{sMg}$ and ventricular ectopy has been reported once previously in a general population context, the Framingham Offspring cohort (Tsuji et al., 1994), but no testing for potential effect modification by diabetic status was made in the study. As T2DM is the most common condition associated with low sMg or hypomagnesemia $(\mathrm{sMg} \leq 0.70 \mathrm{mmol} / \mathrm{L})$ (Rude \& Shils, 2006) and diabetes significantly increases risk of ventricular ectopy and sudden cardiac death (Escobedo \& Caspersen, 1997), diabetic status may modify the association between $\mathrm{sMg}$ and PVC. Chapter 2 (manuscript 1) also reported effect modification for the association between $\mathrm{Mg}$ and glycemic variables by diabetic status. In the following manuscript, the association between $\mathrm{sMg}$ and ventricular ectopy was evaluated in a high cardiovascular risk population, with explicit testing for the potential effect modification by T2DM. 


\section{References}

1. Escobedo, L.G. \& Caspersen, C.J., Risk factors for sudden coronary death in the United States. Epidemiology 1997, 8, 175-180.

2. Rude, R.K. \& Shils, M.E. Magnesium. In: Modern nutrition in health and disease, $10^{\text {th }}$ edition. 2006, Lippincott Williams \& Wilkins: Baltimore, MD. 3. Tsuji, H.; Venditti, F.J.; Evans, J.C.; Larson, M.G.; Levy, D., The associations of levels of serum potassium and magnesium with ventricular premature complexes (The Framingham Heart Study). American Journal of Cardiology 1994, 74, 232-235. 


\section{CHAPTER 5: MANUSCRIPT 3}

\section{Low serum magnesium concentrations are associated with high} prevalence of ventricular ectopy in adults with type 2 diabetes

Short title: Serum magnesium \& ventricular ectopy

L.C. Del Gobbo ${ }^{1}$, Y. Song ${ }^{2}$, P. Poirier ${ }^{3}$, E. Dewailly ${ }^{4}$, R.J. Elin ${ }^{5}$, G.M. Egeland ${ }^{1}$

${ }^{1}$ School of Dietetics \& Human Nutrition, McGill University, St. Anne de Bellevue, Quebec, Canada

${ }^{2}$ Division of Preventive Medicine, Brigham and Women's Hospital, Harvard Medical School, Boston, MA, USA

3Institut universitaire de cardiologie et de pneumologie de Québec, Faculty of pharmacy, Laval University, Quebec, Canada

4Public Health Research Unit, CHUL Research Center, Centre Hospitalier, Universitaire de Quebec Sainte-Foy, Canada

5Department of Pathology and Laboratory Medicine, University of Louisville, Louisville, KY, USA

Corresponding author: Grace M. Egeland (grace.egeland@mcgill.ca)

School of Dietetics and Human Nutrition

Room MS2-039, Macdonald Stewart Building, 21111 Lakeshore Road

Ste. Anne de Bellevue, Quebec H9X 3V9

Tel.: 514-398-8642

Fax: 514-398-1020 


\section{Abstract}

Introduction: PVC predict cardiovascular mortality among several adult populations. Increased arrhythmia prevalence has been reported during controlled magnesium $(\mathrm{Mg})$ depletion studies in adults. We thus hypothesized that $\mathrm{sMg}$ concentrations are inversely associated with the prevalence of PVC in adults at high cardiovascular risk.

Methods: Anthropometric, demographic and lifestyle characteristics were assessed in 750 Cree adults, aged $>18$ yrs, who participated in an age-stratified, cross-sectional health survey in Quebec, Canada. Holter electrocardiograms recorded heart rate variability and cardiac arrhythmias for two consecutive hours. Multivariate logistic regression was used to evaluate the associations between $\mathrm{sMg}$ and PVC.

Results: PVC prevalence in adults with hypomagnesemia $(\mathrm{sMg} \leq 0.70 \mathrm{mmol} / \mathrm{L})$ was more than twice that of adults without hypomagnesemia (50\% vs. $21 \%$, $p=0.015$ ); results were not materially altered when adults with cardiovascular disease history were excluded. All hypomagnesemic adults with PVC had T2DM. Prevalence of PVC declined across the sMg concentration gradient in adults with T2DM only ( $p<0.001$ for linear trend). In multivariate logistic regressions adjusted for age, sex, community, body mass index, smoking, physical activity, alcohol consumption, kidney disease, antihypertensive and cholesterol lowering drug use, and blood docosahexaenoic acid concentrations, the odds ratio of PVC among diabetics with $\mathrm{sMg}>0.70 \mathrm{mmol} / \mathrm{L}$ was 0.24 (95\% CI: $0.06-0.98) p=0.046$ compared to those with $\mathrm{sMg} \leq 0.70 \mathrm{mmol} / \mathrm{L}$. 
Conclusions: $\mathrm{sMg}$ concentrations were inversely associated with the prevalence of PVC in patients with T2DM in a dose response manner, indicating that suboptimal sMg may be a contributor to cardiac arrhythmia among patients with T2DM.

Keywords: magnesium, hypomagnesemia, premature ventricular complexes, premature ventricular beats, ectopic beats, arrhythmia 


\section{Introduction}

Premature ventricular complexes (PVC) are a relatively common electrocardiographic abnormality presenting in individuals with and without overt cardiovascular disease. In the latter case, PVC pathogenesis has traditionally been considered idiopathic and in the absence of severe clinical symptoms or structural cardiac abnormalities, their presence benign (Kennedy et al., 1985; Gaita et al., 2001). Recent prospective studies evaluating the prognostic significance of PVC for sudden and total cardiac death in apparently healthy adults directly challenge this view. Among individuals without history of heart disease or stroke, PVC counts independently predicted future cardiac events or sudden cardiac death compared to those without PVC (Sajadieh et al., 2006; Cheriyath et al., 2011; Stein et al., 2010; Abdalla et al., 1987). These findings are consistent with hypothesis that PVC may indicate electrical instability and increased susceptibility to ventricular fibrillation (Abdalla et al., 1987), the most common cause of sudden cardiac death.

$\mathrm{Mg}^{2+}$ antagonizes calcium on the atrioventricular node (Fawcett et al.,

1999) and myocardial $\mathrm{Mg}^{2+}$ deficiency decreases intracellular potassium, resulting in a less negative resting membrane potential and enhanced vulnerability to ventricular arrhythmia (Abbott \& Rude, 1993; Parikka et al., 1999; Chakraborti et al., 2002). Two randomized, double-blind crossover studies by USDA scientists showed that reducing intake of dietary magnesium $(\mathrm{Mg})$ in postmenopausal women in a metabolic unit to $33-50 \%$ of the $\mathrm{Mg}$ recommended dietary allowance induced ectopic beats and other arrhythmias (Nielsen et al., 2007; Klevay \& Milne, 2002). During the Mg depletion phase, calcium, potassium, copper and 
other nutrients were concomitantly supplemented (Nielsen et al., 2007) and arrhythmias were relieved by $\mathrm{Mg}$ supplementation, providing direct evidence that inadequate $\mathrm{Mg}$ intake from a diet that would not be considered an atypical Western menu can induce heart arrhythmias in older women.

In adults from the Framingham Offspring cohort free of clinically apparent heart disease, total sMg was significantly inversely associated with prevalence of complex or frequent PVC after adjustment for multiple covariates, including serum potassium (Tsuji et al., 1994). As T2DM is the most common condition associated with low $\mathrm{sMg}$ or hypomagnesemia $(\mathrm{sMg} \leq 0.70 \mathrm{mmol} / \mathrm{L})($ Rude $\&$ Shils, 2006) and T2DM significantly increases risk of ventricular ectopy and sudden cardiac death (Escobedo \& Capersen, 1997), the association between sMg and PVC may be modified by diabetic status. However, testing for such potential effect modification has not been reported previously. We hypothesized that $\mathrm{sMg}$ concentrations are inversely associated with the prevalence of PVC in a general adult population at high cardiovascular risk, and separately evaluated the association in the subgroup with T2DM. Mg intakes in Cree adults, particularly Cree men, are inadequate, with $93 \%$ of men $19-30 \mathrm{yrs}$ and $100 \%$ of men $\geq 31 \mathrm{yrs}$ consuming less than the $\mathrm{Mg}$ recommended dietary intake in some communities (Mistissini report, 2007). Due to rapid dietary and lifestyle transition and consequent increasing obesity rates, prevalence of T2DM among Cree is among the highest in the world (Harris et al., 1997).

\section{Methods}

A subset of adults ( $\geq 18 \mathrm{yrs})$ of Cree descent from the James Bay region of Quebec, Canada were selected from a comprehensive aboriginal health survey 
'Nituuchischaayihitaau Aschii: A Multi-Community Environment and Health Longitudinal Study in Iiyiyiu Aschii.' This cross-sectional study included fasting participants from seven communities sampled between 2005-2009 for which sMg, covariates and 2-hr Holter electrocardiogram recordings were available. Bilingual Cree were trained to conduct interviews and recruit participants. Ethics for the health survey was obtained from the Cree Board of Health and Social Services of James Bay (CBHSSJB), Centre Hospitalier Universitaire de Québec (Laval), and McGill universities. A research agreement with communities was developed with the Cree Board of Health and all individual study participants provided informed written consent in Cree or English.

A total of 834 adults were assessed for anthropometric measures, demographic and lifestyle variables (smoking, alcohol consumption, exercise); sMg, full medical history, and Holter data (PVC) were available for 750 adults included in analysis. Individuals with missing values did not differ significantly in covariate distribution from included individuals.

\section{Variable assessment}

Anthropometric variables were measured without shoes by trained nurses. Height, measured in centimetres using a graduated tape, and weight, determined using a foot-to-foot bioelectrical impedance instrument (Tanita Corp, Arlington Heights, IL, USA), were combined to obtain body mass index (BMI). Exercise (frequency in which individuals reported to engage in vigorous physical activity for at least 20 minutes at a time) was assessed by a culturally adapted, short version of the International Physical Activity Questionnaire validated in Cree adults (Egeland et al., 2008). Smoking status (current, former or never) and 
alcohol consumption ( $\geq 3$ drinks/day, $<3$ drinks day, or never, of standard drinks of beer, liquor, wine, mixed drinks, or shooters) were also self-reported. As cellular and animal models, epidemiological studies and clinical trials suggest that long-chain polyunsaturated fatty acids exert anti-arrhythmic effects (Russo et al., 2009; Mozaffarian et al., 2004), we tested the potentially modifying effects of plasma eicosapentaenoic acid (EPA) and docosahexaenoic acid (DHA) as nutritional covariates in models. Medical charts for each participant were reviewed and detailed cardiovascular event history or conditions, metabolic conditions, cardiovascular drugs/ supplement use, and selected other conditions were recorded. In characterizing the metabolic syndrome (MetS), the consensus definition was used (Alberti et al., 2009). Adults with T2DM had previously been diagnosed or presented with fasting glucose (FG) concentrations $\geq 7 \mathrm{mmol} / \mathrm{L}$.

Serum Mg was determined at Trace Elements Laboratory the London Laboratory Services group, London, Ontario, Canada using the colorimetric endpoint method with addition of xylidyl blue. $\mathrm{Mg}$ content was measured photometrically as a function of the decrease in xylidyl blue absorbance (laboratory reference range: $0.65-1.05 \mathrm{mmol} / \mathrm{L}$ ). For the determination of EPA and DHA concentrations, $200-\mu \mathrm{L}$ aliquots of plasma were extracted after the addition of chloroform: methanol (2:1), in the presence of a known amount of internal standard (diheptadecanoyl phospholipid). Total phospholipids were isolated from the lipid extract via thin-layer chromatography with the use of developing solvent heptane:isopropyl ether:acetic acid (60:40:3). Transmethylation with boron trifluoride and methanol preceded capillary gasliquid chromatography to determine fatty acid concentrations. 
Frequency of premature ventricular beats, distinct from supraventricular beats, were derived from a 2-hour Holter monitoring system (GE Marquette Series 8500) with a recording frequency of $128 \mathrm{~Hz}$. Seven leads (derivations V5, $\mathrm{V} 1$, and $\mathrm{AVF}$ ) were installed when subjects arrived to the clinic after blood sample was taken. During the 2-hour recording, subjects remained at the clinic, completing anthropometric measurements and lifestyle questionnaires.

\section{Statistical approach}

PVC prevalence for all adults $\geq 18 y r s$ ( $n=750$ ) on 2-hour Holters was presented stratified by demographic, anthropometric and lifestyle variables. We considered $\geq 1 \mathrm{PVC} / \mathrm{hr}$ and $>6 \mathrm{PVC} / \mathrm{hr}$ recording as endpoints in this high cardiometabolic risk sample; elevated risk for sudden cardiac death was reported for high-risk participants in the Cardiovascular Health Study with >153 PVC over 24 hours, or about 6 events/hr (Stein et al., 2008).

Unadjusted prevalence of PVC across sMg groupings for the entire sample and subgroups (with cardiovascular event history or conditions excluded, those with T2DM, and MetS) was determined. Frequencies were compared using $X^{2}$ tests or Fisher's exact test when sample sizes in contingency tables were small. Odds ratios and $95 \%$ confidence intervals using multivariate logistic regression for $\geq 1 \mathrm{PVC} / \mathrm{hr}$ and $>6 \mathrm{PVC} / \mathrm{hr}$ across the sMg concentration range for the whole population were determined for five different covariate models. In subgroup analysis for adults with type 2 diabetes and no prior cardiovascular disease (CVD) ( $\mathrm{n}=149$ ), only the odds ratio of $\geq 1 \mathrm{PVC} / \mathrm{hr}$ for normomagnesemic diabetics $(\mathrm{sMg}>0.70 \mathrm{mmol} / \mathrm{L})$ relative to the reference group of hypomagnesemic diabetics ( $\mathrm{sMg} \leq 0.70 \mathrm{mmol} / \mathrm{L})$ were determined due to sample size constraints. 
Individuals with prior CVD were defined as those with one or more condition listed under "cardiovascular event history or conditions $\square$ or taking CVD drugs in Table 5.1; hypertensives were excluded from this definition. Additional sensitivity analysis was performed excluding adults with kidney disease, as this condition is associated with altered $\mathrm{Mg}$ homeostasis and sMg concentrations (Alghamdi et al., 1994).

\section{Results}

Our population included 441 females $(58.8 \%)$ and 309 males $(41.2 \%)$ with a mean age of $38.9 \pm 14.8$ yrs. Mean BMI was $33.9 \pm 7.0 \mathrm{~kg} / \mathrm{m}^{2}$. More than half of adults $(51.3 \%)$ identified as current smokers. Hypertension was the most common CVD condition (33.2\%) and antihypertensive drugs the most common class of CVD medications taken $(24.4 \%)$. The percentage of adults with MetS was $46.9 \%$; prevalence of $\mathrm{T} 2 \mathrm{DM}$ (diagnosed or $\mathrm{FG} \geq 7 \mathrm{mmol} / \mathrm{L}$ ) was $23.5 \%$ (Table 5.1).

Prevalence and frequency of PVC differed by smoking status and was significantly higher in males, older participants, those with MetS or T2DM ( $p<0.001$ for each covariate), in participants with CVD history (excluding hypertensives), and in those who do not engage in modest alcohol consumption $(p<0.02)$. Hypertension and lack of exercise approached significance $(p<0.10)$ but obesity was not significantly associated with PVC $(p=0.39)$ (Table 5.2).

Unadjusted prevalence of PVC in adults with hypomagnesemia $(\mathrm{sMg} \leq$ $0.70 \mathrm{mmol} / \mathrm{L}$ ) was over twice that of adults without hypomagnesemia (50\% vs. $21 \%, p=0.015)$; results were not materially altered when adults with cardiovascular disease history $(\mathrm{n}=98)$ were excluded (Figure 5.1). In multivariate logistic regression analyses for all adults ( $\mathrm{n}=750)$, odds of $\geq 1 \mathrm{PVC} / \mathrm{hr}$ declined 
precipitously from the hypomagnesemic reference group to 0.24 (95\% CI: 0.07 0.87) in those with sMg $0.71-0.80 \mathrm{mmol} / \mathrm{L}$ in the fully adjusted model (Model 5); risk did not substantively change at higher sMg concentrations (Table 5.3). Due to low sample size among the hypomagnesemic reference group, it was not possible to further define the $\mathrm{sMg}$ threshold associated with reduced odds $\geq 1 \mathrm{PVC}$ in this sample. Model covariates had little influence on adjusted odds ratios; inclusion of EPA in any model had no impact on estimates and was excluded. Significantly decreased adjusted odds of $>6 \mathrm{PVC} / \mathrm{hr}$ were observed in those with sMg above a $\mathrm{sMg} 0.75 \mathrm{mmol} / \mathrm{L}$ threshold in the whole population for all covariate models (Table 5.4). Odds of $>6 \mathrm{PVC} / \mathrm{hr}$ for those with sMg 0.750.80 relative to those with $<0.75 \mathrm{mmol} / \mathrm{L}$ were 0.10 (95\% CI: $0.02-0.46)$ in the fully adjusted model (Model 5). A sMg threshold of $0.75 \mathrm{mmol} / \mathrm{L}$ was selected for this endpoint because ORs were maximally reduced using this cutoff value (Table 5.5).

Further evaluation of the characteristics of hypomagnesemic adults in this population revealed that all individuals with PVC had T2DM. When participants were stratified by diabetic status, prevalence of PVC declined across the $\mathrm{sMg}$ concentration gradient in adults with T2DM only $(p<0.001)$ (Figure 5.2). Decline in PVC prevalence with increasing sMg among participants with T2DM was significant even when hypomagnesemic adults were excluded $(p=0.005)$. Addition of diabetic medication use (metformin, gluconorm or insulin) as covariates had no influence on model estimates. While only 1\% of subjects without T@DM were hypomagnesemic $(n=5)$, none of these subjects had PVC during recording. In the 
subgroup with MetS but without T2DM, no significant difference in PVC prevalence across the $\mathrm{sMg}$ concentration gradient was detected $(p=0.84)$.

Among adults with T2DM and no CVD history (n=149), individuals without hypomagnesemia ( $\mathrm{sMg}>0.70 \mathrm{mmol} / \mathrm{L}$ ) had significantly lower risk of PVC on 2-hr Holter recording in fully adjusted models [OR 0.24 (95\% CI: 0.06-0.98)] (Table 5.6). Sensitivity analysis excluding remaining individuals with kidney disease ( $n=4$ without CVD history) had no influence on model estimates.

\section{Discussion}

Our finding of significantly elevated PVC prevalence in adults with hypomagnesemia relative to adults without reduced $\mathrm{sMg}$ is consistent with early clinical studies reporting ventricular fibrillation and tachycardia in hypomagnesemia (Loeb et al., 1968; Dykner \& Wester, 1982). Hypomagnesemia is an established risk factor for polymorphic ventricular tachycardia torsades de pointes (Ramme et al., 1985) and intravenous magnesium sulfate remains firstline therapy for tosades de pointes associated with long QT interval according to current ACC/AHA/ESC guidelines for prevention of sudden cardiac death (Zipes et al., 2006). It has been suggested that the trigger for torsades de pointes are ventricular ectopic beats resulting from an early afterdepolarization generated during the abnormally prolonged repolarization phase of affected myocardium (Berlardinelli et al., 2003).

Reports of increased ventricular arrhythmia in hypomagnesemic individuals have been criticized as lacking in evidence that the effect is attributable to $\mathrm{Mg}$ alone as opposed to a combination of hypomagnesemia and hypokalemia (Millante et al., 1992). As we did not measure serum potassium in 
our cross-sectional design, this study provides no evidence to rebuke this claim, particularly as hypomagnesemia and hypokalemia frequently coexist and have similar etologies. In the Framingham Offspring cohort, apparently the only other general population study associating sMg with PVC, multivariate logistic regression analyses revealed that both serum potassium and $\mathrm{Mg}$ concentrations, when simultaneously entered into models, were inversely associated with complex or frequent PVC occurrence $(p<0.04)$. Each standard deviation decrement in potassium $(0.48 \mathrm{mmol} / \mathrm{L})$ or $\mathrm{Mg}(0.80 \mathrm{mmol} / \mathrm{L})$ was associated with a similar increase in odds PVC [27\% (95\% CI 6-51\%) for potassium, and 20\% (95\% CI 3-41\%) for Mg] (Tsuji et al., 1994). From physiologic studies, Mg is an established regulator of major ion channels in the cardiovascular system, including potassium, calcium, sodium, and others (Mubagwa et al., 2007). Potassium is not effective in the suppression of cardiac arrhythmia occurring in the presence of normal serum potassium; by contrast, $\mathrm{Mg}$ can attenuate arrhythmias regardless of sMg concentration (Millante et al., 1992; Harris \& Levin, 1937). Irrespective of the degree to which prevalence of PVC may differ due to $\mathrm{sMg}$ concentration independent of other serum electrolytes, this study supports hypomagnesemia as a risk factor for ventricular arrhythmia.

Hypomagnesemia has been recently associated with T2DM, but not precursor states (Simmons et al., 2010), a finding consistent with our data. In this sample, diabetic status, but not MetS, was a major determinant of very low $\mathrm{sMg}$ levels; $76 \%$ of all hypomagnesemic adults had T2DM, in comparison to a $22 \%$ diabetes prevalence among non-hypomagnesaemic adults. While increased fractional excretion of $\mathrm{Mg}$ at elevated insulin concentrations (Kalaitzidis et al., 
2005) may be at play in both MetS and T2DM, mechanisms for Mg loss specific to diabetes, such as renal $\mathrm{Mg}$ wasting secondary to osmotic diuresis when blood glucose concentrations exceed $\sim 11 \mathrm{mmol} / \mathrm{L} \mathrm{Mg}$ due to glucosuria (de Valk, 1999), might be associated with comparatively greater reductions in $\mathrm{sMg}$.

As T2DM is the most common condition associated with low sMg (Rude \& Shils, 2006) and diabetes significantly increases risk of ventricular ectopy (Escobedo \& Capersen, 1997), there is theoretical basis for the hypothesis that T2DM might modify the association between sMg and PVC. Here, we provide the first supporting evidence that T2DM is an important effect modifier of the association between sMg and PVC, with reductions in PVC prevalence across the sMg gradient in T2DM only, driving the significant associations observed in the entire population. While the PVC outcome variable ( $>30 \mathrm{PVC} / \mathrm{hr}$, multiform or repetitive) in the Framingham Offspring cohort was different than endpoints assessed here and T2DM prevalence was high in our population, whether the significant association between $\mathrm{sMg}$ and PVC risk reported in the Framingham cohort (Tsuji et al., 1994) might be modified by inclusion of T2DM status as a covariate is unknown. Replication studies and explicit testing for potential effect modification by diabetes in future analyses is required.

In this work, risk of $>6 \mathrm{PVC} / \mathrm{hr}$ was maximally reduced above a sMg threshold $(0.75 \mathrm{mmol} / \mathrm{L})$ within the normal $\mathrm{sMg}$ concentration range and prevalence of PVC declined across the normal sMg concentration gradient in adults with T2DM. Previous analyses in this Cree cohort demonstrated significant decreases in fasting glucose and carotid intima-media thickness across $\mathrm{sMg}$ concentration groupings among adults with MetS (Chapter 4). In other 
populations, significantly reduced risk of ventricular arrhythmia and sudden cardiac death at elevated sMg concentrations have been reported (Tsuji eta 1., 1994; Peacock et at., 2010). Altogether, these observational studies provide evidence for cardiovascular risk stratification within the normal $\mathrm{sMg}$ range, with reduced risk of both intermediary adverse outcomes and hard endpoints at higher sMg concentrations. Further investigations evaluating the utility of sMg, an inexpensive and simple measure, as a cardiovascular risk biomarker, and thresholds for various endpoints, are appropriate.

Consistent cut-offs for the number or complexity (multiforms, pairs, runs, R-on-T) of PVC per unit time of Holter recording associated with mortality risk across population groups of different ages, ethnicities or underlying cardiovascular risk have yet to be established (Sajadieh et al., 2006; Cheriyath et al., 2011; Stein et al., 2010; Abdalla et al., 1987). Thus, a main limitation of this work includes the uncertain prognostic significance of PVC endpoints selected in this high-risk population, which can be determined through long term follow-up for incidence of ventricular fibrillation, tachycardia, sudden cardiac death, or CVD mortality. Left ventricular ejection fraction was unknown, and could have modulated prevalence of asymptomatic heart disease and PVC among patients with diabetes. Generalizability of our findings may be limited by the ethnic homogeneity of the sample and high prevalence of T2DM relative to most other general populations. Inclusion of other potentially relevant unmeasured covariates, such as serum potassium and other electrolytes, caffeine use, noncardiovascular drugs, or stress/anxiety might reduce residual confounding, and we cannot completely rule out residual confounding from poorly measured or 
unmeasured covariates. Consistency in sample demographics and CVD risk, monitoring environments, duration and specific PVC endpoints assessed in different populations will be important in reducing heterogeneity among future studies and facilitating comparisons.

In conclusion, this study provides evidence that $\mathrm{T} 2 \mathrm{DM}$ is an important effect modifier of the association between $\mathrm{sMg}$ and ventricular ectopy, with significant reductions in PVC prevalence across the sMg gradient in adults with T2DM. Diabetic status, but not MetS, was a major determinant of very low sMg levels in this population. PVC risk was particularly elevated in diabetic adults with hypomagnesemia, suggesting that future interventions to increase $\mathrm{sMg}$ concentrations among adults with T2DM may confer protection against cardiac arrhythmia. As hypomagnesemia is an under-diagnosed electrolyte abnormality common in T2DM, appropriately-powered randomized controlled Mg trials are required to evaluate the potential of $\mathrm{Mg}$ to reduce arrhythmias and cardiovascular risk.

\section{Acknowledgements}

The authors wish to thank lab managers Donna Leggee and Suzanne Cote. This scientific communication is a report from the Nituuchischaayihtitaau Aschii: Multi-Community Environment-and-Health Longitudinal Study in Iiyiyiu Aschii supported by the Cree people of northern Québec, the Cree First Nations and the Cree Board of Health and Social Services of James Bay. 


\section{Tables}

Table 5.1. Medical chart review of adults ( $\geq 18 \mathrm{yrs})$ of the general Cree population $(\mathrm{n}=750)$

Cardiovascular event history or conditions

Ischemia/infarction

Cardiac insufficiency

Atrial fibrillation

Ventricular arrhythmia/tachycardia

Bradycardia

Ventricular hypertrophy

Angina

Hypertension (diagnosed)

(BP $>130 / 85 \mathrm{mmHg}$, or treatment of diagnosed)

Ischemic heart disease

Diseases of the pulmonary circulation

Stroke

Cerebrovascular diseases

Diseases of arteries, arterioles or capillaries

Cardiometabolic conditions

Metabolic syndrome

(excluding diagnosed type 2 diabetics/FG $\geq 7 \mathrm{mmol} / \mathrm{L}$ )

Gestational diabetes (history of)

Type 1 diabetes

Type 2 diabetes (diagnosed)

(diagnosed or $\mathrm{FG} \geq 7 \mathrm{mmol} / \mathrm{L}$ )

Cardiovascular drug/ supplement use

Antiplatelet

Antihypertensives

Diuretics (specifically)

Cholesterol-lowering drugs

Statins (specifically)

Multivitamins

Mg supplements

Hormonal or menstrual status

Post-menopausal

Hormone replacement therapy

Oral contraceptives

352

140

23

1

140

176

Currently breastfeeding

Other

Kidney disease

Cancer 
Table 5.2. Characteristics of Cree adults ( $\geq 18 \mathrm{yrs})$ according to PVC prevalence during Holter electrocardiogram $(n=750)$

\begin{tabular}{|c|c|c|c|}
\hline Characteristic & $\begin{array}{c}\text { No PVC } \\
n=591\end{array}$ & $\begin{array}{c}1-6 \mathrm{PVC} / \mathrm{hr} \\
\mathrm{n}=118\end{array}$ & $\begin{array}{c}>6 \mathrm{PVC} / \mathrm{hr} \\
\mathrm{N}=41\end{array}$ \\
\hline \multicolumn{4}{|l|}{ Sex } \\
\hline Male & $217(37 \%)$ & $64(54 \%)$ & $28(68 \%)$ \\
\hline Female & $374(63 \%)$ & $54(46 \%)$ & $13(32 \%) * * *$ \\
\hline \multicolumn{4}{|l|}{ Age (yrs) } \\
\hline $18-30$ & $194(33 \%)$ & $23(19 \%)$ & $5(12 \%)$ \\
\hline $30-50$ & $302(51 \%)$ & $44(37 \%)$ & $14(34 \%)$ \\
\hline$\geq 50$ & $95(16 \%)$ & $51(43 \%)$ & $22(54 \%) * * *$ \\
\hline \multicolumn{4}{|l|}{ BMI $\left(\mathrm{kg} / \mathrm{m}^{2}\right)$} \\
\hline$<30$ & $170(29 \%)$ & $36(31 \%)$ & $8(20 \%)$ \\
\hline$\geq 30$ & $421(71 \%)$ & $82(69 \%)$ & $33(80 \%)$ \\
\hline \multicolumn{4}{|l|}{ Smoking } \\
\hline Current & $329(56 \%)$ & $40(34 \%)$ & $16(39 \%)$ \\
\hline Former & $204(34 \%)$ & $61(52 \%)$ & $21(51 \%)$ \\
\hline Never & $58(10 \%)$ & $17(14 \%)$ & $4(10 \%)^{* * *}$ \\
\hline \multicolumn{4}{|l|}{ Alcohol } \\
\hline$<3$ drinks $/ d$ & $271(46 \%)$ & $48(41 \%)$ & $10(24 \%)$ \\
\hline Never & $312(54 \%)$ & $69(59 \%)$ & $31(76 \%)^{* *}$ \\
\hline \multicolumn{4}{|l|}{ Exercise } \\
\hline$\geq 4$ times $/ w k$ & $187(32 \%)$ & $37(31 \%)$ & $13(32 \%)$ \\
\hline 1-3 times/wk & $217(36 \%)$ & $32(27 \%)$ & $10(24 \%)$ \\
\hline None & $187(32 \%)$ & $49(42 \%)$ & $18(44 \%)^{* *}$ \\
\hline Hypertension & $153(26 \%)$ & $41(35 \%)$ & $15(37 \%)^{*}$ \\
\hline CVD history ${ }^{1}$ & $18(3 \%)$ & $7(6 \%)$ & $4(10 \%)^{* *}$ \\
\hline $\operatorname{MetS}^{2}$ & $95(16 \%)$ & $30(25 \%)$ & $15(37 \%) * * *$ \\
\hline Diabetes $^{3}$ & $122(21 \%)$ & $37(31 \%)$ & $17(41 \%) * * *$ \\
\hline$* p<0.01 \quad * * p$ & $* * * p<0.001$ & & \\
\hline
\end{tabular}


Table 5.3. Adjusted odds ratios \& $95 \%$ confidence intervals for presence of $\geq 1$ PVC on 2-hr Holters across the sMg concentration range $(\mathrm{n}=750)$

\begin{tabular}{|c|c|c|c|c|}
\hline $\begin{array}{c}\mathrm{sMg} \\
(\mathrm{mmol} / \mathrm{L})\end{array}$ & $\leq \mathbf{0 . 7}$ & $\mathbf{0 . 7 1 - 0 . 8 0}$ & $\mathbf{0 . 8 1 - 0 . 9 0}$ & $>\mathbf{0 . 9 0}$ \\
\hline Model 1 & 1.00 & $0.26(0.07-0.88)$ & $0.27(0.08-0.93)$ & $0.22(0.06-0.81)$ \\
\hline Model 2 & 1.00 & $0.25(0.07-0.85)$ & $0.26(0.08-0.88)$ & $0.19(0.05-0.71)$ \\
\hline Model 3 & 1.00 & $0.25(0.07-0.85)$ & $0.26(0.08-0.88)$ & $0.20(0.05-0.73)$ \\
\hline Model 4 & 1.00 & $0.24(0.07-0.86)$ & $0.25(0.07-0.92)$ & $0.19(0.05-0.77)$ \\
\hline Model 5 & 1.00 & $0.24(0.07-0.87)$ & $0.26(0.07-0.93)$ & $0.18(0.04-0.73)$ \\
\hline
\end{tabular}

Model 1: adjusted for age and sex

Model 2: additionally adjusted for region and BMI

Model 3: additionally adjusted for smoking, physical activity, alcohol consumption

Model 4: additionally adjusted for history of cardiovascular events/disease, type 2 diabetes, kidney disease, antihypertensive and cholesterol lowering drug use Model 5: additionally adjusted for blood DHA 
Table 5.4. Adjusted odds ratios \& $95 \%$ confidence intervals for presence of $\geq 1$ PVC on 2-hr Holters among patients with type 2 diabetes but without CVD history $(n=149)$

\begin{tabular}{|c|c|c|}
\hline & $\begin{array}{c}\text { Type } 2 \text { diabetics } \\
\mathbf{s M g} \leq \mathbf{0 . 7 0} \mathbf{~ m m o l} / \mathbf{L}\end{array}$ & $\begin{array}{c}\text { Type } 2 \text { diabetics } \\
\mathbf{s M g}>\mathbf{0 . 7 0} \mathbf{m m o l} / \mathbf{L}\end{array}$ \\
\hline Model 1 & 1.00 & $0.28(0.08-0.98)$ \\
\hline Model 2 & 1.00 & $0.25(0.07-0.92)$ \\
\hline Model 3 & 1.00 & $0.26(0.07-1.04)$ \\
\hline Model 4 & 1.00 & $0.25(0.06-1.03)$ \\
\hline Model 5 & 1.00 & $0.24(0.06-0.98)$ \\
\hline
\end{tabular}

Model 1: adjusted for age and sex

Model 2: additionally adjusted for region and BMI

Model 3: additionally adjusted for smoking, physical activity, alcohol consumption

Model 4: additionally adjusted for kidney disease, antihypertensive and cholesterol lowering drug use

Model 5: additionally adjusted for blood DHA 
Table 5.5. Adjusted odds ratios and $95 \%$ confidence intervals for presence of $>6$ $\mathrm{PVC} / \mathrm{hr}$ on Holter monitors across the $\mathrm{sg}$ concentration range $(\mathrm{n}=750)$

\begin{tabular}{|l|c|c|c|c|c|}
\hline $\begin{array}{l}\text { sMg } \\
(\mathrm{mmol} / \mathrm{L})\end{array}$ & $<\mathbf{0 . 7 5}$ & $\mathbf{0 . 7 5 - 0 . 8 0}$ & $\mathbf{0 . 8 0 - 0 . 8 5}$ & $\mathbf{0 . 8 5 - 0 . 9 0}$ & $>\mathbf{0 . 9 0}$ \\
\hline Model 1 & 1.00 & $0.16(0.05-0.54)$ & $0.41(0.17-0.99)$ & $0.19(0.07-0.53)$ & $0.15(0.04-0.53)$ \\
\hline Model 2 & 1.00 & $0.15(0.04-0.53)$ & $0.39(0.16-0.98)$ & $0.17(0.06-0.49)$ & $0.15(0.04-0.56)$ \\
\hline Model 3 & 1.00 & $0.13(0.04-0.45)$ & $0.36(0.14-0.92)$ & $0.16(0.05-0.46)$ & $0.13(0.03-0.54)$ \\
\hline Model 4 & 1.00 & $0.10(0.02-0.45)$ & $0.37(0.13-1.10)$ & $0.17(0.05-0.57)$ & $0.10(0.02-0.53)$ \\
\hline Model 5 & 1.00 & $0.10(0.02-0.46)$ & $0.38(0.13-1.13)$ & $0.16(0.05-0.57)$ & $0.06(0.01-0.39)$ \\
\hline
\end{tabular}

Model 1: adjusted for age and sex

Model 2: additionally adjusted for region and BMI

Model 3: additionally adjusted for smoking, physical activity, alcohol consumption

Model 4: additionally adjusted for history of cardiovascular events/disease, type 2 diabetes, kidney disease, antihypertensive and cholesterol lowering drug use Model 5: additionally adjusted for blood DHA 
Table 5.6. Odds ratios for the fully adjusted model (Model 5) for presence of $>6$ $\mathrm{PVC} / \mathrm{hr}$ on Holters are minimized using $<0.75 \mathrm{mmol} / \mathrm{L} \mathrm{sMg}$ as the reference $(\mathrm{n}=750)$

\begin{tabular}{|l|c|c|c|c|}
\hline $\begin{array}{l}\text { sMg }(\mathrm{x}) ; \\
\text { OR 1.00 }\end{array}$ & $(\mathbf{x + 0 . 1 )}-\mathbf{0 . 8 0}$ & $\mathbf{0 . 8 0 - 0 . 8 5}$ & $\mathbf{0 . 8 5 - 0 . 9 0}$ & $>\mathbf{0 . 9 0}$ \\
\hline$<0.76$ & $0.20(0.05-0.86)$ & $0.55(0.19-1.61)$ & $0.24(0.07-0.81)$ & $0.09(0.01-0.57)$ \\
\hline$<0.75$ & $0.10(0.02-0.46)$ & $0.38(0.13-1.13)$ & $0.16(0.05-0.57)$ & $0.06(0.01-0.39)$ \\
\hline$<0.74$ & $0.21(0.06-0.79)$ & $0.46(0.15-1.46)$ & $0.20(0.06-0.73)$ & $0.07(0.01-0.50)$ \\
\hline$<0.73$ & $0.30(0.08-1.09)$ & $0.52(0.15-1.75)$ & $0.23(0.06-0.87)$ & $0.08(0.01-0.58)$ \\
\hline
\end{tabular}




\section{Figures}

Figure 5.1. Unadjusted prevalence of PVC (\%) during 2-hr Holter electrocardiogram among adults $(n=750)$ according to groupings of $\mathrm{sMg}$ concentrations $(\mathrm{mmol} / \mathrm{L})^{1}$

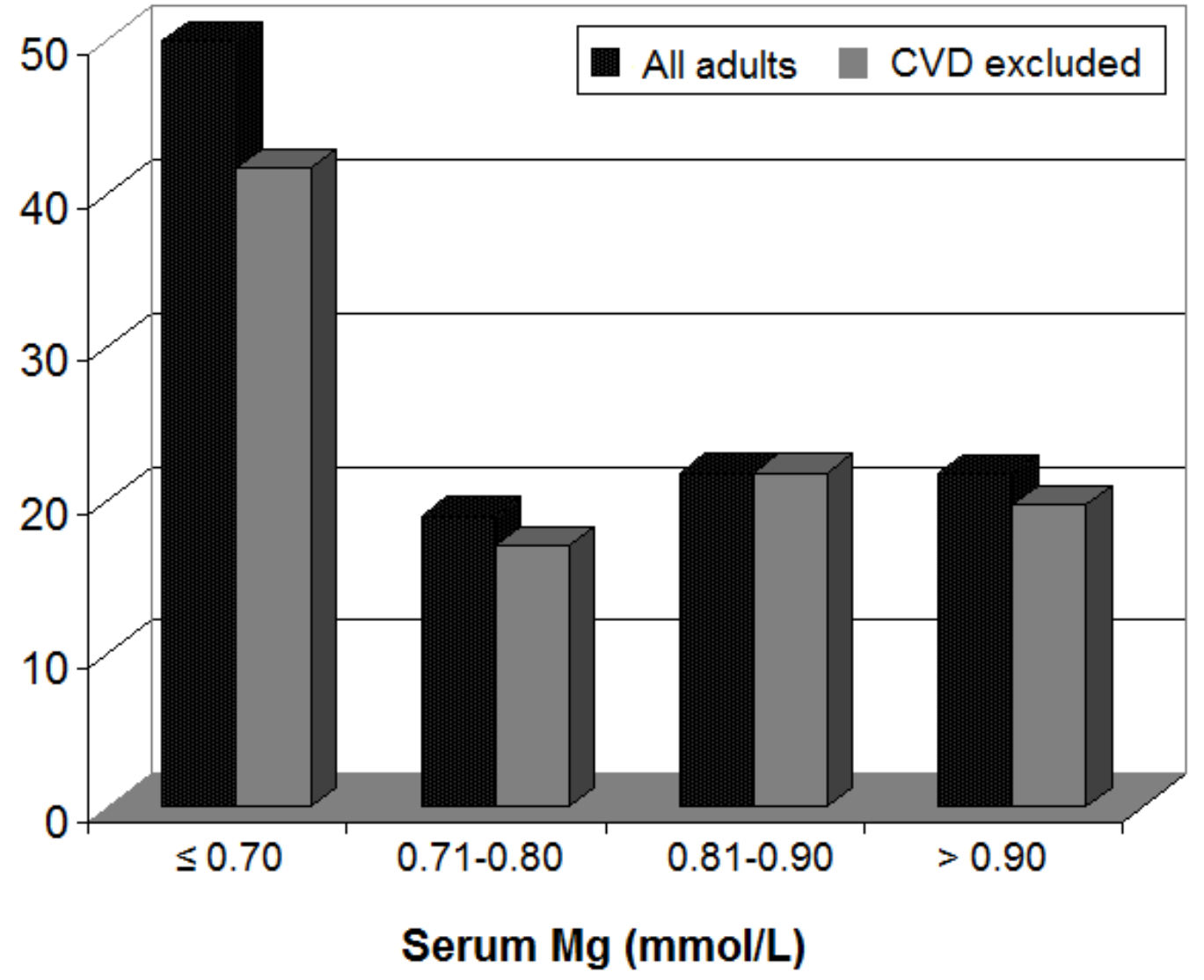

${ }^{1}$ CVD excluded (light grey bars) omits individuals with cardiovascular event history or conditions

Difference in PVC prevalence among $\mathrm{sMg} \leq 0.70$ vs. other groupings: for all adults: $p=0.015$; for CVD excluded: $p=0.07$ 
Figure 5.2. Unadjusted prevalence of PVC (\%) during 2-hr Holter electrocardiogram among adults without CVD $(n=652)$ by groupings of $\mathrm{sMg}$ concentrations $(\mathrm{mmol} / \mathrm{L})$ and diabetic status ${ }^{1}$

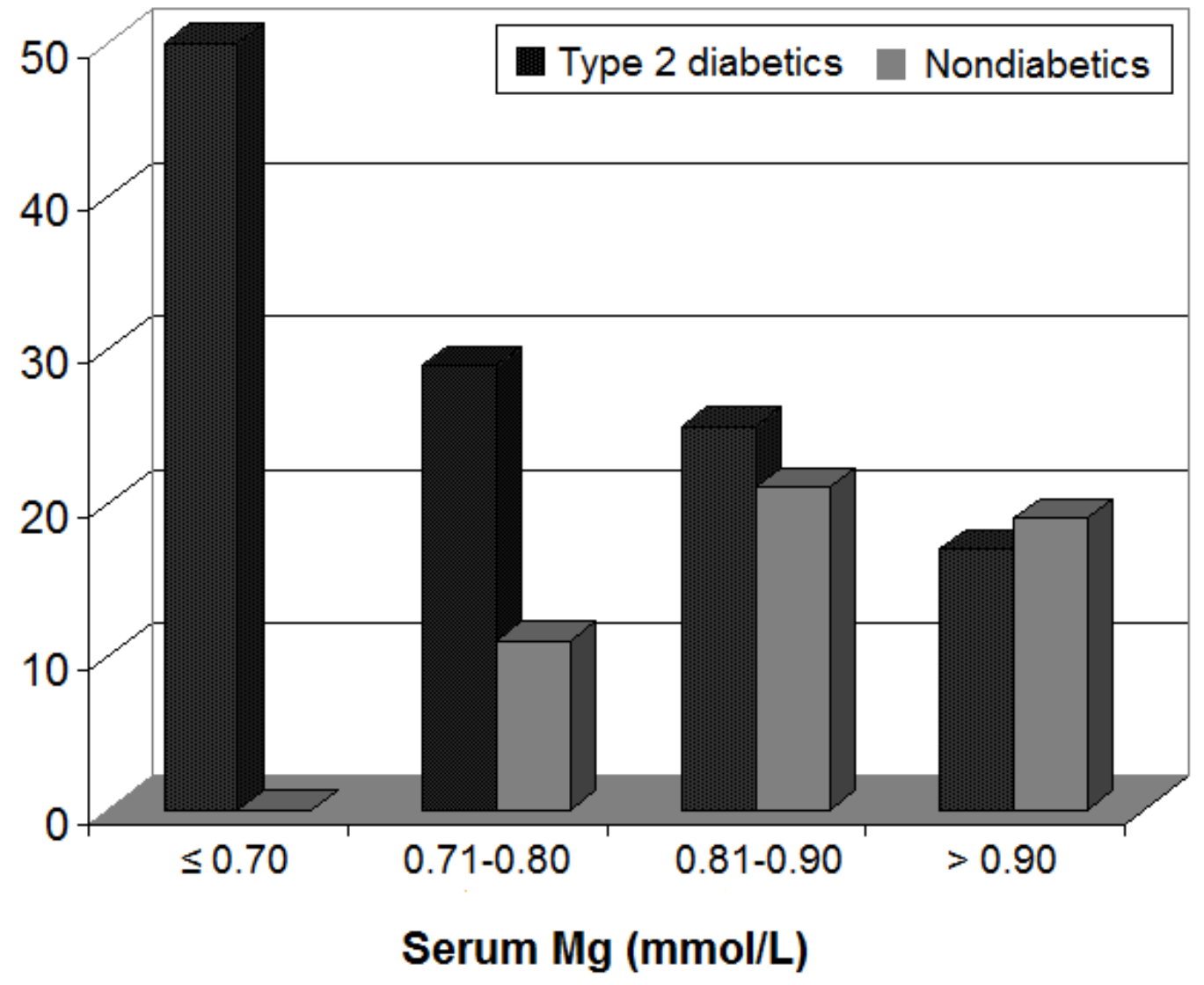

${ }^{1}$ Prevalence of PVC declined across the sMg concentration gradient in adults with T2DM only $(p<0.001)$. Decline in PVC prevalence with increasing sMg among participants with T2DM was significant even when $\mathrm{sMg} \leq 0.70 \mathrm{mmol} / \mathrm{L}$ diabetics were excluded $(p=0.005$ ). While only $1 \%$ of nondiabetics had $\mathrm{sMg} \leq 0.70 \mathrm{mmol} / \mathrm{L}$, none of the nondiabetics in the hypomagnesaemic group had PVC. 


\section{References}

1. Abbot, L.G. \& Rude, R.K., Clinical manifestations of magnesium deficiency. Mineral Electrolyte Metabolism 1993, 19, 314-322.

2. Abdalla, I.S.H.; Prineas, R.J.; Neaton, J.D.; Jacobs, D.R.; Crow, R.S., Relation between ventricular premature complexes and sudden cardiac death in apparently healthy men. American Journal of Cardiology 1987, 60, 1036-1042. 3. Alberti, K.G.M.M.; Ecklel, R.H.; Grundy, S.M.; et al., Harmonizing the Metabolic Syndrome. Circulation 2009, 120, 1640-1645.

4. Alghamdi, S.M.G.; Cameron, E.C.; Sutton, R.A.L, Magnesium deficiency: pathophysiologic and clinical overview. American Journal of Kidney Diseases 1994, 24, 737-752.

5. Barbagallo, M.; Dominguez, L.J., Magnesium metabolism in type 2 diabetes mellitus, metabolic syndrome and insulin resistance. Archives of Biochemistry \& Biophysics 2007, 458, 40-47.

6. Belardinelli, L.; Antzelevitch, C.; Vos, M.A., Assessing predictors of drug-induced torsade de pointes. Trends in Pharmacological Sciences 2003, 24, 619-625.

7. Chakraborti, S.; Chakraborti, T.; Mandal, M.; Mandal, A.; Das, S.; Ghosh, S., Protective role of magnesium in cardiovascular diseases: A review. Molecular \& Cellular Biochemistry 2002, 238, 163-179.

8. Cheriyath, P.; He, F.; Peters, I.; et al., Relation of atrial and/or ventricular premature complexes on a two-minute rhythm strip to the risk of sudden cardiac death (the Atherosclerosis Risk in Communities [ARIC] Study. American Journal Cardiology 2011, 107, 151-155. 
9. de Valk, H.W., Magnesium in diabetes mellitus. Netherlands Journal of Medicine 1999, 54, 139-146.

10. Dyckner, T. \& Wester, P.O., Magnesium deficiency contributing to ventricular tachycardia. Acta Medica Scandinavica 1982, 212, 89-91.

11. Egeland, G.M.; Denomme, D.; Lejeune, P.; Pereg, D., Concurrent validity of the International Physical Activity Questionnaire (IPAQ) in an Iiyiyiu Aschii (Cree) community. Canadian Journal of Pubic Health 2008, 99, 307-310.

12. Escobedo, L.G. \& Caspersen, C.J., Risk factors for sudden coronary death in the United States. Epidemiology 1997, 8, 175-180.

13. Fawcett, W.J.; Haxby, E.J.; Male, D.A., Magnesium: physiology and pharmacology. British Journal of Anaesthesia 1999, 83, 302-320.

14. Gaita, F.; Giustetto, C.; Di Donna, P.; et al., Long-term follow-up of right ventricular monomorphic extrasystoles. Journal of American College of Cardiology 2001, 38, 364-370.

15. Harris, S.B.; Gittelsohn, J.; Hanley, A.; et al., The prevalence of NIDDM and associated risk factors in native Canadians. Diabetes Care 1997, 20, 185-187. 16. Harris, I. \& Levin, D., The effects upon the human electrocardiogram of the introduction of calcium and potassium into the blood. Journal of Physiology 1937, 89, 153.

17. Kalaitzidis, R.; Tismihodimos, V.; Bairaktari, E.; Siamopoulos, K.; Elisaf, M., Disturbances of phosphate metabolism: another feature of the metabolic syndrome. Journal of Kidney Diseases 2005, 45, 851-858.

18. Kennedy, H.L.; Whitlock, J.A.; Sprague, M.K.; Kennedy, L.J.; Buckingham, T.A.; Goldberg, R.J., Long-term follow-up of asymptomatic healthy 
subjects with frequent and complex ventricular ectopy. New England Journal of Medicine 1985, 312, 193-197.

19. Klevay, L.M. \& Milne, D.B., Low dietary magnesium increases supraventricular ectopy. American Journal of Clinical Nutrition 2002, 75, 550554.

20. Limaye, C.S.; Londhey, V.A.; Nadkar, M.Y.; Borges, N.E., Hypomagnesemia in critically ill medical patients. Journal of the Association of Physicians of India 2011, 59, 19-22.

21. Loeb, H.S.; Pietras, R.J.; Gunnar, R.M.; Tobin, J.R., Paroxysmal ventricular fibrillation in two patients with hypomagnesemia. Circulation 1968, 3, 210-215.

22. Millante, T.A.; Ward, D.E.; Camm, A.J., Is hypomagnesemia arrhythmogenic? Clinical Cardiology 1992, 15, 103-108.

23. Mistissini technical report: summary of activities, results and recommendations of Nituuchischaayihtitaau Aschii Multi-community Environment-and-health Longitudinal Study in Iiyiyiu Aschii. 2007. Available online:

[http://www.creehealth.org/sites/default/files/Environmental\%20Health\%20Study -\%20Technical\%20Report\%20of\%20Mistissini.pdf]. Last accessed: Sept 2011. 24. Mozaffarian, D.; Psaty, B.M.; Rimm, E.B.; et al., Fish intake and risk of incident atrial fibrillation. Circulation 2004, 110, 368-373.

25. Mubagwa, K.; Gwanyanya, A.; Zakharov, S.; Macianskiene, R., Regulation of cation channels in cardiac and smooth muscle cells by intracellular magnesium. Archives of Biochemistry \& Biophysics 2007, 458, 73-89. 
26. Nielsen, F.H.; Milne, D.B.; Klevay, L.M.; Gallagher, S.; Johnson, L., Dietary magnesium deficiency induces heart rhythm changes, impairs glucose tolerance, and decreases serum cholesterol in post menopausal women. Journal of the American College of Nutrition 2007, 26, 121-132.

27. Parikka, H.; Toivonen, L.; Naukkarinen, V.; et al., Decreases by magnesium of QT dispersion and ventricular arrhythmias in patients with acute myocardial infarction. European Heart Journal 1999, 20, 111-120.

28. Peacock, J.M.; Ohira, T.; Post, W.; Sotoodehnia, N.; Rosamond, W.; Folsom, A.R., Serum magnesium and risk of sudden cardiac death in the Atherosclerosis Risk in Communities (ARIC) Study. American Heart Journal 2010, 160, 464-470.

29. Raiha, I.J.; Piha, S.J.; Seppanen, A.; Puukka, P.; Sourander, L., Predictive value of continuous ambulatory electrocardiographic monitoring in elderly people. British Medical Journal 1994, 309, 1263-1267.

30. Ramme, S.P.; White, C.J.; Svinarich, J.T.; Watson, T.D.; Fox, R.F., Torsade de pointes and magnesium deficiency. American Heart Journal 1985, 109, 89-91.

31. Rude, R.K. \& Shils, M.E. Magnesium. In: Modern nutrition in health and disease, $10^{\text {th }}$ edition. Edited by M.E. Shils; M. Shike; A.C. Ross; B. Caballero; R.J. Cousins. Lippincott Williams \& Wilkins. 2006, 223-242.

32. Russo, G.L., Dietary n-6 and n-3 polyunsaturated fatty acids: From biochemistry to clinical implications in cardiovascular prevention. Biochemical Pharmacology 2009, 77, 937-946. 
33. Sajadieh, A.; Nielsen, O.W.; Rasmussen, V.; et al., Ventricular arrhythmias and risk of death and acute myocardial infarction in apparently healthy subjects of age >= 55 years. American Journal of Cardiology 2006, 97, $1351-1357$.

34. Simmons, D.; Joshi, S.; Shaw, J., Hypomagnesaemia is associated with diabetes: Not pre-diabetes, obesity or the metabolic syndrome. Diabetes Research in Clinical Practice 2010, 87, 261-266.

35. Stein, P.K.; Barzilay, J.I.; Chaves, P.H.M.; et al., Novel measures of heart rate variability predict cardiovascular mortality in older adults independent of traditional cardiovascular risk factors: The Cardiovascular Health Study (CHS). Journal of Cardiovascular Electrophysiology 2008, 19, 1169 -1174.

36. Stein, P.K.; Sanghavi, D.; Sotoodehnia, N.; Siscovick, D.S.; Gottdiener, J., Association of Holter-based measures including T-wave altemans with risk of sudden cardiac death in the community-dwelling elderly: the Cardiovascular Health Study. Journal of Electrocardiology 2010, 43, 251-259.

37. Tsuji, H.; Venditti, F.J.; Evans, J.C.; Larson, M.G.; Levy, D., The associations of levels of serum potassium and magnesium with ventricular premature complexes (The Framingham Heart Study). American Journal of Cardiology 1994, 74, 232 -235.

38. Zipes, D.P.; Camm, A.J.; Borggrefe, M.; et al. ACC/AHA/ESC 2006 guidelines for management of patients with ventricular arrhythmias and the prevention of sudden cardiac death. Europace 2006, 8 (9), 746-837. 


\section{CHAPTER 6: CONCLUSIONS \& SIGNIFICANCE}

Among the 7 billion people alive today, cardiovascular mortality

(ischemic heart disease and stroke) claims the most lives: nearly one quarter of the total global population (23.6\%) currently succumb to either condition (WHO, 2011a). Since worldwide obesity has more than doubled since 1980 (WHO, 2011b) and incidence of T2DM continues to increase, mortality attributed to cardiovascular causes is projected to grow. This trend has particular salience as lower income nations become increasingly developed and transition toward a greater burden of chronic diseases. In developed nations, cardiovascular mortality accounts for half of all deaths (WHO, 2011c). Cardiovascular events and their complications reduce the quality of life of survivors and impose considerable direct health care costs in Canada (O'Brian et al., 2001). Preventive measures guided by public health policy should play an increasing role in reducing the burden induced by cardiovascular disease and T2DM. Among Cree and Inuit in Canada, increased rates of cardiometabolic complications and mortality relative to general North American population (Dannenbaum et al., 2008), exacerbated by constraints in healthcare resources, underscore the importance of prevention.

This thesis has provided evidence from three diverse cross-sectional studies demonstrating associations between Mg biomarkers and cardiometabolic variables. Results from this work, along with a growing body of literature, increase the foundation for prospective follow-up studies and randomized controlled trials to improve $\mathrm{Mg}$ biomarkers and potentially reduce cardiometabolic risk. Main findings include the observation that not only is T2DM status an important effect modifier of associations between $\mathrm{Mg}$ and 
ventricular arrhythmia (Chapter 5) but that transient diabetic states (gestational diabetes) may influence associations between $\mathrm{Mg}$ and cardiometabolic variables in affected mothers and offspring 15-years post-partum (Chapter 3). For the first time, $\mathrm{rMg}$ is evaluated as a cardiovascular risk biomarker, and the correlation between $\mathrm{sMg}$ and $\mathrm{rMg}$ is reported, with differences in strength of the correlation depending on age and sex (Chapter 4). In the latter work, sMg emerges as an imperfect but promising cardiovascular risk biomarker, whereas there is no evidence that $\mathrm{rMg}$ is favourably associated with cardiovascular risk nor contributes to cardiovascular risk assessment. Finally, inverse associations between $\mathrm{pMg}, \mathrm{sMg}$ and cardiometabolic variables emerge in diverse ethnic populations (Chapters 3, 4 and 5). Several large prospective studies have reported reduced risk of hard endpoints (sudden cardiac death, ischemic heart disease and all cause mortality) at higher pMg and sMg concentrations (Peacock et al., 2010; Chuive et al., 2011; Ford et al., 1999). This work reports reduced risk of intermediary adverse variables (fasting glucose and insulin, insulin sensitivity, glycated haemoglobin, hsCRP, carotid intima-media thickness, and ventricular premature beats) at elevated $\mathrm{Mg}$ concentrations, consistent with emerging literature on intermediary cardiovascular outcomes (eg. Reffelmann et al., 2010; Hashimoto et al., 2010).

Frequently, observational studies reporting associations between circulating $\mathrm{Mg}$ (sMg or $\mathrm{pMg}$ ) and cardiovascular endpoints conclude with statements suggesting that increases in dietary $\mathrm{Mg}$ may improve $\mathrm{Mg}$ status and hence risk modification. While such statements appear non-controversial and even intuitive, I argue that these conclusions are problematic for several reasons I will 
discuss here, as the commentary has relevance for future research on $\mathrm{Mg}$ and cardiovascular health.

The first problem with such statements is the conflation of circulating $\mathrm{Mg}$ as a marker of $\mathrm{Mg}$ status, or at the very least the use of 'Mg status' as shorthand for circulating $\mathrm{Mg}$. While the loading test is the gold standard for $\mathrm{Mg}$ status, it is time and resource intensive, and inappropriate for patients with kidney and intestinal disorders when orally administered (Arnaud, 2008). In adults, only 25\% of total body $\mathrm{Mg}$ can be studied using stable isotopes, which captures rapid exchanges between the plasma and extra-plasma pools; most total body $\mathrm{Mg}$ evades this analysis and resides in long-term storage pools, such as bone (Sabatier et al., 2003). In adolescents and children, compartmental analysis using stable isotopes show it is not possible to directly relate $\mathrm{Mg}$ deficiency to fluxes in the exchangeable pool size or pool turnover (Abrams \& Ellis, 1998). Inexpensive and accessible, circulating $\mathrm{Mg}$ has thus remained popular for use in research investigations and clinically, but less than $1 \%$ of total body $\mathrm{Mg}$ is present in blood (Elin, 1991), pMg and sMg are not validated as markers of Mg status (IOM, 1997) and appear to be under homeostatic regulation (Arnaud, 2008).

If circulating $\mathrm{Mg}$ is a poor surrogate for $\mathrm{Mg}$ status, its predominant use as a $\mathrm{Mg}$ measure over the decades might be justified by evidence that $\mathrm{sMg}$ and $\mathrm{pMg}$ biomarkers are surrogates of $\mathrm{Mg}$ dietary intakes, implying that they might be highly modifiable. In fact, there is no good evidence that these biomarkers are closely associated with $\mathrm{dMg}$, nor is there convincing evidence that these biomarkers are highly modifiable in normomagnesemic individuals. The correlation between $\mathrm{sMg}$ and $\mathrm{dMg}$ in the ARIC cohort $(\mathrm{n}=14,882)$ was less than 
0.06 in all race and sex groups (Ma et al., 1995). In the Nurses' Health Study, the correlation between $\mathrm{pMg}$ and $\mathrm{dMg}$ was 0.07 ( $p=0.23$ ) (Chiuve et al., 2011).

Chapter 3 of this works shows that the correlation between $\mathrm{pMg}$ and $\mathrm{dMg}$ in mothers and in daughters was not significant $(p=0.16$ for mothers; $p=0.67$ for daughters). In the Cree population discussed in Chapter 5, the correlation between sMg and $\mathrm{dMg}$ was 0.06 ( $p=0.09)$. Consistent with observations that these biomarkers are under homeostatic regulation, USDA scientists demonstrated that while sMg initially decreased during dietary $\mathrm{Mg}$ deprivation, it rebounded to baseline values on day 40 and only slightly decreased thereafter (Nielsen et al., 2007).

Assumptions of a close relationship between circulating $\mathrm{Mg}$ and $\mathrm{dMg}$ are especially inappropriate given that these blood measures and $\mathrm{dMg}$ may be associated with different risks of hard cardiovascular endpoints. In the Nurses Health Study, the relative risk of sudden cardiac death in women in the highest quartile compared with those in the lowest quartile of dMg (RR: 0.63 ; 95\% CI: 0.44- 0.91) was weaker than that of pMg (RR: 0.23; 95\% CI: 0.09- 0.60) (Chiuve et al., 2011). In the ARIC study, the corresponding RR of sudden cardiac death in the highest compared to the lowest quartile of sMg was significant (RR: 0.62; 95\% CI: 0.42- 0.93), but $\mathrm{dMg}$ was not associated with risk of sudden cardiac death (Peacock et al., 2010).

While lack of associations between dietary intakes of nutrients and nutrient biomarkers are sometimes attributed to imprecision in dietary measuring tools (24-hr recalls, food frequency questionnaires or diaries), direct administration of $\mathrm{Mg}$ in randomized controlled trials demonstrates that circulating 
$\mathrm{Mg}$ is only modestly changed even by relatively large doses of $\mathrm{Mg}$ in normomagnesemic individuals (Chacko et al., 2011; Hadjistavri et al., 2010). Among obese nondiabetic adults, sMg concentrations increased only slightly $(0.90 \pm 0.08$ to $0.92 \pm 0.07 \mathrm{mmol} / \mathrm{L})$ after six months of $\mathrm{Mg}$ supplementation (365mg/day) (Mooren et al., 2011). In a meta-analysis of Mg supplementation in T2DM (median dose: $15 \mathrm{mmol} /$ day (360 mg/day), the weighted mean difference in circulating $\mathrm{Mg}$ was $0.06 \mathrm{mmol} / \mathrm{L}$ higher in treatment groups, with no linear trend and complex relationship to the time course of supplementation (Song et al., 2006). In an experimental $\mathrm{Mg}$ dietary deprivation study, mean $\mathrm{sMg}$ concentration declined from $0.86 \pm 0.007 \mathrm{mmol} / \mathrm{L}$ to $0.83 \pm 0.007 \mathrm{mmol} / \mathrm{L}$ when postmenopausal women consumed a 130mg/day Mg diet for 81 days vs. a $411 \mathrm{mg} /$ day $\mathrm{Mg}$ diet for 81 days (Klevay et al., 2002). These $\mathrm{Mg}$ changes are small relative to the range of the reference interval for $\mathrm{sMg}(\sim 0.75-0.96 \mathrm{mmol} / \mathrm{L})$ (Lowenstein \& Stanton, 1986) and if $\mathrm{sMg}$ associations to cardiovascular risk are causal, larger changes in circulating Mg might be needed to maximize cardiovascular risk reduction. As previously mentioned (Chapter 5), risk of sudden cardiac death was maximally reduced in individuals in the highest relative to the lowest quartile of sMg and pMg (Peacock et al., 2010; Chiuve et al., 2011).

Nondietary influences on $\mathrm{pMg}$ and $\mathrm{sMg}$ also have established influence in epidemiological studies. While diabetes, even for transient periods, may substantially modify $\mathrm{Mg}$ homeostasis or associations with cardiometabolic endpoints (Chapter 3), kidney and gastrointestinal diseases, moderate alcohol consumption (Rylander, 2001) and use of cardiovascular medications (eg. 
diuretics, proton pump inhibitors) increase Mg loss and are associated with reduced circulating $\mathrm{Mg}$.

To summarize this commentary, if there is no convincing evidence that $\mathrm{pMg}$ and $\mathrm{sMg}$ are good biomarkers of $\mathrm{Mg}$ status, nor good biomarkers of dietary $\mathrm{Mg}$, and are subject to multiple, often incompletely measured external influences, what are they good for? The implications of this thesis, contextualized with emerging literature, suggest that these $\mathrm{Mg}$ measures warrant further investigation as cardiovascular risk biomarkers. An important finding of this thesis work and recent literature findings is evidence of cardiovascular risk stratification within the 'normal' sMg concentration range, implying that the ranges currently deemed 'normal' may not be optimal. Specifically, Chapter 4 reports significant decreases in fasting glucose and carotid intima-media thickness across $\mathrm{sMg}$ concentration groupings among adults with MetS. In Chapter 5, risk of $>6 \mathrm{PVC} /$ hour was maximally reduced above a sMg threshold within the 'normal' sMg concentration range $(0.75 \mathrm{mmol} / \mathrm{L})$ in Cree adults. In the Framingham Offspring Cohort, significantly reduced prevalence of ventricular arrhythmia across the $\mathrm{sMg}$ concentration range has also been reported (Tsuji et al., 1994). Emerging evidence from prospective analyses show that elevated $\mathrm{sMg}$ is associated with reduced left ventricular mass independent of common cardiovascular risk factors (Reffelmann et al., 2010) and has been linked to a reduced risk of total CVD morality (Ford et al., 1999). Consistent with evidence of cardiovascular risk stratification within the 'normal' sMg concentration range, Elin (2010) argued that the traditional method to establish a reference interval for $\mathrm{sMg}$ is flawed, since there are a large number of 'normal' individuals with subtle chronic negative Mg balance. 
Earlier in this concluding chapter, $\mathrm{sMg}$ was referred to as an imperfect cardiovascular risk biomarker, largely on the basis of findings that $\mathrm{sMg}$ is positively associated with atherogenic lipoprotein LDL and total cholesterol (Randell et al., 2008; Ma et al., 1995; Hashimoto et al., 2010; Chapter 4). In Chapter 4, it was argued that despite these epidemiological correlations, there is no evidence for a causal association between $\mathrm{sMg}$ and an atherogenic lipid profile. The best evidence for this conclusion is derived from $\mathrm{Mg}$ supplementation trials demonstrating either no significant influence on blood lipids (Mooren et al., 2011), increases in HDL only (Song et al., 2006), and at the dose and formulation of $600 \mathrm{mg} \mathrm{Mg}^{2+}$ pidolate $(25 \mathrm{mmol})$ daily, decreases in total cholesterol, LDL, TG, and increases in HDL (Hadjistauri et al., 2010).

In conclusion, the major contribution of this thesis was the demonstration that circulating $\mathrm{Mg}$ ( $\mathrm{pMg}$ or $\mathrm{sMg}$ ) holds promise as risk biomarker for not only endpoints relating to T2DM but also cardiovascular disease. Based on the work from this thesis and well-designed prospective trials that emerged while the thesis was composed, further adequately powered randomized controlled $\mathrm{Mg}$ trials for cardiometabolic health are warranted. In general, trials to date have shown promising results despite small sample sizes and heterogeneous designs (eg. Mooren et al., 2011; Chacko et al., 2011; Hadjistavri et al., 2010; Song et al., 2006). In older adults, Mg supplementation more effectively decreased insulin resistance than strict dietary and lifestyle intervention (Hays et al., 2006). Similar effects of 16-week therapy with metformin (Chazova et al., 2006) in comparison to 6 months on a $365 \mathrm{mg}(15 \mathrm{mmol}) \mathrm{Mg}$ supplementation regimen were reported on insulin sensitivity indices (Mooren et al., 2011). Optimal Mg dosing, formulations 
and duration to maximally improve cardiometabolic outcomes in various populations remain to be determined.

Recently, a one serving per day increase in fruit, vegetables, whole grains, and consumption of nuts twice weekly, have been estimated to decrease relative risk of CVD mortality by 36\% (Mozaffarian \& Capewell, 2011). Incidentally, all of these foods are good sources of $\mathrm{Mg}$; therefore, dietary interventions designed to increase $\mathrm{Mg}$ consumption would be consistent with established dietary patterns associated with cardiovascular risk reduction. Indeed, higher $\mathrm{dMg}$ intakes have been associated with reduced markers of systemic inflammation and endothelial dysfunction (Chacko et al., 2010; Song et al., 2007) and reduced risk of developing MetS (Song et al., 2005).

While this thesis has reviewed the promise of $\mathrm{Mg}$ for reducing cardiometabolic risk (Chapter 2) and presented original epidemiological analyses consistent with this hypothesis (Chapter 3-5), Mg should not be considered in isolation in devising public health recommendations. Without question, established modifiable measures for primary prevention of T2DM and cardiovascular disease are of prime importance. In the mother-daughter gestational diabetes study population, GDM mothers were more likely to be glucose intolerant 15 -yrs post-partum than control mothers, and daughters who developed during GDM pregnancy have increased risk of central adiposity and insulin resistance 15-yrs post-partum (Egeland \& Meltzer, 2010). Effective interventions to reduce weight gain and hence diabetes during pregnancy remain challenging (Gray-Donald et al., 2000) but vital. Smoking, obesity, and high blood pressure must be reduced, particularly in aboriginal communities where 
prevalence of these risk factors are elevated (Chapter 4, Chateau-Degat et al., 2010). The poor dietary quality of Aboriginal youth needs targeting; among three of the Cree villages surveyed in this thesis, $92.8 \%$ of youth consumed high-sugar food and beverages, accounting for $12.8 \%$ of total energy intakes. Increasing dietary quality through traditional food, and increased fruit and vegetable consumption, were significantly correlated with adiposity measures (Khalil et al., 2010), and must be considered in interventional approaches. Healthy lifestyle promoting workshops offered to a Mohawk community in Kahnawake have been shown to improve perceptions of health and created role modelling and advocacy for healthier lifestyles among participants (Murdoch, 2011).

The advent of public health epidemiology in the modern age has allowed us to identify risk factors for disease otherwise unobservable to the naked eye. In our continuing era of gross economic inequity among and within nations and consequent unequal access to high-tech and expensive technologies, the importance of initiating preventive or public health interventions before overt disease is present cannot be overstated. This is particularly true during the ongoing epidemic in obesity, MetS and T2DM, with cardiovascular disease claiming the lives of nearly $80 \%$ of individuals with the latter condition (IDF, 2006). Multidrug regimens and coronary stents have become mainstay in the modern medical toolbox for the prevention and treatment of cardiovascular disease, and indeed, have resulted in improvements in patient care and longevity. Ironically, the same electrolytes infused intravenously during and after certain coronary events and surgery, namely Mg (Miller et al., 2005; Zipes et al., 2006; Onalan et al., 2007), are depleted by some modern cardiovascular drugs. 
In 1878, using a Lippmann capillary electrometer, Sanderson \& Page recorded and published their findings on the 'rhythmical and excitatory motions' of the heart. If coronary risk is stratified across the concentration range of a key electrolyte, failure to invest research efforts in such cardiovascular fundamentals in our sophisticated medical age would be a potentially tremendous opportunity lost and terrible irony. 


\section{References}

1. Abrams, S.A. \& Ellis, K.J., Multicompartmental analysis of magnesium and calcium kinetics during growth: relationships with body composition. Magnesium Research 1998, 11, 307-313.

2. Arnaud, M.J., Update on the assessment of magnesium status. British Journal of Nutrition 2008, 99, S24-S36.

3. Chacko, S.A.; Sul, J.; Song, Y.Q., et al., Magnesium supplementation, metabolic and inflammatory markers, and global genomic and proteomic profiling: a randomized, double-blind, controlled, crossover trial in overweight individuals. American Journal of Clinical Nutrition 2011, 93 (2), 463-473

4. Chacko, S.A.; Song, Y.; Nathan, L.; et al., Relations of dietary magnesium intake to biomarkers of inflammation and endothelial dysfunction in an ethnically diverse cohort of postmenopausal women. Diabetes Care 2010, 33, 304-310.

5. Chateau-Degat, M.; Dewailly, E.; Louchini, R.; et al., Cardiovascular burden and related risk factors among Nunavik (Quebec) Inuit: insights from baseline findings in the circumpolar Inuit health in transition cohort study. The Canadian Journal of Cardiology 2010, 26, 190-196.

6. Chazova, I.; Almazov, V.A.; Shlyakhto, E., Moxonidine improves glycaemic control in mildly hypertensive, overweight patients: a comparison with metformin. Diabetes, Obesity \& Metabolism 2006, 8, 456-465.

7. Chiuve, S.E.; Korngold, E.C.; Januzzi J.L.; Gantzer, M.L.; Albert, C.M., Plasma and dietary magnesium and risk of sudden cardiac death in women. American Journal of Clinical Nutrition 2011, 93, 253-260. 
8. Dannenbaum, D.; Kuzmina, E.; Lejeune, P.; Torrie, J.; Gangbe, M., Prevalence of diabetes and diabetes-related complications in First Nations communities in northern Quebec (Eeyou Istchee), Canada. Canadian Journal of Diabetes 2008, 32, 46-52.

9. Egeland, G.M. \& Meltzer, S.J., Following in mother's footsteps? Motherdaughter risks for insulin resistance and cardiovascular disease 15 years after gestational diabetes. Diabetic Medicine 2010, 27, 257-265.

10. Elin, R.J., Laboratory tests for the assessment of magnesium status in humans. Magnesium \& Trace Elements 1991, 92, 172-181.

11. Elin, R.J., Assessment of magnesium status for diagnosis and therapy. Magnesium Research 2010, 23 (4), S194-S198.

12. Ford ES. Serum magnesium and ischaemic heart disease: findings from a national sample of US adults. International Journal of Epidemiology 1999, 28, 645-651.

13. Gray-Donald, K.; Robinson, E.; Collier, A.; David, K.; Renaud, L.; Rodrigues, S., Intervening to reduce weight gain in pregnancy and gestational diabetes mellitus in Cree communities: an evaluation. Canadian Medical Association Journal 2000, 163, 1247-1251.

14. Guerrero-Romero, F.; Tamez-Perez, H.E.; Gonzalez-Gonzalez, G.; et al., Oral magnesium supplementation improves insulin sensitivity in non-diabetic subjects with insulin resistance. A double-blind placebo-controlled randomized trial. Diabetes \& Metabolism 2004, 30, 253-258. 
15. Hadjistavri, L.S.; Sarafidis, P.A.; Georgianos, P.I., Beneficial effects of oral magnesium supplementation on insulin sensitivity and serum lipid profile. Medical Science Monitor 2010, 16 (6), CR307-CR312.

16. Hashimoto, T.; Hara, A.; Ohkubo, T.; et al., Serum magnesium, ambulatory blood pressure, and carotid artery alteration: the Ohasama study. American Journal of Hypertension 2010, 23, 1292-1298.

17. Hays, N.P.; Starlinge, R.D.; Sullivana, D.H.; Fluckeya, J.D.; Cokera, R.H.; Evansa, W.J., Comparison of insulin sensitivity assessment indices with euglycemic-hyperinsulinemic clamp data after a dietary and exercise intervention in older adults. Metabolism- Clinical \& Experimental 2006, 55, 525-532.

18. International Diabetes Federation (IDF). The IDF consensus worldwide definition of the metabolic syndrome. 2006. Available online: http://www.idf.org/webdata/docs/IDF_Meta_def_final.pdf. Last accessed: Oct 2011.

19. Institute of Medicine (IOM). Dietary Reference Intakes for Calcium, Phosphorus, Magnesium, Vitamin D, and Fluoride 1997, National Academies Press: Washington, DC.

20. Khalil, C.B.; Johnson-Down, L.; Egeland, G.M., Emerging obesity and dietary habits among James Bay Cree youth. Public Health Nutrition 2010, 13, 1829-1837.

21. Klevay, L.M. \& Milne, D.B. Low dietary magnesium increases supraventricular ectopy. American Journal of Clinical Nutrition 2002; 75: 550554. 
22. Lowenstein, F.W. \& Stanton, M.F., Serum Mg levels in the United States, 1971-1974. Journal of the American College of Nutrition 1986, 5, 399-414.

23. Ma, J.; Folsom, A.R.; Melnick, S.L.; Eckfeldt, J.H.; Sharrett, A.R.; Nabulsi, A.A.; Hutchinson, R.G.; Metcalf, P.A., Associations of serum and dietary magnesium with cardiovascular disease, hypertension, diabetes, insulin and carotid arterial-wall thickness- the ARIC study. Journal of Clinical Epidemiology 1995, 48, 927-940.

24. Miller, S.; Crystal, E.; Garfinkle, M.; Lau, C.; Lashevsky, I.; Connolly, S. J., Effects of magnesium on atrial fibrillation after cardiac surgery: a metaanalysis. Heart 2005, 91 (5), 618-623.

25. Mooren FC, Kruger K, Volker K, Golf SW, Wadepuhl M, Kraus A. Oral magnesium supplementation reduces insulin resistance in non-diabetic subjects - a double-blind, placebo-controlled, randomized trial. Diabetes Obes Metab 2011; 13: $281-284$.

26. Mozaffarian, D. \& Capewell, S., United Nations' dietary policies to prevent cardiovascular disease. British Medical Journal 2011, DOI: 10.1136/bmj.d5747.

27. Murdoch, J., Understanding how workshops transform participants lives by exploring their perceived experiences: The Kahnawake Schools Diabetes Prevention Project. MSc thesis. 2011. McGill University, Montreal. 28. Nielsen, F.H.; Milne, D.B.; Klevay, L.M.; Gallagher, S.; Johnson, L., Dietary magnesium deficiency induces heart rhythm changes, impairs glucose tolerance, and decreases serum cholesterol in post menopausal women. Journal of American College of Nutrition 2007, 26, 121-132. 
29. O'Brien, J.A.; Caro, I.; Getsios, D.; Caro, J.J., Diabetes in Canada: direct medical costs of major macrovascular complications. Value Health 2001, 4 (3), 258-265.

30. Onalan, O.; Crystal, E.; Daoulah, A.; Lau, C.; Crystal, A.; Lashevsky, I., Meta-analysis of magnesium therapy for the acute management of rapid atrial fibrillation. American Journal of Cardiology 2007, 99 (12), 1726-1732.

31. Peacock, J.M.; Ohira, T.; Post, W.; Sotoodehnia, N.; Rosamond, W.; Folsom, A.R., Serum magnesium and risk of sudden cardiac death in the Atherosclerosis Risk in Communities (ARIC) Study. American Heart Journal 2010, 160, 464-470.

32. Randell, E.W.; Mathews, M.; Gadag, V.; Zhang, H.W.; G. Sun, G., Relationship between serum magnesium values, lipids and anthropometric risk factors, Atherosclerosis 2008, 196, 413-419.

33. Reffelmann, T.; Dorr, M.; Ittermann, T.; et al., Low serum magnesium concentrations predict increase in left ventricular mass over 5 years independently of common cardiovascular risk factors. Atherosclerosis 2010, 213, 563-569.

34. Rylander, R.; Mégevan, Y.; Lasserre, B.; Amstutz, W.; Granbom, S., Moderate alcohol consumption and urinary excretion of magnesium and calcium. Scandanavian Journal of Clinical \& Laboratory Investigations 2001, 61, 401405.

35. Sabatier, M.; Pont, F.; Arnaud, M.J.; Tumlund, J.R., A compartmental model of magnesium metabolism in healthy men based on two stable isotope tracers. American Journal of Physiology-Regulatory, Integrative \& Comparative Physiology 2003, 285, R656-R663. 
36. Sanderson, J. \& Page, F.J.M., Experimental results relating to the rhythmical and excitatory motions of the ventricle of the frog heart. Proceedings of the Royal Society of London 1878, 27, 410-414.

37. Song, Y.; He, K.; Levitan, E.B.; Manson, J.E.; Liu, S., Effects of oral magnesium supplementation on glycaemic control in Type 2 diabetes: a metaanalysis of randomized double-blind controlled trials. Diabetic Medicine 2006, 23, 1050-1056.

38. Tsuji, H.; Venditti, F.J.; Evans, J.C.; Larson, M.G.; Levy, D., The associations of levels of serum potassium and magnesium with ventricular premature complexes (The Framingham Heart Study). American Journal of Cardiology 1994, 74, $232-235$.

39. Weglicki, W.B. \& Phillips, T.M., Pathobiology of magnesium deficiency: a cytokine/ neurogenic inflammation hypothesis. American Journal of Physiology - Regulatory Physiology 1992, 263, R734-R737.

40. World Health Organization (WHO) \& Centre for Indigenous Peoples’ Nutrition and Environment (CINE), Indigenous peoples and participatory health research. 2003. Available online: http://www.mcgill.ca/files/cine/partreresearch.english.pdf. Last accessed: Sept 2011.

41. World Health Organization (WHO). The top 10 causes of death: Fact sheet 310. 2011a. Available online: http://www.who.int/mediacentre/factsheets/fs310/en/. Last accessed: Oct 2011. 
42. World Health Organization (WHO). Obesity and overweight: Fact sheet 311. 2011b. Available online: http://www.who.int/mediacentre/factsheets/fs311/en/. Last accessed: Oct 2011. 43. World Health Organization (WHO). Presentation by Zsuzsanna Jakab, WHO Regional Director for Europe on "The future of health care in Europe." The Economist Conference; Geneva, Switzerland. 2011c. Available online: http://www.euro.who.int/_data/assets/pdf_file/0010/135586/RD_speech_Econo mist_20110317.pdf. Last accessed: Oct 2011.

44. Zipes, D.P.; Camm, A.J.; Borggrefe, M.; et al. ACC/AHA/ESC 2006 guidelines for management of patients with ventricular arrhythmias and the prevention of sudden cardiac death. Europace 2006, 8 (9), 746-837. 